\title{
An Applications Guide to Pedestrian SNM Monitors
}

\author{
Paus E. Fehlau
}

\section{TISCLAIMER}

This report was prepared as an account of work sponsored by an agency of the United States Government. Neither the United States Government nor any agency thereof, nor any of their employees, makes any warranty, express or implied, or assumes any legal liability or responsibility for the accuracy, completeness, or usefu'ness of any information, apparatus, product, or process disclosed, or represents that its use would not infringe privately owned rights. Reference herein to any specific commercial product, process, or service by trade name, trademark, manufacturer, or orherwise does not necessarily constitute or imply its endorsement, recommendation, or favoring by the United States Government or any agency thereof. The views and opinions of authors expressed herein do not necessarily state or reflect those of the United States Government or any agency thereof.
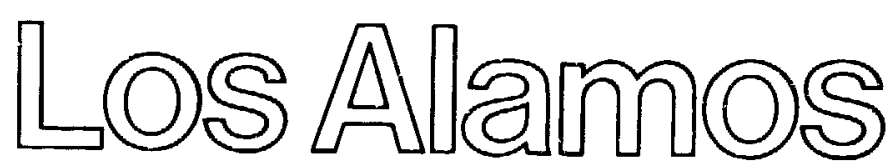
CONTENTS

INTRODUCTION $\ldots \ldots \ldots \ldots \ldots \ldots \ldots \ldots \ldots \ldots \ldots \ldots \ldots$

Part 1. AN OVERVIEW OF PEDESTRIAN SNM MONITORING . . . . . . . . . . 2

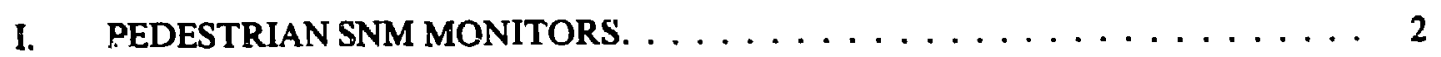

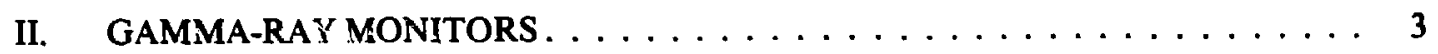

III. FACTORS THAT AFFECT PEDESTRIAN SNM MONITOR PERFORMANCE. . . 4

A. Monitoring Statistics. . . . . . . . . . . . . . . . . . . . . 4

B. SNM Radiation Intensity $\ldots \ldots \ldots \ldots \ldots \ldots \ldots \ldots \ldots$

C. Monitoring Times ........................ 6

IV. EXAMPLES OF SNM MONITOR MASS DETECTION SENSI'TIVITY _ . . . . . . 8

V. APPLYING AUTOMATIC SNM PEDESTRIAN MONITOR TECHNOLOGY _ . 8

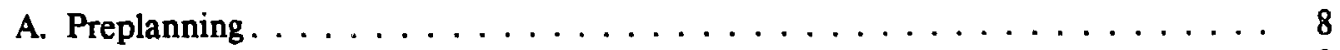

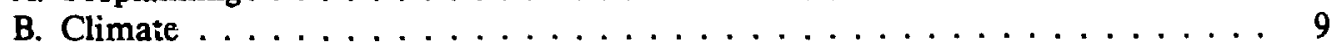

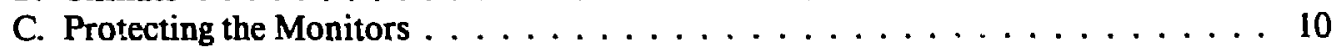

D. Calibrating and Servicing the Monitors . . . . . . . . . . . . . 10

E. Testing the Monitors . . . . . . . . . . . . . . . . . . 10

F. An Example of an SNM Monitor Application . . . . . . . . . . . . 11

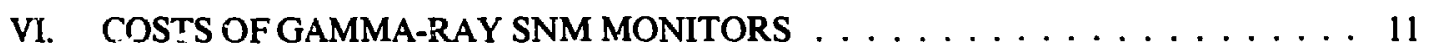

vII. WHAT ABOUT NEUTRON MONITORS? . . . . . . . . . . . . . . . . 12

Part 2. THE TECHNICAL BASIS OF RADIATION MONITORING . . . . . . . . . . . 13

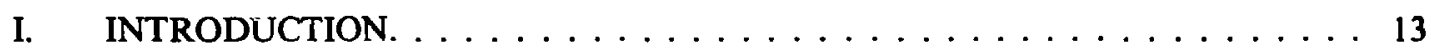

II. A BRIEF HISTORY OF RADIATION MONITORING . . . . . . . . . . 13

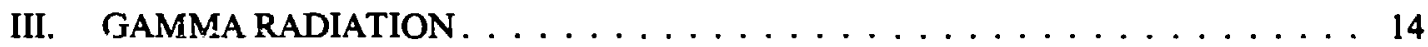

A. Radioactive Decay . . . . . . . . . . . . . . . . . . . . . . . 14

B. Gamma-Ray Energy Spectra . . . . . . . . . . . . . . . . . . 15

C. Gamma-Ray Interactions with Materials . . . . . . . . . . . . . . . . 15

D. The Inverse Square Law of Radiation Intensity. . . . . . . . . . . . . . . . 17

IV. GAMIMA-RAY SOURCE CHARACTERISTICS $\ldots \ldots \ldots \ldots \ldots$

A. Background Radiation . . . . . . . . . . . . . . . . . . 18

B. Gamma-Radiation Test Sources . . . . . . . . . . . . . . . . . . . 20

C. Characteristics of Transient Diversion Signals . . . . . . . . . . . . . . 21

1. SNM Self-Absorption. . . . . . . . . . . . . . . . . . 21

2. SNM Diversion Signal Profiles . . . . . . . . . . . . . . . 22

V. SNM GAMMA-RAY SOURCE DETECTION . . . . . . . . . . . . . . . . . 24

A. Statistics of Radiation Detection . . . . . . . . . . . . . . . . 24

B. A Detection Method . . . . . . . . . . . . . . . . . . 26

C. Shielding Effects . . . . . . . . . . . . . . . . . . 28

D. Detection Electronics . . . . . . . . . . . . . . . . . 28 
VI. GAMMA-RAY DETECTORS . . . . . . . . . . . . . . . . . . 29

A. MaI(Tl) Scintillation Detectors . . . . . . . . . . . . . . . . 29

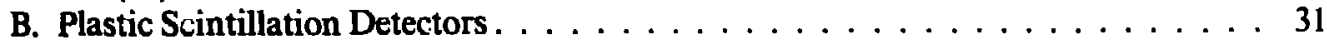

C. Scintillation Detector Construction. . . . . . . . . . . . . . 33

VII. SCINTILLATION DETECTOR ELECTRONICS . . . . . . . . . . . . . . 35

A. Power and Signal Conditioning. . . . . . . . . . . . . . . 35

B. Single-Channel Analyzers . . . . . . . . . . . . . . . . . 35

C. Electronics Diagnostic Techniques . . . . . . . . . . . . . . 35

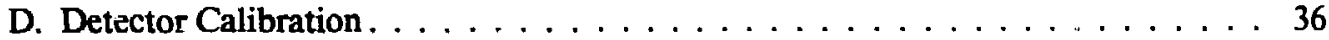

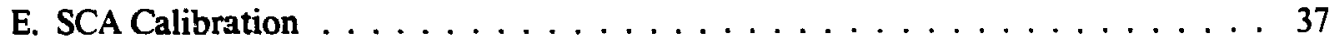

F. Periodic Calibration Checks . . . . . . . . . . . . . . . . . 37

VIII. AN EXAMPLE OF AN SNM PORTAL MONITOR . . . . . . . . . . . . . 37

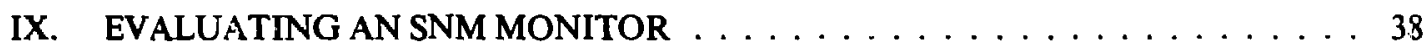

A. Statistical False-Alarm Measurement . . . . . . . . . . . . . . . . . 39

B. Determining Detection Sensitivity . . . . . . . . . . . . . . . . . 39

Part 3. A CATALOG OF SNM RADIATION MONITORS . . . . . . . . . . . . . . . . . 42

I. HAND-HELD SNM RADIATION MONITORS . . . . . . . . . . . . . 43

II. NATIONAL NUCLEAR CORPORATION DM-2 PEDESTRIAN SNM MONITOR . 44

III. IRT CORPORATION PRM 110 PEDESTRIAN MONITOR . . . . . . . . . . 45

IV. IRT CORPORATION PRM 120 PEDESTRIAN MONITOR . . . . . . . . . . . 46

v. TSA SYSTEMS PM 203/101 PEDESTRIAN MONITOR . . . . . . . . . . . . . 47

V1. TSA SYSTEMS PM 310 PEDESTRIAN MONITOR . . . . . . . . . . . . . 48

VII. OAK RIDGE Y-12 PLANT PEDESTRIAN MONITOR . . . . . . . . . . . . . . 49

VIII. LOS ALAMOS PEDESTRIAN SNM MONITOR . . . . . . . . . . . . . . . 50

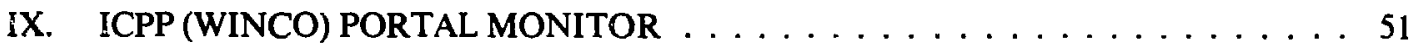

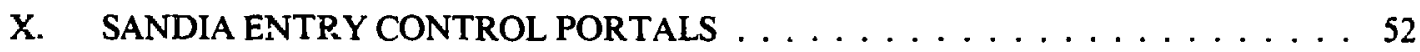

XI. HERFURTH GAMMA DOORWAY MONITOR . . . . . . . . . . . . . 53

XII. BEFIC PSMR SNM PORTAL MONITORS . . . . . . . . . . . . . . . . . 54

XIII. HARWELL SNM DOORWAY MONITORS. . . . . . . . . . . . . . . . 55

ACKNOWLEDGMENTS $\ldots \ldots \ldots \ldots \ldots \ldots \ldots \ldots \ldots$

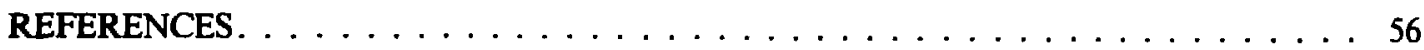




\title{
AN APPLICATIONS GUIDE TO PEDESTRIAN SNM MONITORS
}

by

\author{
Paul E. Fehlau
}

\begin{abstract}
The applications guide introduces readers to the pedestrian special nuclear material (SNM) monitors that provide nuclear material control at DOE contractor facilities. It explains the principles of operation, the strong and weal points, and steps for calibration and maintenance of the monitors. Administrators and security specialists will find an overview of pedestrian monitor application and upkeep in Part 1 of the guide and a descriptive catalog of present-day monitors in Part 3. Technically oriented readers will be interested in the more detailed discussion of SNM monitoring physics and SNM monitor design principles found in Part 2.
\end{abstract}

\section{INTRODLCTION}

Pedestrian special nuclear material (SNM) monitors offer a rapid, effective means to search for SNM as an individual departs a material-access or protected area. The SNM monitors sense gamma radiation emitted by nuclear materials, which is a more specific clue to the presence of the material than is its visual or tactile appearance. Best performance is obtained from well-designed monitors when the monitors are situated away from interfering radiation fields, when they are properly calibrated and adjusted, and when the monitors are periodically tested to be sure that they are in a good state of repair.

The purpose of this applications guide is to make you familiar with the SNM pedestrian monitors that are applied at DOE contractor facilities. Our goal is to familiarize you with the monitors and their principles of operation is well as to tell you how the monitors should be maintained once they have been put into use. We hope to make you aware of the monitors' limitations as well as their strong points.

Our task is not as simple as we would like it to be because many different people are involved in de- signing, manufacturing, and applying SNM monitors. Some of these people are the technically trained engineers and technicians who manufacture or maintain the monitors and others are the administrators and security specialists who regulate or control the use of SNM monitors. Each person needs an appropriate understanding of SNM monitors that will allow him to do his part to best use the monitors. Because it must provide an appropriate understanding to each member of such a varied audience, this applications guide covers a lot of ground; few readers will be interested in all of it. To help you locate what will interest you in the guide, we have organized it into an introductory section (Part 1), a technical section (Part 2), and a final catalog section (Part 3).

The text of the applications guide is arranged to present an overview of pedestrian monitoring in the introductory Part 1, followed by a technical discussion of monitoring physics, monitor design, and calibration and repair of SNM monitors in Part 2, and finally a catalog in Part 3 that briefly describes a large number of present-day pedestrian SNM monitors. 


\section{PART 1}

\section{AN OVERVIEW OF PEDESTRIAN SNM MONITORING}

\section{PEDESTRIAN SNM MONITORS}

DOE regulations' require a search for SNM each time an individual departs a material-access area and certain protected areas. Radiation monitoring offers a convenient and effective means to search pedestrians for SNM because all forms of SNM are radioactive. Radiation that an SNM monitor might sense takes the form of gamma rays and hard $x$ rays (100$k \in V^{m}$ or higher energy $x$ rays like those used for dental $x$-ray photography), both of which are photons similar to visible light but with greater ability to penetrate materials, and neutrons, which are highly penetrating neutral particles. Some of the other forms of radiation emitted by nuciear materials are beta rays (energetic electrons) and soft $x$ rays (less than 30 $\mathrm{keV}$ energy photons as in color-TV radiation), but these may not penetrate through SNM packaging or the monitor's detector cabinets and therefore may not be detected by SNM monitors. As a result, diversion monitors are designed to sense the more penetrating gamma-ray and neutron radiation. But, although some forms of SNM emit both gamma rays and neutrons, not all forms of SNM emit neutrons, so most SNM monitors have been based on gamma-ray detection. For most of this discussion we will concentrate on the two types of gamma-ray monitors; manually operated, hand-held monitors that a guard must sweep over an individual's body and automatic SNM portal monitors that monitor pedestrians walking through a portal formed by gamma-ray detectors.

An example of an automatic pedestrian monitor is the National Nuclear Corporation (NNC) ${ }^{\dagger}$ DM-2 portal monitor (Fig. 1) that senses the presense of a pedestrian and sounds an alarm if the gamma-radia-

\footnotetext{
"DOE regulation is in very general terms. SNM monitors are part of plant security plans. This applications guide offers guidance to DOE contractors on SNM monitors, their technical basis, and their upkeep.

"The unit of energy for $x$ rays and gamma rays is the kiloelectron volt, $\mathrm{keV}$. The concept of energy for these photons can be likened to the familiar concept of color for visible-light photons: The energy of the $x$ rays is an important attribute that influences how easily they are absorbed in materials or detected in a radiation detector.

National Nuclear Corporation, 1904 Colony Street, Mountain View, CA 93117, (415) 962-9220.
}

tion intensity increases while he is in the monitor. In contrast to the automatic DM-2, the NNC hand-held monitor in Fig. 2 is used manually by a guard, who detects SNM by sweeping the hand-held monitor over a person's body while listening for the monitor's audible alarm signal. These and other commercially available pedestrian SNM monitors marufactured in the US and $a$ few of the SNM monitors manufactured in foreign countries are more fully described in Part 3.

The most significant difference between the handheld and automatic pedestrian monitors is the human factor that strongly influences the performance of the hand-held monitor. If the guard does not move the monitor to within about 5 to $15 \mathrm{~cm}$ ( 2 to 6 in.) of any SNM that may be present, it may be overlooked. But the small distances that can be obtained between SNM and the monitor's radiation detector give the hand-held monitor the greatest poteritial sensitivity of any of the SNM monitors. To achieve that sensitivity, guards must be trained in the proper technique to conduct effective searches, and the training must be repeated periodically. Guards also must be effectively supervised on the job to be sure that they continually employ an effective search technique. Properly used, the versatile hand-held monitors can effectively monitor pedestrians, packages, or motor vehicles.

Good hand-monitoring technique gets the radiation detector close to SNM. This principle is important for both hand-held and automatic portal monitors; in the portal monitor, narrow portal widths minimize the distance between SNM and detectors and give the best sensitivity. At a given portal width, the automatic monitor searches with about the same effectiveness each time a pedestrian passes through. Of course, as with the hand-hels monitor, the automatic portal monitor must be calibrated and tested periodically to be sure that it is giving its best performance.

Both hand-held and automatic portal monitors should be checked Jaily with small radioactive sources to verify that they can detect a radiation intensity increase. This simple test verifies that the system is operating and that no immediate repair is required. The hand-held monitor search procedure employed by guards also should be observed daily to disclose any shortcoming in the technique. Reference 1 , a training-aid brochure that describes the

\footnotetext{
"Calibration makes each detector response identicai, sets the gain of the signal-conditioning electronics, and adjusts the monitor to cbserve radiation from the energy-emission region of SNM.
} 


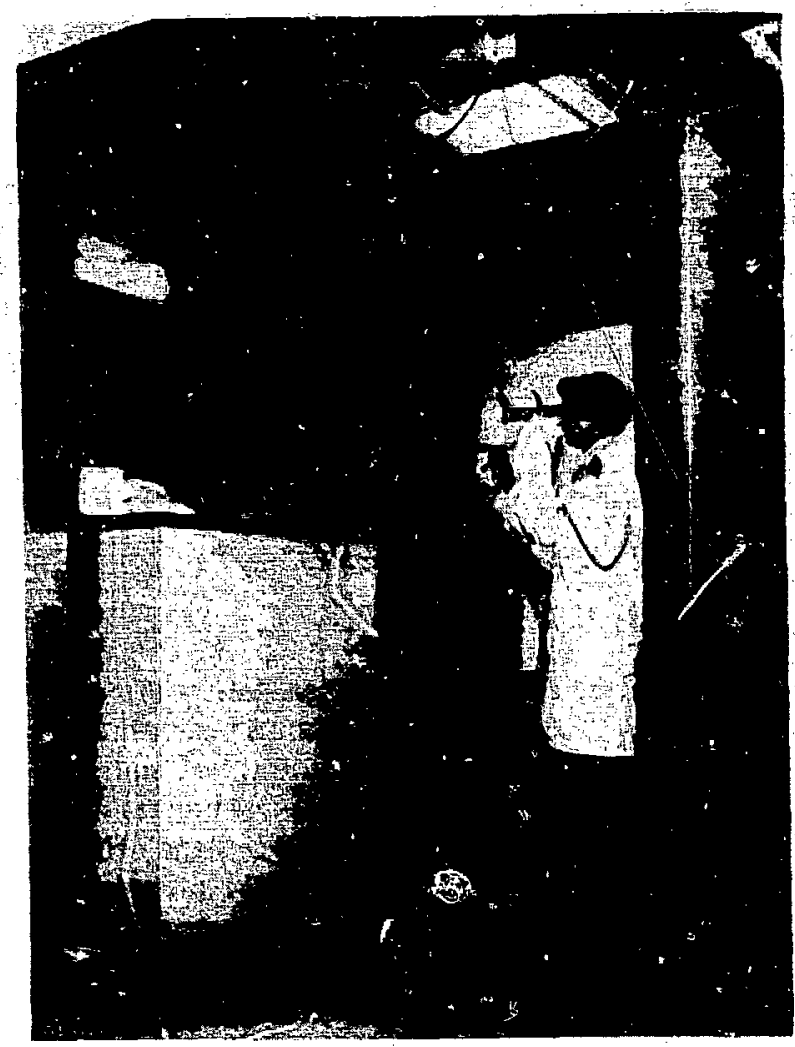

Fig. 1. The NNC model DM-2 SNM portal monitor automatically monitors each pedestrian who walks through the portal.

hand-held monitor search technique, can serve as a guide for judging proper search technique for handheld monitors.

In addition to daily testing, more elaborate longterm checks of SNM monitor performance should be conducted. At least quarterly, each monitor should be recalibrated and then tested by pedestrians transporting SNM through the monitoring station. The purpose of the quarterly check is to make sure that the monitors operate effectively and can detect adequately small quantities of SNM.

\section{GAMMA-RAY MONITORS}

The elements of hand-held and automatic portal monitors are essentially the same (Fig. 3). A radiation detector, which is a sensitive plastic or sodium iodide $[\mathrm{NaI}(\mathrm{Tl})]$ gamma-ray scintillator, responds to gamma rays and sends electrical signal pulses to electronic circuits that select the pulses from gamma-ray energy

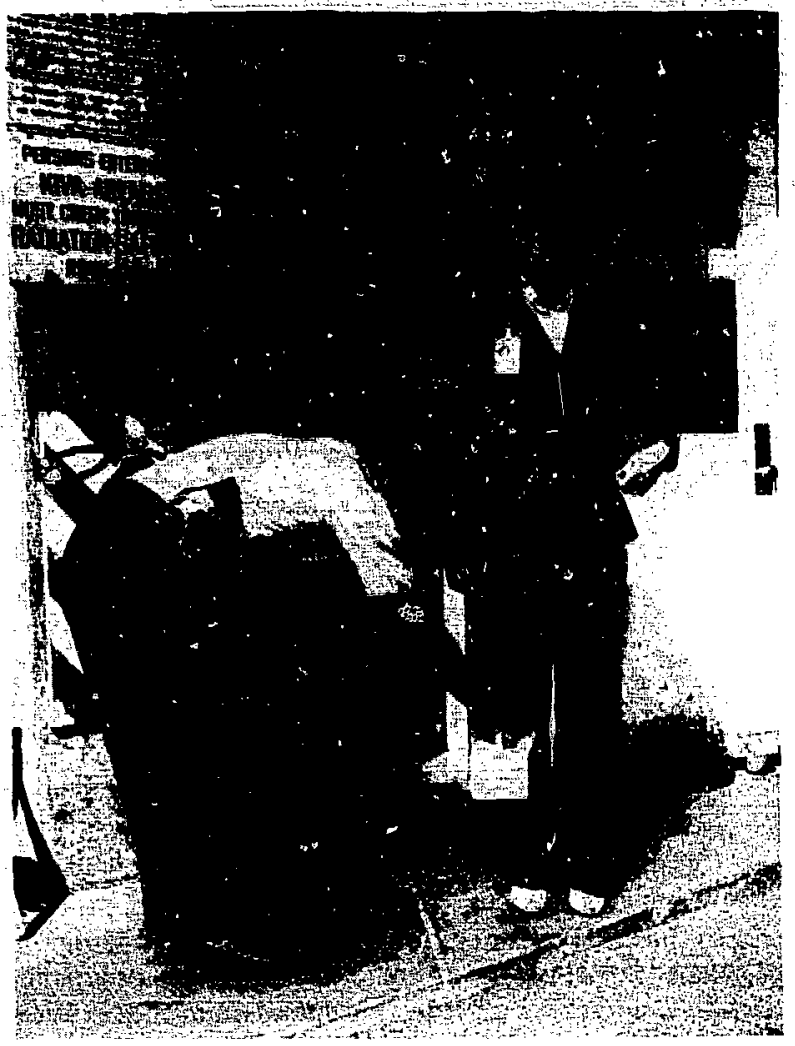

Fig. 2. The NINC model HM-3 hand-held SNM monitor must be swept over a pedestrian's body by the guard, who interprets the monitor's audible alarm signals.

regions that typify SNM. To achieve the best monitoring sensitivity, specific regions can be employed for uranium or plutonium to cover their range of garmma-ray emission energies. Setting the appropriate energy region is particularly important for detecting low-energy, low-radiation-intensity materials such as highly enriched" uranium (HEU).

The appropriate signals from the detector are counted by the monitor's detection electronics for a relatively long time when the monitor is unoccupied to measure the average background-radiation intensity. Then, when the monitor is occupied (sensed by the switchmat in Fig. 3), signals are counted for a relatively short time to measure the monitoring intensity. An increase in radiation intensity during monitoring is detected when the monitoring count

"Uranium becomes SNM when it undergoes an enrichment process to increase its content of the ${ }^{235} \mathrm{U}$ isotope to $20 \%$ or more. HEU is enriched to the point that it contains $93 \%$ ${ }^{235} \mathrm{U}$. 


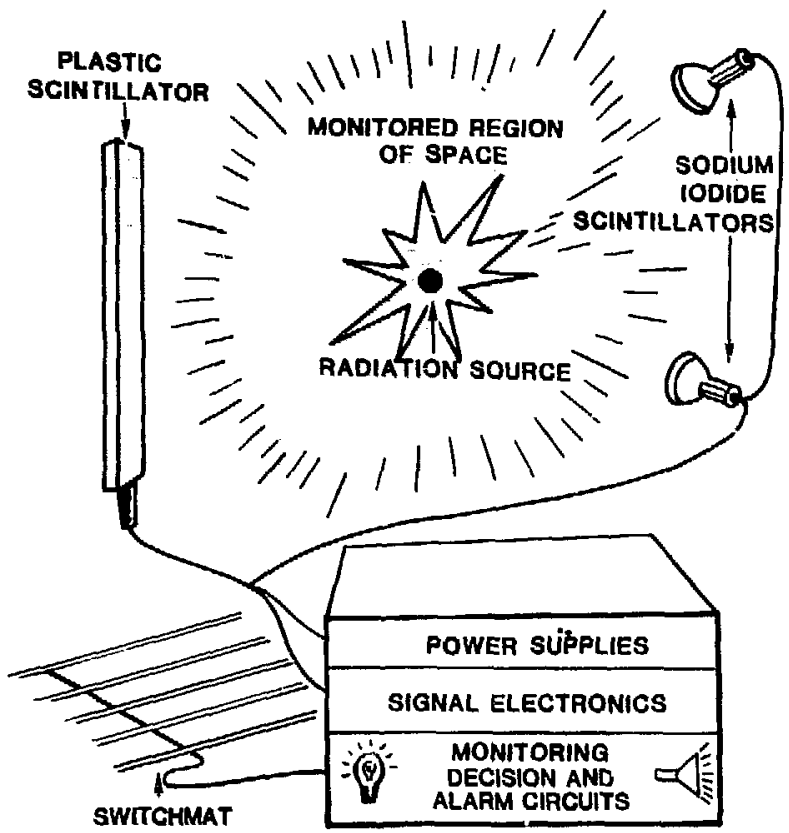

Fig. 3. The elements of a radiation monitor are a radiation detector, signal-conditioning electronics, an occupancy sensor, transient-signal-detection circuits, and communication devices.

significantly exceeds the count expected from the previously measured background intensity. Any measurement has some statistical variation in its result; what we mean by significant is that a diversion signal must exceed that variation to cause an alarm. A diversion signal causes an alarm when it exceeds the average background count plus a threshold number of counts called the alarm increment. The size of the alarm increment used by the monitor's detection scheme is quite important because it influences both the likelihood of a false alarm and the likelihood of detecting SNM.

The way that hand-held and automatic portal monitors are used makes a difference in the way we interpret the significance of their real or false alarms. For example, a hand-held monitor can reasonably operate with one or two false alarms caused by statistical variation during each minute of operation. In a manual search (Fig. 2), the hand-held instrument continuously monitors the radiation intensity, and to detect SNM the operator listens for repetitive alarm signals in one area, so infrequent single alarms are not significant or unreasonable. The automatic portal monitors, however, monitor the entire region of space within the portal at once. Each portal-monitor alarm is significant and may represent SNM diversion. Hence, automatic portal monitors must be made relatively free from false alarms by having a larger alarm increment than the hand-held instrument, an increment that accepts a larger amount of statistical variation without alarming. For instance, we may expect automatic portal monitors to operate for an entire 8-h-long work shift with an average of no more than one statistical false alarm even though several thousand pedestrians may pass through the portal during the shift.

\section{FACTORS THAT AFFECT PEDESTRIAN SNM MONITOR PERFORMANCE}

\section{A. Monitoring Statistics}

As might be expected, statistical false alarms and detection sensitivity of an automatic monitor are closely related; when larger amounts of statistical variation are accommodated by a higher alarm increment, an SNM alarm requires a larger signal. Hence, the overall performance of any SNM monitor depends markedly on its alarm increment. Furthermore, the alarm increment itself can be altered by the monitor's radiation environment because monitors usually do not apply fixed alarm thresholds, which would have to be relatively high and insensitive to accommodate natural background intensity variation. Instead, monitor designers make the likelihood of a false alarm the same at each measured background intensity by automatically adjusting the alarm increment. This procedure keeps the false-alarm rate constant but also causes the monitor's detection sensitivity to decrease at higher background intensity. Alternatively, the designer can make the detection sensitivity constant at any background intensity, but in that case false alarms become more likely at higher oackground intensity. Neither way is perfect but either is better than simply using a fixed alarm threshold. In any case, best SNM monitoring performance is obtained in the lowest possible radiation intensity environment having the least possible amount of intensity variation from natural or facility-related causes.

\section{B. SNM Radiation Intensity}

Another important factor affecting monitor performance is the type and form of the SNM that must be detected. The type is important because the gamma radiation from each SNM is different (Figs. 4 and 5). For example, ${ }^{239} \mathrm{Pu}$ is a more intense gammaray emitter than the ${ }^{235} U$ isotope, and some of its 

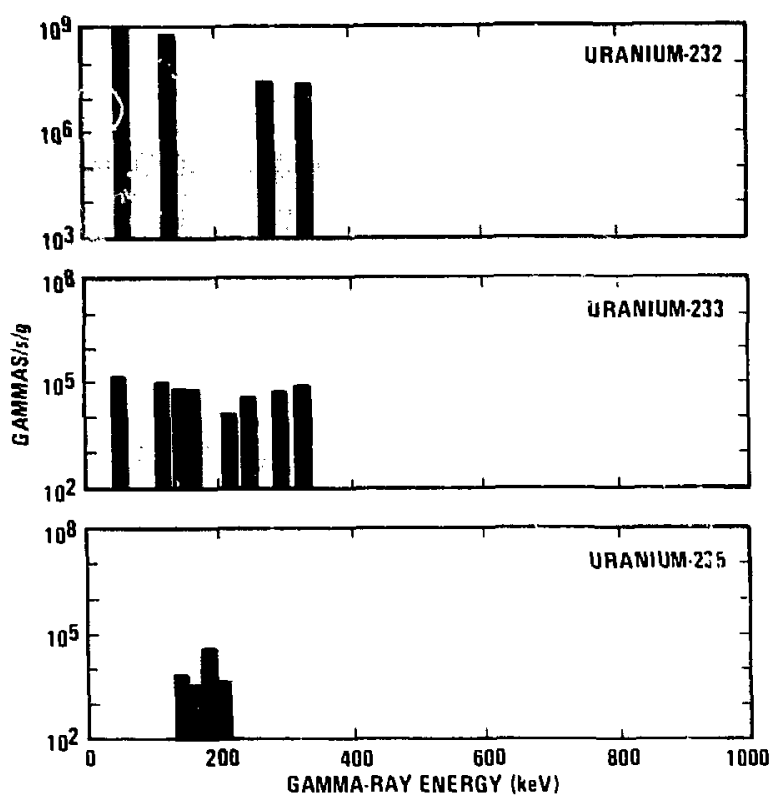

Fig. 5. The great variety of gamma radiation from plutonium isotopes appears to some extent in almost all plutonium samples. Seldom are highly pure samples of a single piutonium isotope available with appreciable mass. Geometry-dependent $100-\mathrm{keV} \times$ rays supplement the gamma rays shown here.
Fig. 4. Gamma radiation from the individual uranium isotopes in SNM is supplemented by geometry-dependent $100-\mathrm{keV} x$ rays that are not shown here. The lower graph for ${ }^{235} \mathrm{U}$ is the one we are most concerned with as representing the least intense radiation emission.
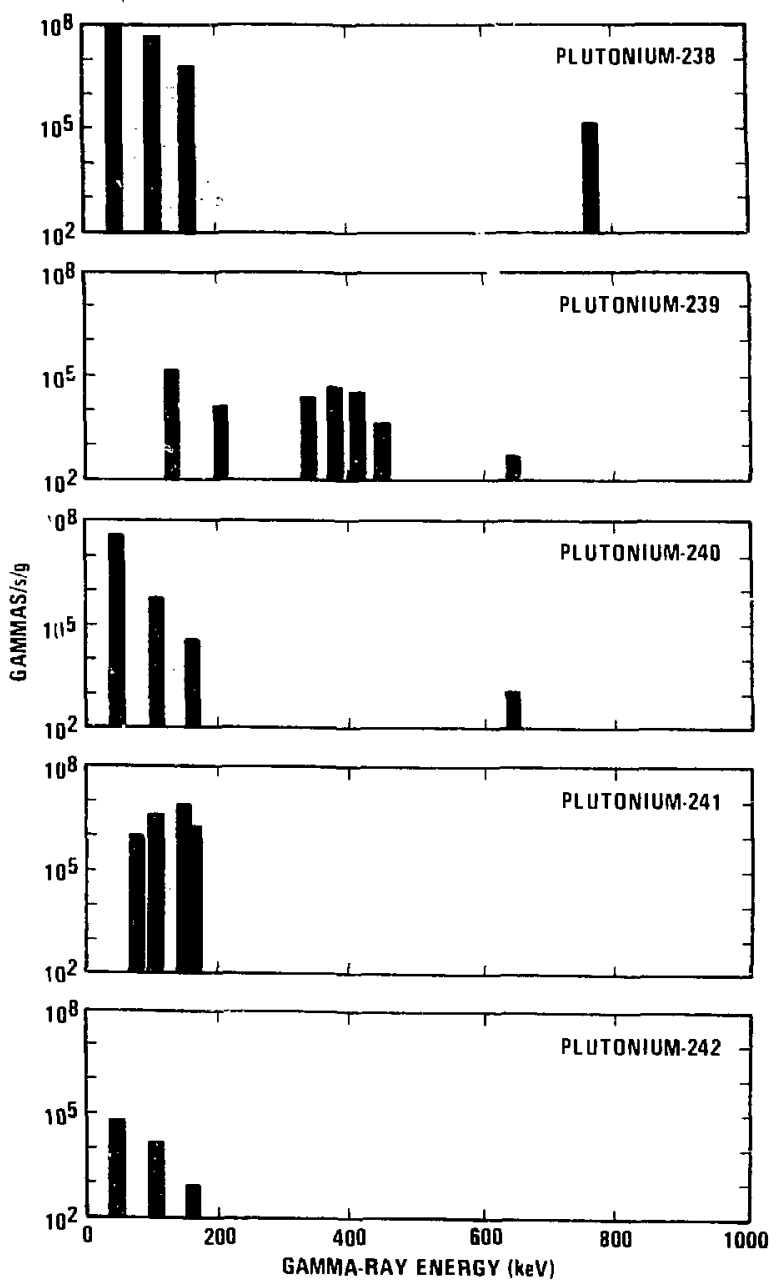
radiation is more readily transmitted through SNM packaging and the detector cabinets of SNM monitors. Hence plutonium usually can be detected in much smaller amounts than uranium. The physical form of the SNM is also important because SNM can self-absorb some of its own gamma radiation.

Self-absorption of radiation within a material causes larger amounts of SNM to emit less radiation than might otherwise be expected. For example, when the flat side of a tt:in sheet of material (Fig. 6) is viewed by a radiation detector, doubling the length of the edges of the sheet would quadruple the gammaray signal because the area viewed by the detector would then be four times as great. In this case, the increase in sample size results in a corresponding increase in signal. On the other hand, if only one edge of the sheet is in view, then the signal would be smaller to begin with, and it would increase in proportion to the length of that edge rather than the area of the sheet; as the length of the side doubles so does the signal. In this case the increase in signal is not proportional to the increase in area. The size of the sheet still quadruples, and it still produces four times as much radiation on the whole, but only twice as much radiation reaches the detector that views the edge. The rest of the increased amount of radiation that starts toward the edge detector is internally absorbed in the sheet. In general, compact metallic forms of SNM emit the least amount of radiation; granular material, solutions, foils, and shavings with the same mass but larger surface area emit much more radiation and are more easily detected than compact metallic forms.

Other factors that can influence SNM radiation intensity are the enrichment, composition, and purity of the material. HEU with its low-energy, lowintensity radiation is the most difficult form of uranium to detect. Low-burnup" plutonium, with its more intense radiation and radioactive impurities gained from the radioactive decay of ${ }^{241} \mathrm{Pu}$, is much more easily detected. In addition, the ${ }^{241} \mathrm{Pu}$ decay products accumulate as time goes on, making the plutonium an even more intense gamma-radiation emitter that becomes easier to detect as it ages.

Most applications of SNM monitors require detecting the common forms of SNM, enriched uranium and low-burnup plutonium. These materials are mixtures of various uranium or plutonium isotopes rather than absolutely pure single isotopes. Each possible mixture of isotopes has its

\footnotetext{
Low-burnup plutonium contains about 6\% of the isotope ${ }^{240} \mathrm{Pu}$ and is a type of plutonium used for weapons production.
}

own radiation signature to which an SNM monitor may respond differently. The two particular types of SNM producing the lowest monitor response, HEU and low-burnup plutonium, are most often used to gauge SNM monitor performance. Other types of SNM are more readily detected or are less attractive to a diverter. We have adopted HEU as the standard test material for pedestrian monitors. The HEU, in the form of a metallic sphere, has about half of its radiation spectrum in common with a smaller metallic sphere of low-burnup plutonium: the $\mathrm{x}$-ray region at $100 \mathrm{keV}$. Hence, HEU is a representative test material; moreover, it is a constant-intensity test material that has no radioactive impurity build-up as has plutonium.

The HEU radiation inisnsity per gram of material is much lower than that for plutonium; a $10-\mathrm{g}$ metallic sphere of HEU is equivalent in most monitors to a $0.29 \mathrm{gg}$ sphere of low-burnup ple tonium having a low impurity content. A calibrated monitor that detects the $10 \mathrm{~g}$ uranium source in the standard walk-through test described in Part 2 also detects the 0.29-g plutonium source. Los Alamos provides standard 10-g HEU spheres without charge to DOE contractor facilities and SNM monitor manufacturers. The spheres are used to test SNM monitor performance in a standard fashion.

\section{Monitoring Times}

The length of time available for monitoring influences the performance of a monitor; longer counting times give more precise results that permit use of a lower alarm increment without an increase in falsealarm likelihood. Walk-through monitors allow free pedestrian motion and have only a second or two of monitoring time available. In addition, they monitor a moving target that produces an appreciable signal for only part of the time (Fig. 7). If slight exit delays are tolerable, monitoring performance can be improved. Pedestrians can be slowed with turnstiles or stopped completely by traffic signals or doors to obtain a few seconds of additional monitoring time. Placing detectors in a booth is an appropriate way to extend the monitoring time, particularly when a TV surveillance system already is being used in an entry control booth.

An example of the range of mass detection sensitivity for one particular SNM monitor (Table i) illustrates the increased sensitivity obtained with longer monitoring periods. Unfortunately, extended monitoring times are unpopular because rapid exit 


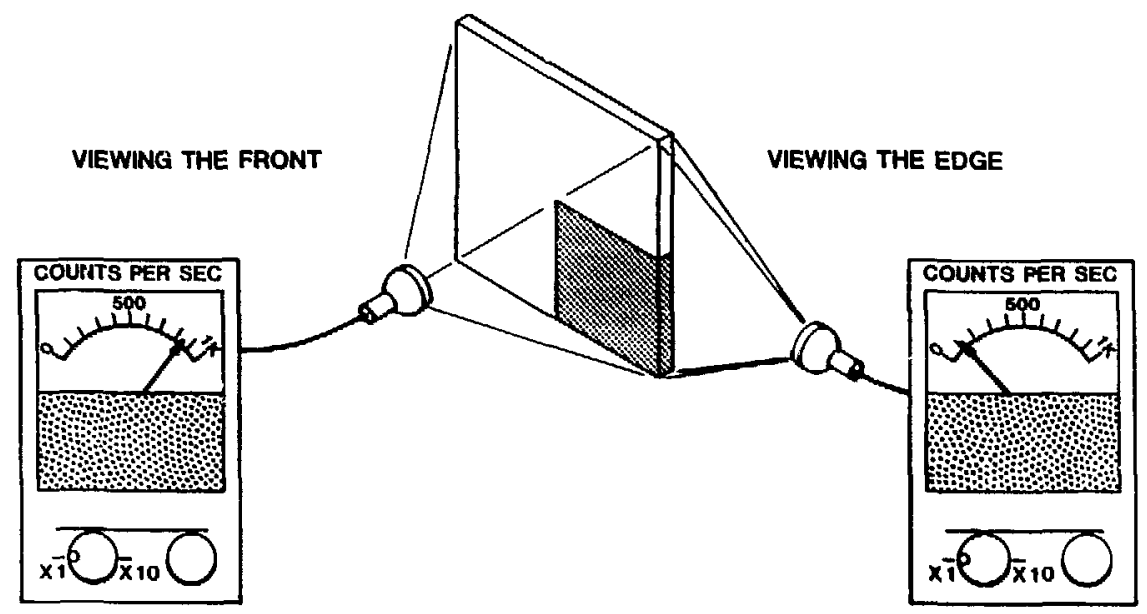

Fig. 6. The physical form of SNM has an important influence on the amount of radiation that is absorbed within the material itself. Thin sheets of material emit much more radiation from their flat surfaces than from their edges.

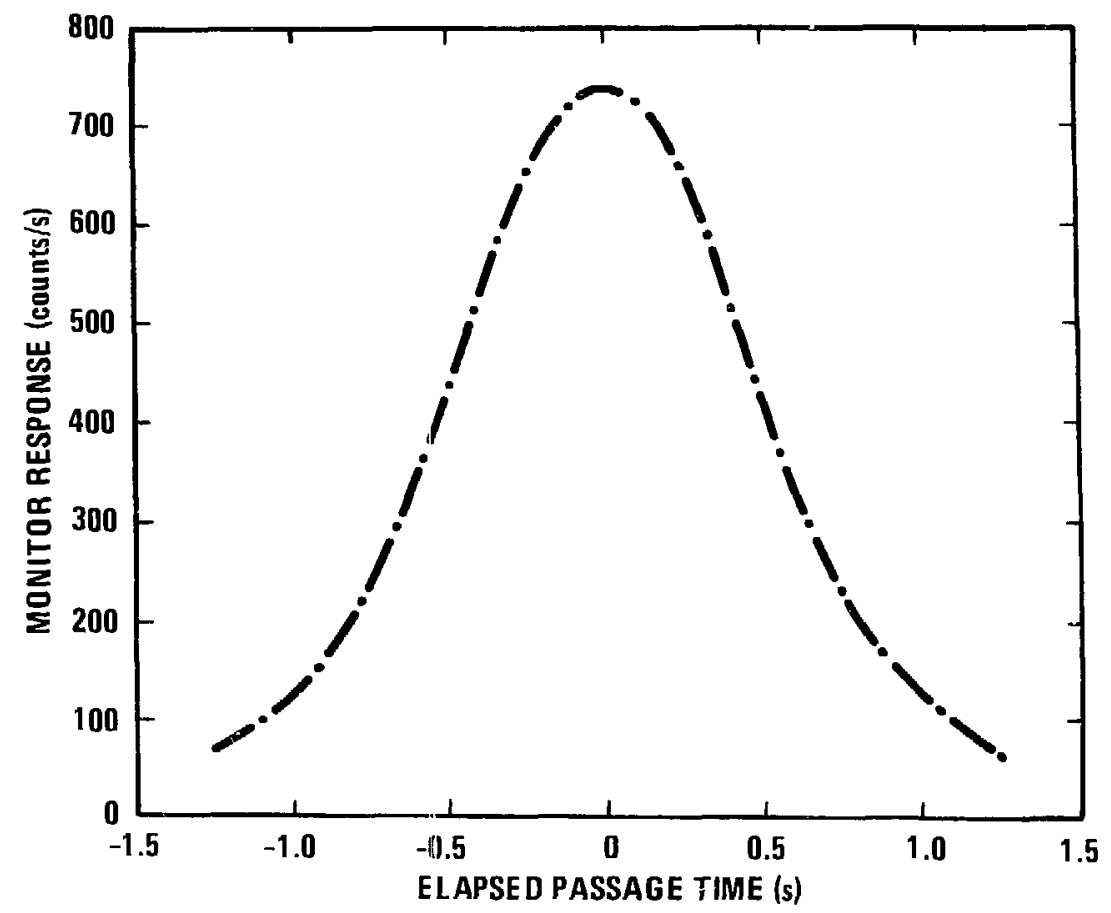

Fig. 7. The signal from SNM in a walk-through monitor exhibits a profile that is intense only for a short period for the average pedestrian traveling at $1.2 \mathrm{~m} / \mathrm{s}$. 


\begin{tabular}{|c|c|}
\hline $\begin{array}{c}\text { Mionitoring } \\
\text { Time (s) }\end{array}$ & $\begin{array}{c}\text { HEU Mass } \\
\text { Detected“ (g) }^{\text {(g) }} \\
\end{array}$ \\
\hline $\begin{array}{l}0.1 \\
0.5 \\
1 \\
2 \\
4 \\
8 \\
\end{array}$ & $\begin{array}{l}27.6 \\
13.4 \\
10 \\
2.7 \\
1.6 \\
1\end{array}$ \\
\hline \multicolumn{2}{|c|}{$\begin{array}{l}\text { The HEU is a metallic sphere. Ten, } \\
\text { two, and one attempts to detect the } \\
\text { material are made as a pedestrian } \\
\text { walks through the monitor at the } 0.1 \text {-, } \\
\text { 0.5-, and 1-s monitoring times, re- } \\
\text { spectively. Otherwise, the occupant is } \\
\text { stationary for the entire monitoring } \\
\text { time. }\end{array}$} \\
\hline
\end{tabular}

during shift changes is the pedestrian's goal; at present, the walk-through SNM portal monitor is by far the most common one being used. But these walkthrough portal monitors can be adapted for slower passage to obtain improved sensitivity similar to the results in Table I. The advantage to eliminating free passage is twofold; an extended counting time and a more constant signal intensity, both of which increase the monitor's sensitivity.

\section{EXAMPLES OF SNM MONITOR MASS DETECTION SENSITIVITY}

If we pick the worst-case values for the factors affecting monitor performance, the bare SNM detection sensitivity under those least favorable conditions in a walk-through SNM portal monitor divides the monitors into the catagories listed in Table II. Walk-through monitors in the first two categories have been commercially available for many years. These commercial monitors were qualified under a set of least favorable conditions in DOE testing during the mid-1970s. ${ }^{24}$ The last two categories are more recent. Category III performance was demonstrated in a laboratory evaluation, ${ }^{5}$ and Category III performance also has been claimed for some Category II monitors with additional radiation detectors as head and foot counters. No commercial walk-through monitor with head and foot counters has yet been evaluated. No walk-through monitor meeting Category IV sensitivity under least favorable conditions has been offered commercially, but such performance is within the capability of modern technology. Note that if free passage is not permitted and the pedestrian is delayed in a monitoring portal, a monitor may achieve sensitivity matching or exceeding the highest walk-through monitor category. Keep in mind that the categories in the table are for least favorable conditions in walk-through monitors; the actual performance of monitors will exceed that listed in the table if the plant environment has lower background intensity or more favorable forms of SNM.

Any monitor performs less well when SNM is shielded. Published results for detecting shielded material under unfavorable test conditions are given in Reference 6 and are repeated here in Table III. The minimum detected uranium masses increase more rapidly because HEU radiation is less penetrating than plutonium radiation. As for bare material, monitoring effectiveness for shielded material is better in more favorable background environments or with extended monitoring time.

We have not mentioned detection sensitivity for the other protected materials: ${ }^{233} \mathrm{U}$, reactor-grade plutonium containing a larger percentage of both ${ }^{240} \mathrm{Pu}$ and ${ }^{241} \mathrm{Pu}$, and heat-source plutonium materials containing a great deal of ${ }^{238} \mathrm{Pu}$. These highly radioactive materials are readily detected in smaller quantity than the less radioactive low-burnup plutonium. On the other hand, the uncommon isotopes ${ }^{240} \mathrm{Pu}$ and ${ }^{242} \mathrm{Pu}$ emit relatively low-intensity, low-energy gamma radiation and if either of these isotopes were available in pure form, they would be detected only in somewhat larger quantity than ${ }^{235} U$.

\section{APPLYING AUTOMATIC SNM PEDESTRIAN MONITOR TECHNOLOGY}

\section{A. Preplanning}

In many cases, whether and how to monitor and where to locate pedestrian SNM monitors is dictated by circumstance rather than being a matter of informed choice. Given a choice, there is an opportunity to select a location that will offer best performance from the monitor and the least amount of inconvenience to everyone involved. The major objectives of preplanning should be to select a location that has a relatively low and constant background radiation intensity, has room to position the monitor without interfering with normal traffic, has adequate space for servicing the monitor but not room to bypass it, has a direct line of sight to an 


\begin{tabular}{|c|c|c|c|}
\hline \multicolumn{4}{|c|}{ TABLE II. Mass Detection Sensitivities of Walk-Through SNM Monitors" } \\
\hline Category & Description & Uranium $^{\mathrm{b}}(\mathrm{g})$ & Plutonium' (8) \\
\hline $\mathbf{I}$ & Standard plutonium & 64 & 1 \\
\hline II & Standard uranium & 10 & 0.29 \\
\hline II & Improv sensitivity & 3 & 0.08 \\
\hline IV & High sensitivity & 1 & 0.03 \\
\hline \multicolumn{4}{|c|}{ 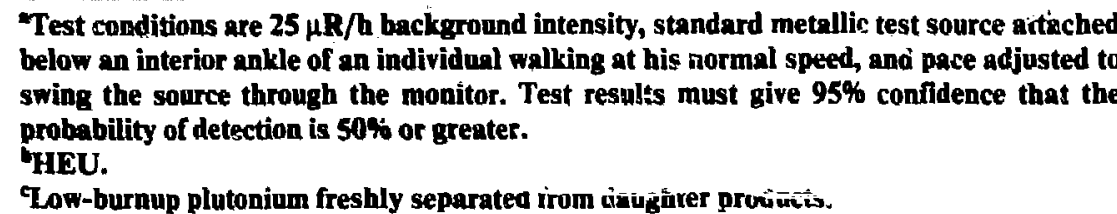 } \\
\hline
\end{tabular}

\begin{tabular}{|c|c|c|}
\hline $\begin{array}{l}\text { Lead Shielding } \\
\text { Thickness (mm) }\end{array}$ & HEU Mass (g) & Plutonium Mass (g) \\
\hline 0 & 4 & 0.1 \\
\hline 1.6 & 300 & 1 \\
\hline 3.2 & 1000 & 3 \\
\hline 6.4 & - & 10 \\
\hline 12.7 & --. & 50 \\
\hline
\end{tabular}

attendant or television camera, and has freedom from interference by other perimeter security monitors.

Certainly, ideal conditions are never fully realized; however, preplanning allows time to cope with some of the problems. For example, if the background intensity is higher than natural intensity, perhaps a contaminated area can be cleaned or covered with shielding material. Or perhaps the monitor can be put into its own shielded maze or room. Concrete walls offer good shielding in many cases. If high background radiation is from a local source, perhaps a monitor with built-in detector collimation will improve the situation and permit interference-free operation. Both collimation and shielding are easily applied and effective although the monitor may have to be placed in a lead-shielded room to achieve background low enough for uranium detection. When low-burnup plutonium or HEU is the source of excessive background, shielding with fairly thin lead, $1 / 8$ in. or so thick, is often adequate. In other cases, interference from reactor-grade or heat-source pluto- nium material for example, much heavier shielding is required.

\section{B. Climate}

Monitors located indocrs in climate-controlled environments are the ones that operate best. Outdoor monitors demand measures to control both physical damage and performance degradation from temperature extremes, moisture, or corrosive chemicals. Good waterproofing is easily provided and climate can be controlled in air-conditioned electronics cabinets. Detectors can be cooled thermoelectrically. In each case, cabinets should be painted white to minirnize the heat load and insulated to minimize the amount of active cooling that is required.

Heating is necessary in cold climates, and white paint and insulation also help here. Where both heating and cooling are required, a dead band in the temperature control at intermediate ten neratures will prevent continuous switching back and forth between heating and cooling throughout the year. 


\section{Protecting the Monitors}

Tamper protection should, of course, be provided, and this includes installing don switches and placing external wiring in metallic conduit. Most monitors provide high- and low-intensity test thresholds for background intensity to sense if someone is artificially increasing background with sources and to sense if someone is somehow shielding the detectors to redruce their response to SNM, two things that could diminish the monitor's effectiveness. The background test thresholds also warn of detector failure. Bypass barriers are another antisubversion measure, which prevent SNM being transported aron und an SNMI monitor or monitoring station.

Besides the measures to prevent subversior. tine monitors also need fhysical protection against damage. Outcoor monitors in particular need crash protection, perhaps by concrete-filled steel pirs: located where they can prevent damage. Indocr monitors usually need to be firmly bolted to the floor and, in some cases, crash barriers are necessary to prevent damage from fork-lift vehicles.

\section{Caibrating and Servieing the Monitors}

Few monitor manufacturers are able to develop good calibration manuals, a task that requires not only technical expertise but also SNM source materials and adequate experience with plant maiutenance practices. Some DOE facilities have developed their own calibration procedures for commercial monitors; Los Alamos has written calibration manuals ${ }^{7,8}$ for the monitors evaluated there and provides them to other DOE facilities. LOS Alamos also has begun to provide SNM test sources to DOE facilities and SNM monitor manufacturers to standardize the source available for gauging monitor performance. The standard sources allow manufacturers and users to communicate in the same frame of reference.

Manufacturers are better at providing service information, but sometimes this information is inadequate. Equipment may have to be returned to the manuíasturer for repair, or plant service personnel may have to be trained by the manufacturer. Before purchasing training by a manufacturer, a monitor user should specify that training include good written material thit can be used by others. Trained service people often advance in their careers, leaving SNMi monitors for cthers to maintain without adequate means to carry out the task. Written text helps make on-the-job training possible, as do detailed written records of service and calibration for individual monitors.

Spare parts are often overlooked but they are essential to monitor upkeep. Monitors may have limited-lifetima components such as lamp bulbs or switchmats. These items must be stocked at the user's plant to ailow quick repair and return of a disabled monitor to service. Otilerwise, weeiks can go by before replacements are obtained. Also, if a number of identical monitors are in use, there is a benefit in stocking at least one of any component that can wear out or need repair. The stock allows components to be replaced immediately when they fail, returning the disabled monitor to service while the failed componont is repaired or replaced.

\section{E. Testing the Monitors}

On a daily and quarterly basis, monitors should be tested. The daily test is easy and is quickly done; simply occupy the mo-itor while holding a $1-\mu \mathrm{Ci}$ ${ }^{137} \mathrm{Cs}$ ( 1 microcurie of cesium-137) source and see whether the monitor alarms. Tbe object is to check the continuity of the system and verify that increased radiation intensity results in an audible alarm. Each side of a detector portal should be tested. This test detects failures suon after thcy appear so that any failure can be quickly repaired.

Quarterly tests have a differeat purpose. They follow recalibration and vesify the calibration to assure that the monitor does not lack sensitivity for detecting SNM. Hence, an SNM source is used and more than a single test is required. The object is to pass the source through the monitor repeatedly with the source positioned in one of the harder-to-detect locations on the pedestrian's body. For walk-through monitors, we recommend placing the source in one of the pedestrian's shoes at the inside ankle. The pedestrian's pace should plant the source foot at the portal threshold and then swing it through the monitor at a normal walking pace. The pedestrian can pass through the monitor and move well away from it, then reverse or swing around the monitor to pass through repeatedly until perhaps 20 passages have taken place. With the $10-\mathrm{g}{ }^{233} \mathrm{U}$ source, Category III and IV monitors should alarm every time. Category II monitors should alarm more than half the time. Section IX.B in Part 2 provides more information on interpreting the results of walk-through testing.

A smaller uranium source may be needed to test wait-in monitors having higher sen itivity. When these monitors come into use, Los Alamos will provide smaller uranium spherical test sources that 
are closer to the limit of detection ror these monitoring systems.

\section{F. An Example of an SNM Monitor Application}

The points we have been discussing that affect SNM monitor operation are illustrated in Fig. 8. The following list summarizes them; items 3-8 are keyed to the numbers that are circled in the illustration.

1. Provide a monitoring area with low-intensity, low-variability background radiation.

2. Provide adequate climate control for the monitor, either by room heating and air conditioning or by heating and cooling the monitor cabinets.

3. Supervise the SNM monitoring area. Station a guard in the area as an observer or let him observe remotely with good television surveillance.
4. Adequately test and maintain the monitor.

5. Keep the monitor's detectors as close as possible to pedestrians.

6. Slow pedestriar passage speed as much as possible.

7. Allow only one person at a time near the monitor.

8. Provide bypass barriers.

\section{COSTS OF GAMMA-RAY SNM MONITORS}

Gumma-ray SNM monitors can be obtained for $\$ 2,000$ or less for the hand-held units, but a much larger continuing investment is necessary for the services, training, and supervision of the person who does the monitoring. Automatic walk-through SNM portal monitors can be obtained for about $\$ 20,000$ in their simplest form. Wait-in monitors require at least as large an investment for the radiation detection

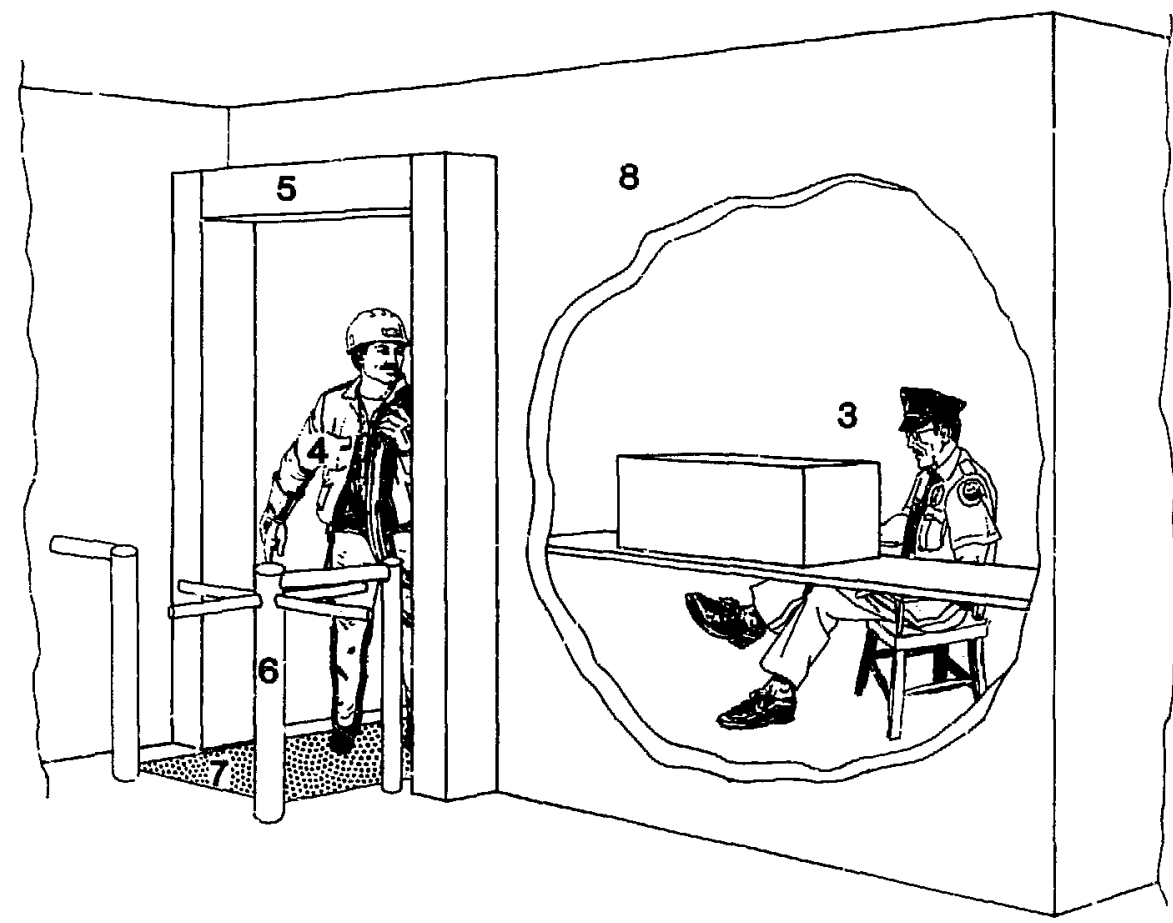

Fig. 8. The factors affecting SNM monitor performance are illustrated here, numbered as they are summarized in the text. 
system and, of course, additional expense when a booth structure and systems for entry control metal detection and positive personal identification are included. The total cost in that case exceeds $\$ 200,000$.

Installation costs for SNM monitors begin at a few thousand dollars for supervised indoor portal monitors and can increase to many tens of thousands of dollars for monitor installations that require extensive construction work.

\section{WHAT ABOUT NEUTRON MONITORS?}

We have not said much about neutron monitoring because few neutron monitors have been developed and evaluated as SNM monitors. The reason is that there has been no impetus to develop a commercial neutron monitoring system in the US. Neutron monitors that have been developed in other countries are intended to detect intense neutron emitting materials and are not high-sensitivity monitoring systems that could compete with gamma-ray monitors for detecting small quantities of bare SNM. The situation may change in the future as new SNM monitoring technology is investigated; more sensitive neutron monitors may find application as vehicle SNM monitors for plutonium (Fig. 9), most likely as a redundant monitoring system opcrating beside a gamnia-ray monitor.
The problem with neutron monitoring is that few forms of SNM are intense neutron emitters. For example, low-burnup plutonium emits about 50 neutrons per second per gram of plutonium compared with perhaps $10^{6}$ gamma rays and $x$ rays per second per gram of plutonium. Neutron monitoring would not be possible except for the extremely low natural background intensity for neutrons. Still, fairly large neutron detectors are required and these can be very expensive.

Neutron monitoring systems may be cost effective for vehicle monitoring. These detection systems are now used together with highly skilled operators as part of semiautomatic assay or source detection systems. Fully automatic neutron SNM monitoring systems attended by relatively unskilled personnel are being developed at Los Alamos.

A final note on neutron monitoring: gamma-ray monitors do have some neutron señsitivity. Large plastic scintillation detectors used in many pedestrian monitors also are quite effective neutron detectors. They do experience a large gamma-ray backgrnund that limits their sensitivity to much larger quantities of bare plutonium than can be detected by gamma-ray emission. However, their neutron sensitivity limits the amount of plutonium that can be removed inside a gamma-ray shield. Under worstcase test conditions, this limit is less than $100 \mathrm{~g}$ of shielded low-burnup plutonium in a Category if waik-through monitor.

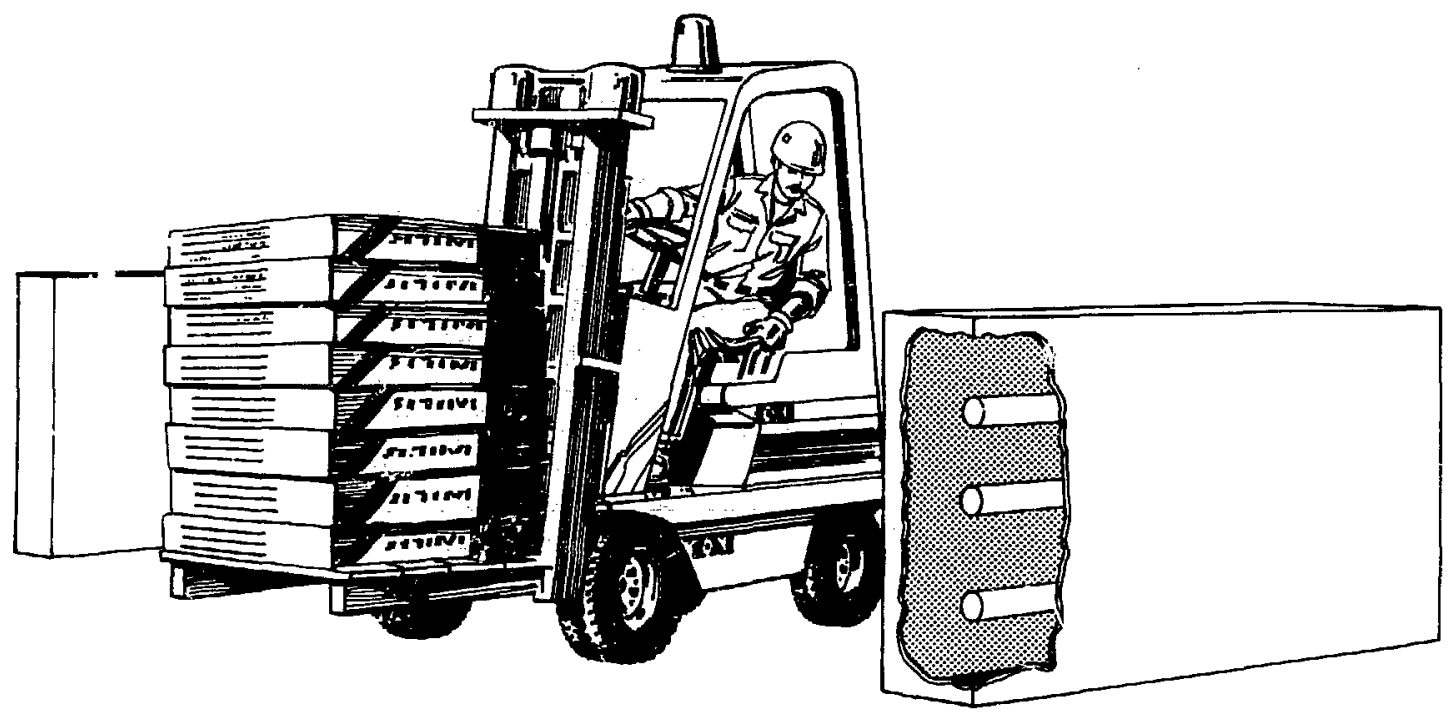

Fig. 9. Neutron monitoring may be practical for monitoring motor vehicles to detect large quantities of shielded plutonium. 


\section{PAKT 2}

\section{THE TECHNICAL BASIS OF RADIATION MONITORING}

\section{INTRODUCTION}

In this part, we give an introductory technical background to radiation monitoring. We describe the operation of gamma-radiation monitors that detect pedestrians carrying SNM by sensing gamma rays emitted by the materials. The SNMs, enriched uranium and plutonium, are primarily gamma-ray emitters but plutonium also emits neutrons with low intensity. However, most present-day pedestrian SNM monitors primarily sense ganma radiation: the detecters respond best to gamma rays and although they do respond to neutrons or secondary gamma rays from a neutron source, the response is small in comparison with the detector's gamma-ray background response. Far more gamma rays than neutrons are enitted by SNM, hence the most effective approach to SNM monitoring is by gamma-ray detection. Specialized neutron monitors that detect SNM by its neutron emission alone are not commercially available but are being investigated.

In this guide, we discuss basic information about gamma radiation and the operation of gamma-radiation monitors. Where appropriate, we discuss the rechnical aspects of neutron monitoring and how neutron monitoring might differ from gamma-ray monitoring. In fact, a pedestrian SNM monitor based on neutron detection alone would most likely be a redurdant detection system employed beside a gamma-raciation monitor. Not all forms of SNM emit neutrons; a high-sensitivity neutron pedestrian. monitor could suffice only at a material-access area containing plutonium alone.

We begin with a short historicai discussien of gamma-ray monitoring and continue by describing gamma rays, SNM gamma-ray emission, and gamma-ray spectrā. Later, after a discussion of gamma-ray detectors and gamma-ray source detection, we describe analog and digital SNM tnonitors and their calibration, evaluation, and testing.

\section{A BRIEF HISTORY OF RADIATION MONITORING}

The means to detect radiation have been developing since the late nineteenth century when photoelectric currents were noticed in evacuated tubes and photographic films were seen to darken in the presence of uranium saits. At first, the impetus for developing radiation detectors was to study the nature and origins of the radiation itself. In later years, the increasing amount of radioactive substance and radiation-producing machines made it necessary to develop special instiuments to determine radiation field intensities as a safety measure and to monitor for radjoactive contamination. This simple equipment soon spread to uranium prospecting and, when the need arose, to SNM monitoring. The need to improve protection against. SNM diversion then fostered development of very sensitive hand-held and automatic portal monitoring systems.

Scintillation detectors used in SNM monitors are the key to obtaining high detection sensitivity in radiation monitoring. The scintillation detectors-inorganic crystal scintillators such as scdium iodide $[\mathrm{NaI}(\mathrm{Tl})]$ or organic scintillators containing fluors in solid or liquid solution-enhance the capabilities of radiation monitors, making them highly effective for SNM diversion monitoring. In addition, the availability of solid-state electronics makes digital circuitry possible, allowing information to be rnore effectively extracted from the signals detected in SNM monitors.

Along with the detectors and detection circuits, the methods to interpret the information produced by a detector have evolved. An early method eniployed a simple analog court-rate meter to indicate the radiation intensity. The meter could be observed repeatedly to detect transient changes in radiation intensity. Adding an adjustabie alarm threshold to the count-rate meter then made it possible to select a point to suund an alarm so that a radiation intensity excursion could be announced without an observer. Later, more complex analog circuitry detected transient intensity increases in a variable background environment. The circuitry used long-term intensity data as background to compare with short-term siginal intensity, and it alarmed when the two differed significantly. One commercial monitor employing this technique sîll operates at several DOE contractor facilities. In the 1970 s, simple aigital logic circuits duplicated analog circuit pe:formance without need. ing analog circuit calibration adjustments. These digital circuits are not only free from many calibration requirements but perform precisely as prt:dicted, another advantage over analog circuits.

The most recent developments in digital circuitry are microprocessors that further enhance the capabilities of radiation monitors. With microprocessor programs, transient increases in radiation intensity are detected, and self-diagnostic information, 
calibration aids, and a menu of keyboard-selected operational choices are also available within the microprocessor control logic repertoire.

\section{GAMMA RADIATION}

Gamma rays are electromagnetic radiation similar to light of radio waves. However, gamma rays are very energetic forms of electromagnetic radiation that are not sensed by the eye or radio receivers in any practical manner. Gamma rays interacting with the eye, for instance, simply cause heating without imparting visual information. On the other hand, ionization by gamma rays in some materials can lead to useful information after the ionization is converted to an electrical current or visible fluorescence radiation. These materials may form practical radiation detectors.

Gamma rays are produced in gamma-ray sources as a result of radioactive decay in which the nucleus of a source atom undergoes spontaneous rearrangement that changes its internal energy. The energy difference between two states of the nucleus can appear as gamma radiation. After first discussing the radioactive decay process, we will examine the energy distribution of the gamma rays from various forms of SNM.

\section{A. Radioactive Decay}

The number of radioactive atoms in a radioactive source is continually decreasing because the atoms have a constant probability of decaying. The constant decay probability leads to an exponential decay law that relates the number of atoms present $R$, at an elapsed time $t$, to the original amount at time zero. This takes the form

$$
\mathbf{R}=\mathbf{R}_{0} \mathrm{e}^{-0.693 \mathrm{t} / \mathrm{t} / \mathrm{L} /},
$$

where $\mathbf{R}_{\mathbf{0}}$ is the original number of atoms in the source, and $T_{1 / 2}$ is a unique constant for each source called the half-life of the source. The half-life represents the time required for half of the atoms present to decay.

The decay rate or activity of a radioactive source is the average number of atoms that decay per second, and this quantity is directly proportional to the number of atoms in the source but inversely proportional to its half-life. The most familiar unit of activity is the curie, which equals $3.7 \times 10^{10}$ disintegrations per second. Notice that the more active sources are the ones with shortest half-life because they are decaying faster.

The other variable factor in radioactive decay is the number of gamma rays that are emitted for each decay. In the course of radioactive decay, the radioactive atom changes its internal energy state at least once but perhaps more than once; it may even pass through a sequence $G_{1}$ many energy states. As a result of such decay chains, it is not uncommon for many gamma rays to be emitted in each decay. Besides decay chains, alternative docay modes for the atom may be possible, each with its own probability of taking place. In this case, a particular source may emit a particular gamma ray in only a fraction of its disintegrations. The fraction is called the abundance of that particular gamma ray. The $185-\mathrm{keV}^{*}$ gamma ray i: Fig. 10 is emitted $56 \%$ of the time when ${ }^{235} \mathrm{U}$, the common fissile isotope of uranium, decays. Other

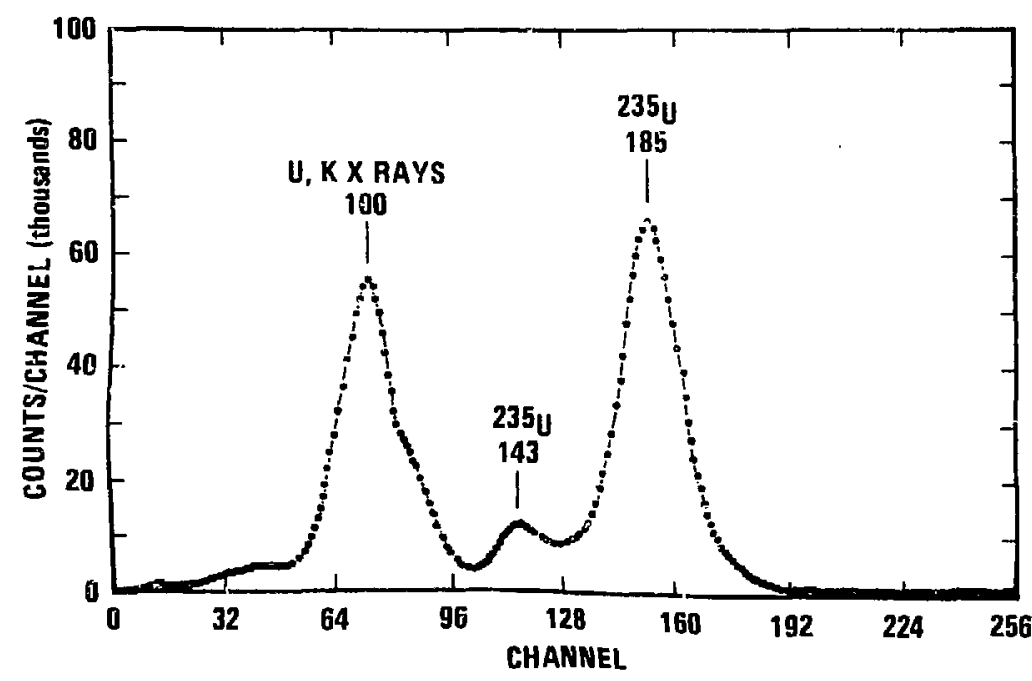

Fig. 10. The NaI(TI) scintillation ietector pulse-height spectrum of HEU has a prominent 185 -keV peak characteristic of ${ }^{235} \mathrm{U}$. The rest of the spectrum incluciing the $x$-ray peak is also important for monitoring. 
radioactive species may have a variety of gamma rays, each with a different abundance reflected in a variety of intensities in the gamma-ray spectrum. And other peaks that are not caused by gamma rays also appear in some spectra; in Fig. 10 the $100-\mathrm{keV}$ area is a well-mixed peak containing $x$-ray peaks from decay chains and $x$-ray fluorescence interactions in uranium.

The fact that SNM is a mixture of isotopes of uranium or plutonium together with daughter species also complicates SNM gamma-ray spectra. The intensity of peaks in SNM spectra varies over a tremendous range, for example from a few hundrea gamma rays/s/g of isotope to hundreds of millions of garnma rays/s/g of isotope for ${ }^{232} \mathrm{U}$ (Fig. 4). Oniy the most intense gamma rays are useful for diversion monitoring; and these are not necessarily from the principal isotopes in the material. They are from the isotopes with the best combination of activity and abundance.

\section{B. Gamma-Ray Energy Spectra}

SINM isotopes emit gamma rays tha: have unique energy characteristics. For example, the gamma-ray energy spectrum that was obtained with a $\mathrm{NaI}(\mathrm{Tl})$ scintillator and ${ }^{235} \mathrm{U}$ (Fig. 10) has a peak associated with the 185-keV gamma ray. The presence of this gamma ray, along with its intensity and our knowiedge of the geometry of the material, can identify the isotope and reflect how much of the material is present.

But the relationship between the amount of material and the detected radiation intensity can be altered by three factors.

- Gamma rays interact with all materials including the emitting material itself (self-shielding) and surrounding materials (external shielding).

- Only a small fraction of the total number of emitted gamma rays is actually intercepted and detected by the SNM monitor (solid angle factor).

- Gamma rays from background or other sources may produce events of the same energy that underlie the gamma-ray region of interest (background effecis).

\footnotetext{
"Do not confuse the terms intensity and energy. Both terms are important, and SNM is most easily detected when it emits high-energy (many kiloelectron volts per photon) radiation with high intensity (many photons per second).
}

We discuss the importance of these factors in the following sections.

\section{Gamma-Ray Interactions with Materials}

In practice, not all of the gamma rays emitted by SNM are detected. First of all, some of the gamma rays may be absorbed in the source itself, or perhaps by its encapsulating material. Second, the detector will respond differently to gamma rays of different energies. For example, the housing of the detector may prevent low-energy radiation from passing through to reach the detector, while on the other hand, very high energy radiation may pass through the detector material itself without being absorbed (or detected). A quantity called the intrinsic detector efficiency has a value at each particular gamma-ray energy that expresses the probability of detecting a gamma ray of that energy entering the detector. The intrinsic detector efficiency includes the probability of detection for each of three separate absorption interactions.

The absorption interactions result when electrically neutral gamma rays interact with any material and produce charged particles (ionization). Charged particles are produced when energy is transferred to electrons in a material by interactions that vary with the energy of the interacting gamma ray. The three principal interaction processes leading to ionization are

- the photcelectric effect,

- Compton scattering, and

- pair production.

The importance of each of these processes varies with gamma-ray energy. Photoelectric processes dominate at low energy, pair production at high energy, and Compton scattering is most important in between.

- Photoelsctric Effect. The photoelectric effect is a process by which an incident gamma ray is totally absorbed by an atomic electron in an absorbing medium; this is the most important absorption mechanism for SNM radiation in crystal scintillators such as $\mathrm{NaI}(\mathrm{Tl})$. Absorption gives the bound electron additional energy that ejects it from the atom. The energy of the ejected electron is equal to the incident gamma-ray energy minus the binding energy of the atomic electron in its original atom. This energy later 
reappears partly as ionization and partly as characteristic $x$ rays of the absorbing atom, when a free electron replaces the ejected one. When energy is collected, the result in a detector is an electrical pulse or is simply heating in an absorbing material. In a radiation detector, when all of the radiation energy is collected, the magnitude of the detected pulse is related to the incident gamma-ray energy. This is important in SNM monitors; regions of interest matching the SNM spectrum can be set using the relationship between incident radiation energy and the detected pulse height.

- Compton Scattering. Compton scattering is a process in which a gamma ray is deflected from its path, or scattered, by outer, loosely bound electrons in an atom of an absorber or detector. Compton scattering is the most important absor) Jtion mechanism in organic (plastic) scintillators but plays a less important role in other scintillators. The Compton process reduces the energy of the incident ganma ray and produces a recoil electron having an energy that depends on the amount of deflection of the incilent gamma ray. The scattered gamma rays can escape the medium or undergo further Compton or other inter- actions within the medium. As a result of Compion interactions, a detected radiation pulse in a detector may have a variety of pulse heights, all of which are lower than a photoelectric-peak pulse height would be. The maximum energy, $E_{\max }$, that can be transferred in a single Compton event depends on the incident gamma-ray energy $\mathbf{E}_{\mathrm{z}}$. In units of $\mathrm{keV}$, the expression for maximum transferred energy is written below; note that it is nonlinear. When we discuss calibration procedures in Sec. VII.E, we will give examples of maximum recoil energy for particular gamma-ray energies.

$$
E_{\max }=\frac{E_{g}}{1+\frac{511}{2 E_{B}}} .
$$

At very high energies, the maximum energy transferred to an electron can be near the incident gammaray energy. At very low energies, very little encrgy can be transferred. But in all cases, there is a distribution in energy transfer that is illustrated in the solidorganic (plastic) scintillator spectrum in Fig. 11.

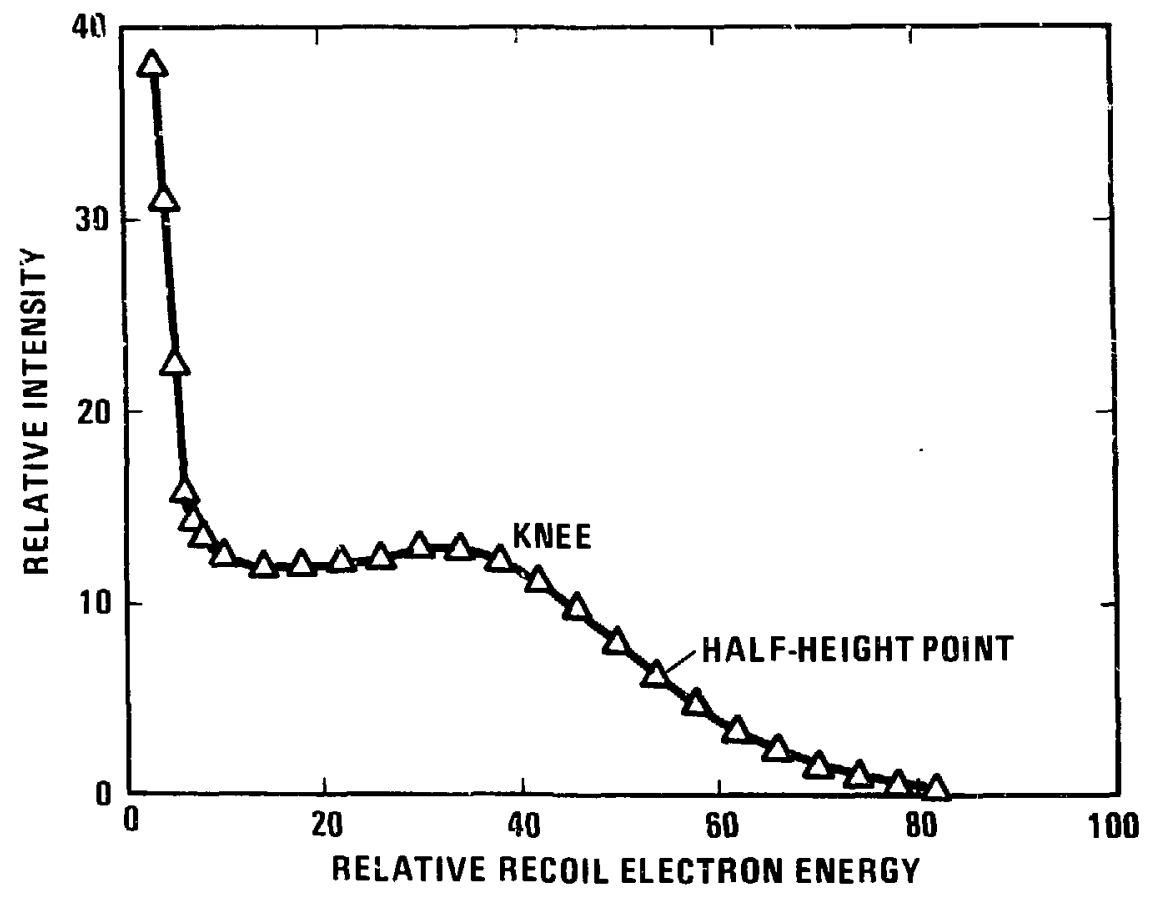

Fig. 11. The organic scintillator pulse-height spectrum has no photoelectric peaks, just a continucus distribution of Compton recoil electron energies. Monoenergetic $662-\mathrm{keV}$ radiation produces a knee shape with its half-height point proportional to the maximum recoil electron energy. 
- Pair Production. The third energy-transfer process produces an electron-positron pair when the gamma ray interacts with a strong electric field near an electron or a nucleus. It appears only when the incident gamma-ray energy exceeds $1.02 \mathrm{MeV}$, usually well above the region of interest for SNM monitoring.

The effect of these absorption processes is that radiation passing through matter decreases in intensity and that the fractional decrease in intensity is the same for equal distances traversed at any particular gamma-ray energy. As a result, the transmitted intensity $I$ at a distance $x$ into a material decreases exponentially from the intensity $I(O)$ at entry according to the relationship

$$
I(x)=I(0) \exp \left(-\mu_{1} x\right)
$$

where $\mu_{1}$ is the linear absorption coefficient.

Values of the linear absorption coefficient include the effects of each of the processes that we have discussed; hence the absorption coefficient values depend not only on the kind of absorbing material but also on the gamma-ray energy. The inverse of the linear absorption coefficient $1 / \mu_{1}$ is called the mean free path of the particular gamma ray in the particular material. It numerically represents the thickness of absorber required to reduce the garnma-radiation intensity to $37 \%$ of its initial value. The mean free path estimates now much radiation will penetrate a shielding material or be absorbed.

In detectors, knowing whether the gamma ray is likely to be absorbed can indicate whether that gamma ray will be detected. The gamma ray must first be absorbed to be detected. In a source or in shielding material, knowing whether the gamma ray is likely to be absorbed can indicate whether it will reach the outside world where it would be available for detection in a monitor. Table IV illustrates the range of values for $\mu_{1}$ and mean free path for source, absorber, and detector materials.

\section{The Inverse Square Law of Radiation Intensity}

Intervening materials may lower radiation intensity by absorbing radiation from a source before it can reach the detector. The distance between the detector and source can have a similar effect. A point source of radiation emits radiation uniformly in all
TABLE IV. Absorption Coeficient and Mean Free Path for 100-keV Photons in Absorbers and Detectors

\begin{tabular}{lcc}
\hline Material & $\begin{array}{c}\text { Linear Absorption } \\
\text { Coeficient }\left(\mathrm{cm}^{-1}\right)\end{array}$ & $\begin{array}{c}\text { Mean Free Path } \\
\text { (cm) }\end{array}$ \\
\hline Source: & & \\
$\quad$ Plutonium & 27 & 0.037 \\
Uranium & 32 & 0.031 \\
Detector: & & \\
$\quad$ NaI(T1) & 6.5 & 0.15 \\
$\quad$ Plastic & 0.15 & 6.6 \\
Shielding: & & \\
$\quad$ Aluminum & 0.44 & 2.3 \\
Iron & 2.7 & 0.37 \\
Lead & 59.3 & 0.017 \\
\hline \hline
\end{tabular}

directions, causing the radiation flux to fall off as the square of the distance traveled. For example, the flux $I$ at a distance $d$ from a point source having flux $I_{0}$ at 1 unit distance would be the following:

$$
\mathrm{I}=\mathrm{I}_{0} / \mathbf{d}^{2} \text {. }
$$

Combining the inverse square factor and size of the detector gives the solid angle subtended $b /$ a detector, which, when divided by $4 \pi$ steradians, is the fraction of source radiation intercepted by a detector. The product of solid angle factor and intrinsic efficiency is called the total efficiency and relates an observed detector count rate at a particular gamma-ray eneriby to the emission rate of that particular gamma ray (Fig. 12).

The inverse square factor is important in SNM monitoring because the closer a monitor is to SNM, the more intense is the signal. Hence SNM is easier to detect the closer we come to it. This is the reason that hand-held monitors are so effective when they are properly used. Hand-held monitors can approach diverted material, perhaps coming within centimeters of it, whereas portal monitors have fixed detector positions that may be $70 \mathrm{~cm}$ or more apart. At their center, portal monitor detectors may be no nearer than $35 \mathrm{~cm}$ to SNM, where the signal is much smaller than near a hand-held monitor-perhaps only $1 \%$ as much. To compensate for the smaller

\footnotetext{
"The radiation flux is the number of photons per second that would cross a $\mathrm{I}-\mathrm{cm}^{2}$ area.
} 

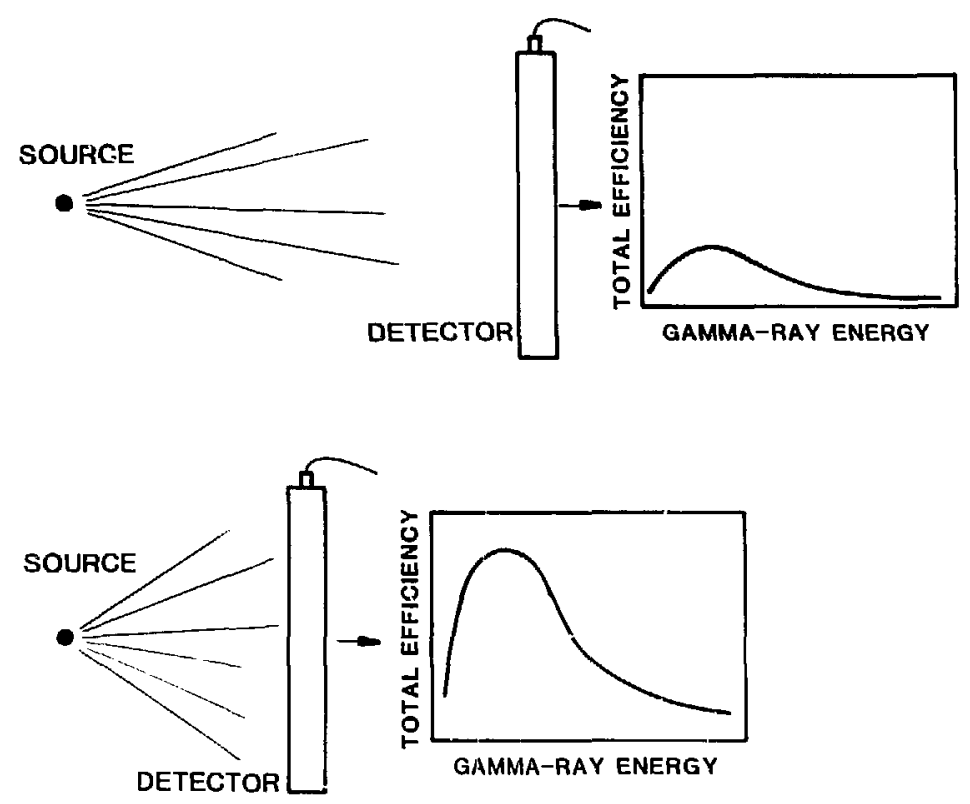

Fig. 12. Total efficiency of a radiation detector includes the effects of the scintillator intrinsic efficiency, its size, and its distance from the radiation source.

signals, portal monitor detectors are much larger, perhaps 100 or more times as large as hand-held monitor detectors.

\section{GAMMA-RAY SOURCE CHARACTERISTICS}

Both the SNM bein? monitored and the radiation en vironment are sources of gamma radiation. Each source of gamma rays is important in SNM monitoring; SNM gamma rays provide the diversion signal and natural gamma rays introduce a background intensity above which SNM gamma rays must be detected.

\section{A. Background Radiation}

Natural gamma-ray background stems from cosmic rays and from naturally radioactive material in soil and building materials, principally uranium and thorium and their radioactive-decay daughters, and ${ }^{40} \mathrm{~K}$ (potassium-40). Other background stems from artificially produced or enhanced radiation emitters such as process materials, waste materials, stored inventory items, or radiation-producing machinery of some sort. At most monitoring locations, a com- bination of these sources of background radiation will be present and many of them will have intensities that vary with time.

Some specific background contributors are

- Cosmic Rays. Part of the natural background is produced when cosmic rays interact with the atmosphere. The importance of this contribution varies with altitude and may vary by as much as a factor of 6 over the range of altitudes where SNM radiation monitors are used. This is an important natural variable factor for neutron backgrounds, and highest neutron backgrounds are found at highest altitudes.

- Geological Sources. Natural gamma-radiation emitters in soil and rock are found in varying concentrations at different locations in the US, and their radiation can directly influence a radiation monitor according to their concentration near the surface. In addition, a natural isotope ${ }^{226} \mathrm{Ra}$ decays in soil and rock, producing a daughter that is gaseous and can move into the aimosphere. The daughter isotope ${ }^{222} \mathrm{Rn}$ decays in steps that include two short-lived gamma-ray-emitting isotopes that produce part of the natural gamma-ray oackground, which can vary. The ${ }^{22} \mathrm{Rn}$ daughters attach to dust particles in the atmosphere, and therefore the amount of these 
materials present in the atmosphere varies for two reasons. One is that precipitation alters the amount of the parent ${ }^{222} \mathrm{Rn}$ that can leave the soil to enter the atmosphere. The other is that during precipitation, dust with attached ${ }^{222} \mathrm{Rn}$ daughters serves as a nucleation point for raindrops that precipitate the radiation emitters. On the ground, the ${ }^{222} \mathrm{Rn}$ daughters increas the background intensity for periods of an itour (Fig. 13) or so following precipitation.

- Building Materials. Radiation-emitting soil or rock can boduced into building materials. These $m g t a j$ are often removed from their native areas and are used at other places where they become localized sources of radiation. Decorative stone and paving materials are two very common localized radiation sources.

s Artificial Sources. Background radiation may include emissions from the SNM being protected or from other incidental radioactive materials. These may introduce a steady background signal or one that changes as material is moved about or shielded by intervening objects. A particularly troublesome situation arises when stored radioactive material is temporarily shielded long enougk for an SNM portal monitor to record a lower backgro'nd intensity. Then when the shield is removed and background increases, a person passing through the portal monitor at the time may experience an alarm from the increasing background. This situation can bc investigated with a hand-held monitor to verify that the individual did not cause the alarm. Other timevarying background sign: may originate from radiation-producing suschinery. For example, the highly varying background in Fig. 14 results from a wind-borne plume of short-lived gaseous isotopes iom a linear accelerator beam stop.

Terrestrial gamma-ray background intensity varies from place to place as the concentration of the terrestrial gamma-ray emitters varies. Seashores may have low background radiation intensities of only a few microRoentgens per hour $(\mu R / h)$. On the other hand, mountainous areas or the Colorado Plateau states of Utah, Colorado, and New Mexico may have high radiation intensities of $15 \mu \mathrm{R} / \mathrm{h}$ or more. Building materials containing radiation emitters that reflect the origin of the macerial may cause wide variation in ambient-radiation intensity in cities.

Natural neutron backgrounds produced by cosmic rays are augmented most often by backgrounds from plutonium in transit or storage. A fe $v$ neutronproducing machines are in use, but processing large quantities of neutron-emitting materials is the most common cause of variable neutron background.

Wherever any background variation is possible, a timely determination of the ambien bac sround

The unit of radiation exposure used here, the $\mu R / h$, is approximately the exposure from a 3 -microcurie $(\mu \mathrm{Ci})$

${ }^{137} \mathrm{Cs}$ source at a distance of $1 \mathrm{~m}$ and is an appropriate unit for background intensities.

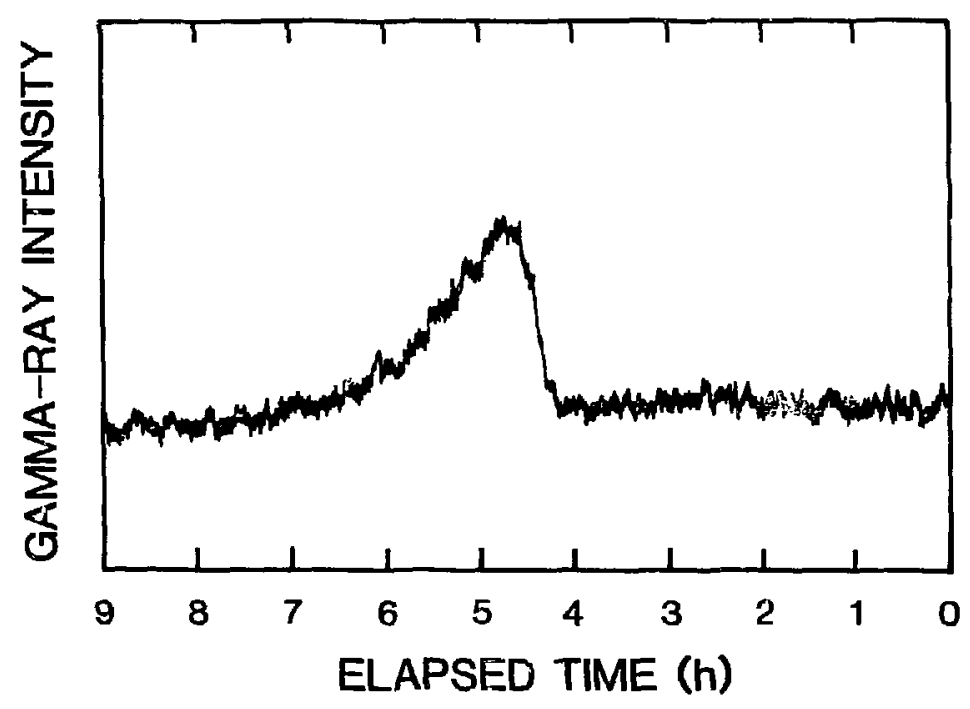

Fig. 13. A brief intense snowfall deposited radioactive ${ }^{222} \mathrm{Rn}$ daughters on a gamma-radiation detector, causing the measured background to increase for an hour or so as the short-lived daughters decayed. 


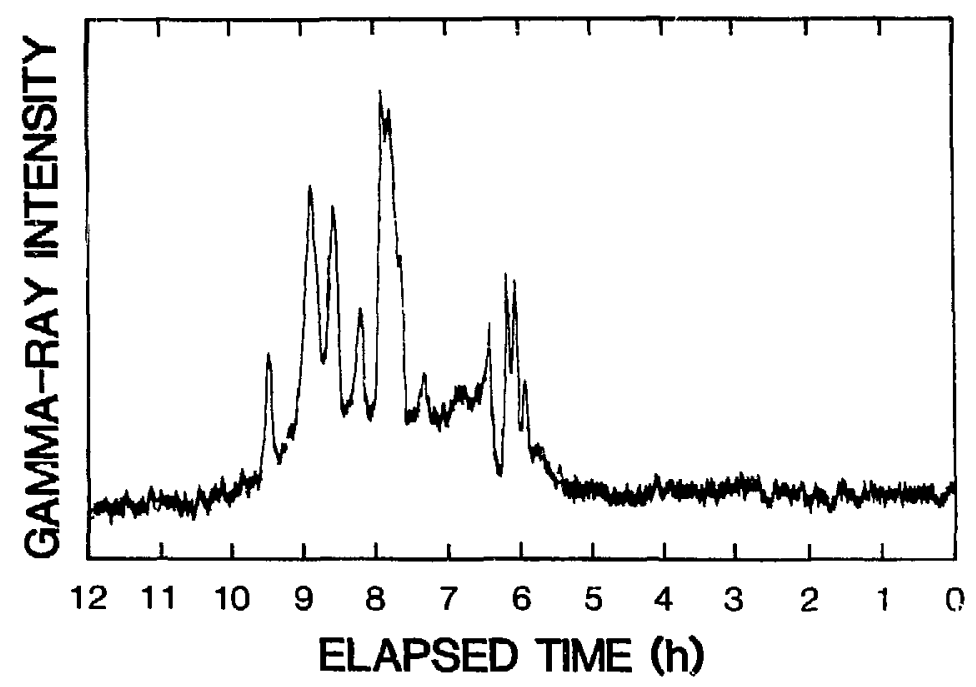

Fig. 14. An important manmade contribution to background intensity near particle accelerators is a radioactive plume of very short-lived radioactive gases that produced this highly variable plot.

intensity is quite important to sensitive radiation monitoring. The alarm threshold for radiation monitoring must be determined from a recent background measurement. In most cases, this background determination will be updated continuousiy when the monitor is unocclipied.

Background snatial variability is as important as its time variability. If a monitor is installed at a location where the background is higher-ihan necessary, we can intuitively expect that monitor to have lower sensitivity. Section V.B gives a specific example of the influence of background intensity on detection sensitivity.

\section{B. Gamma-Radiation Test Sources}

Test sources art: used to measure the performance of radiation monitors. Pecause they are radioactive, the test sources' emission rates change as they age. When SNM is used as a test source, the effect of aging is quite different for uranium and plutonium. The emission rate from HEU is practically consiant. Plutonium, on the other hand, continuously increases in intensity and would best be replaced by a different test source, but it is impossible to devise an exact substitute.

Gamma-ray sources are unique in the sense that the gamma-ray emission energies and intensities for a particular source are not exactly duplicated by any other source or combination of sources. In particular, the radioactive isotopes in SNM have unique gamma-ray emissions that cannot be imitated by a gamma-ray spectrum from a combination of other radioactive sources. Even if we could initially match the energies and intensities, the intensity match woulc later be destroyed because the original and initiating sources have different haif-lives.

The gamma-ray spectrum of low-burnup plutonium changes with time as the isotope ${ }^{241} \mathrm{Pu}$ decays to ${ }^{241} \mathrm{Am}$, which is a very prolific $60-\mathrm{keV}$ gamma-ray emitter, causing a plutonium test source to increase intensity and become easier to detect. Figure 15 illustrates the change in intensity during a l-year periou for a particular sample of low-burnup plutcnium.

False assurance would result by testing a monitor with SNM that is a more intense radiation sotite than the process material being safeguarded. One alternative to using low-burnup plutonium is to depend on HEU test sources alone as a standard SNM source for monitor comparison. Comparing Figs. 10 and 15 , you will notice that the HEU has a $100-\mathrm{keV}$ region in common with low-burnup plutonium. Tlie 100-keV region forms a significant part of both spectra, making the HEU a reasonable substitute source when tests with SNM are necessary.

If tests with SNM are not necessary or are impracticu - for example, where a wide range of test source sizes are required-there is one commercially available isotope that can be used, with caution, as a substitute for low-burnup plutonium. The isotope 


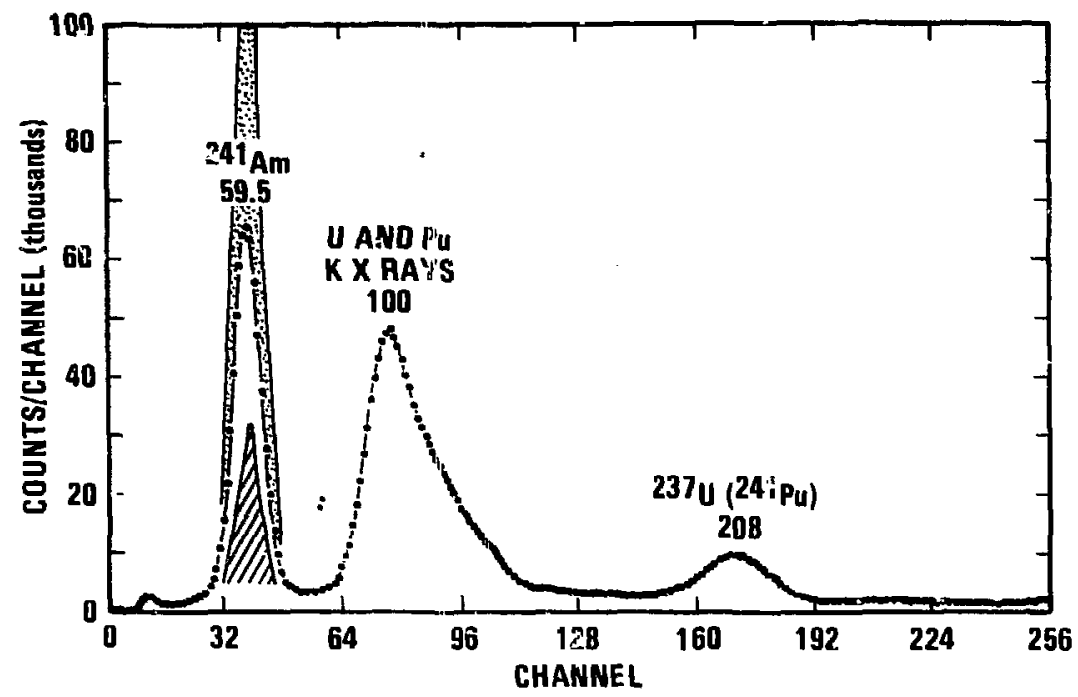

Fig. 15. During a 1-year period, the $59.5-\mathrm{keV}$ peak in this low-burnup plutonium sample doubled its intensity twice. Starting with the crosshatched area, the peak doubled and then doubled again to the area shaded in gray.

${ }^{133} \mathrm{Ba}$ can be used for daily monitor testing and as a substitute for plutonium for some performance: testing. However, ${ }^{133} \mathrm{Ba}$ does have a different gamma-ray energy spectrum (Fig. 16) and the ${ }^{133} \mathrm{Ba}$ intensity decreases with age, unlike that of plutonium. The spectrum differences will cause different monitors to respond differently to ${ }^{1.33} \mathrm{Ba}$ even though they may respond identically to plutonium. For example, equivalent monitors for detecting HEU and plutonium in Table II would be tested with slightly aifferent amounts of ${ }^{133} \mathrm{Ba}$ tononding on whether their detectors are $\mathrm{NaI}(\mathrm{Tl})$ or plastic scintillators (Table V).

\section{Characteristics of Transient Diversion Signals}

Diversion signals from SNM cannot be expected to be simple. The material will nost likely not be un. shielded and it will most likely not be stationary in an SNM monitor. At the very least, the SNM will itself shield some of its own radiation.

1. SNM Self-Absorption. Diverted materials are detectable because they spontaneously emit radiation. Shielding by normal encapsulation, other containers, and the radiation monitor's own detector cabinets decreases the radiation intensity and our ability to detect the material. In addition, radiationemitting materials may shield their own radiation by reabsorbing part of it. This is important for gamma radiation where the atomic properties of an atom allow it to absorb its own nuclear radiation. Such selfabsorption is influenced by the physical form of the material. Figure 17 shows the effect of self-absorption on radiation intensity from different shapes and sizes of HEU. Thun sources, fowders or foils for example emit most of their radiation whereas more compact shanes such as spheres and cylinders can reabsorb $.90 \%$ of their radiation. In Fig. 17, reabsorption places the curve for uranium cylinders at about $10 \%$ the intensity for thin sources with corresponding mass.

As a result of self-absorption, detection performance varies with SNM form, and test results must include information about the physical form of the material. If the inore compact shapes are used for specifying, evaluating, and repoting performance, then other forms having less self-absorption will more readily be detected. Hence, there will be no perceived loss in performance once the monitor leaves the testing laboratory for the outside world.

Another advantage of compact, regular-shaped test sources is that source size can be scaled from desired gamma-ray response; spheres, for example, follow the law that monitor response is proportional to the twothirds power of the mass. This law reflects the fact that most of the emitted radiation is from the surface of the test source, which grows in size as the twothirds power of the mass (note the slope of 0.67 in the curve in Fig. 17). An application of the two-thirds 


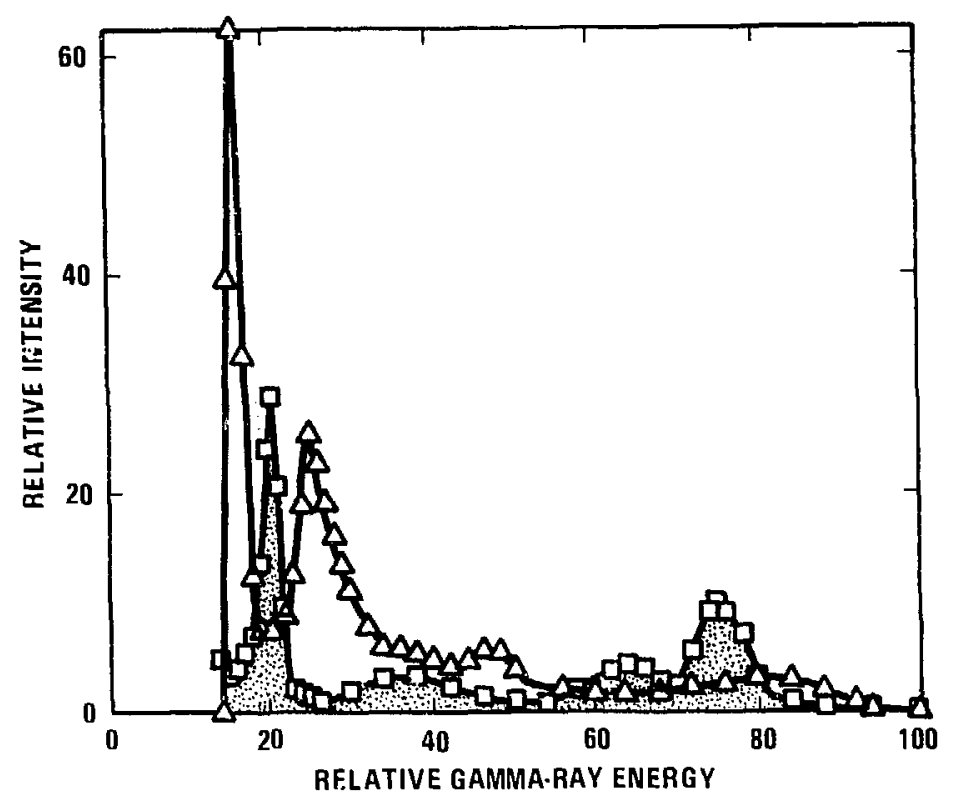

Fig. 16. The ${ }^{133} \mathrm{Ba}$ spectrum (shaded) is similar to the one for low-burnup plutonium (not shaded) but the differences are very significant. Monitors with different types of radiation detector respond differently to ${ }^{133} \mathrm{Ba}$ as a substitute source for plutonium.

power law estimates the importance of shielding in terms of how much source mass is required to detect shielded SNM in a gamma-ray monitor. For example, if shielding reduces the source intensity to one half, then a shielded mass giving the original intensity is about 2.8 times as much SNM: the original mass multiplied by the ratio $\left(\mathrm{I}_{0} / \mathrm{I}\right)^{3 / 2}$. For neutron sources, there is little self-absorption and the neutron intensity is simply proportional to the mass of SNM.

An additional comment about shielding is that thick shielding may not totally eliminate radiation that can be sensed by an SNM monitor. Neutrons may not be absorbed and part of the absorbed gamma radiation may reappear as scattered or fluorescence radiation from the shield; build-up radiation in shielding terminology. This phenomenon produces $\mathrm{x}$ rays, which vary with the amcunt of self-shielding at about $100 \mathrm{keV}$ in SNM spectra. As an example, buildup radiation and neutrons from shielded SNM in a pedestrian monitor (Fig. 18) cause the detected mass curve to increase much more slowly than the similar curve for shielded SNM in a vehicle monitor. The vehicle monitor curve is straight because vehicles and thick detector covers absorb the fluorescence build-up radiation and the detectors are less sensitive to neutrons. An analogous gamma-ray build-up in neutron shields stems from neutrun capture interactions in the shield.

2. SNM Diversion Signal Profiles. Diversion signals are present in a monitor for a short period during which monitoring can take place: the monitoring

\begin{tabular}{|c|c|c|c|}
\hline \multicolumn{4}{|c|}{ TABLE V. Equivalent Test Quantities of ${ }^{133} \mathbf{B a}$} \\
\hline \multirow[b]{2}{*}{ Categrary } & \multirow[b]{2}{*}{ Description } & \multicolumn{2}{|c|}{${ }^{\mathbf{1 3 3}} \mathbf{B a}(\mu \mathrm{Ci})$ Required in } \\
\hline & & $\begin{array}{c}\text { Nal(Tl) } \\
\text { Monitors } \\
\end{array}$ & $\begin{array}{c}\text { Plastic Scintillator } \\
\text { Monitors }\end{array}$ \\
\hline I & Standard plutonium & 2.5 & 3.2 \\
\hline II & Standard uranium & 0.9 & 1.4 \\
\hline III & Improved sensitivity & 0.2 & 0.6 \\
\hline IV & High sensitivity & 0.1 & 0.3 \\
\hline
\end{tabular}




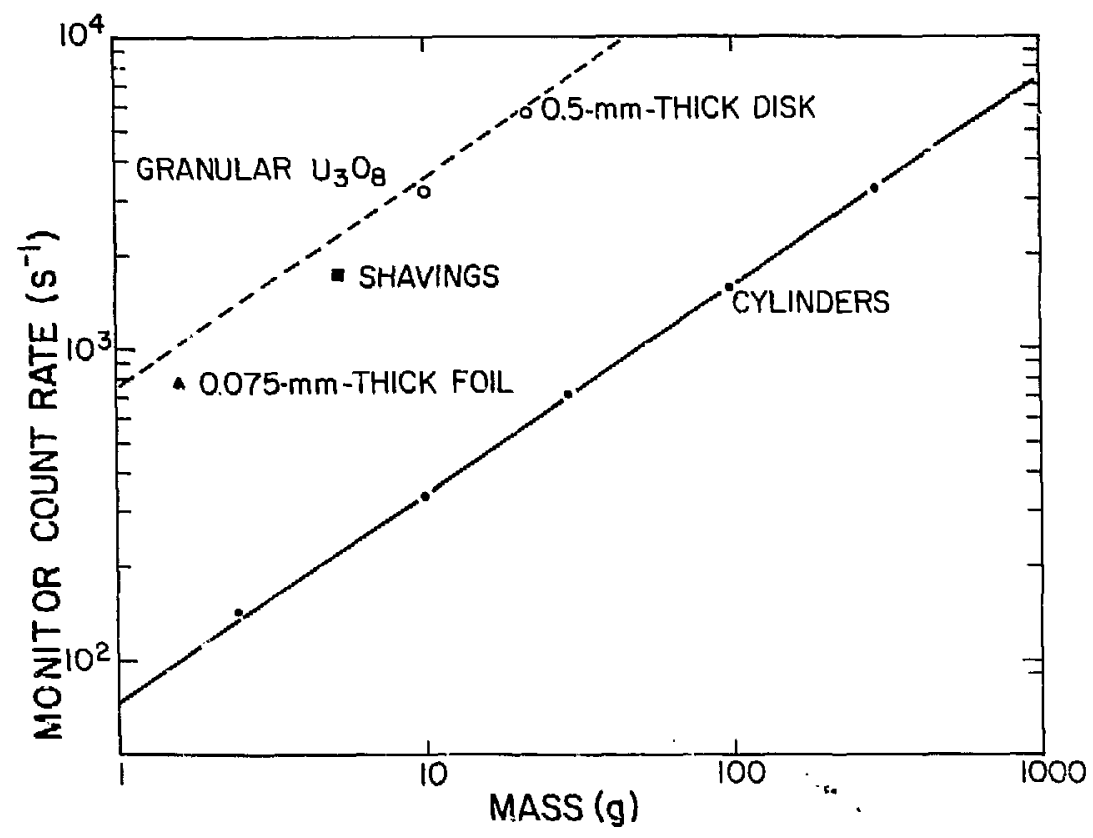

Fig. 17. Self-absor stion of gamma-rays in compact metallic SNM, plotted along the line, reduces the amount of radiation available for detection. The individnal thin or granular SNM types above the line emit about 10 times as much radiation (dashed line) as the cylinders.

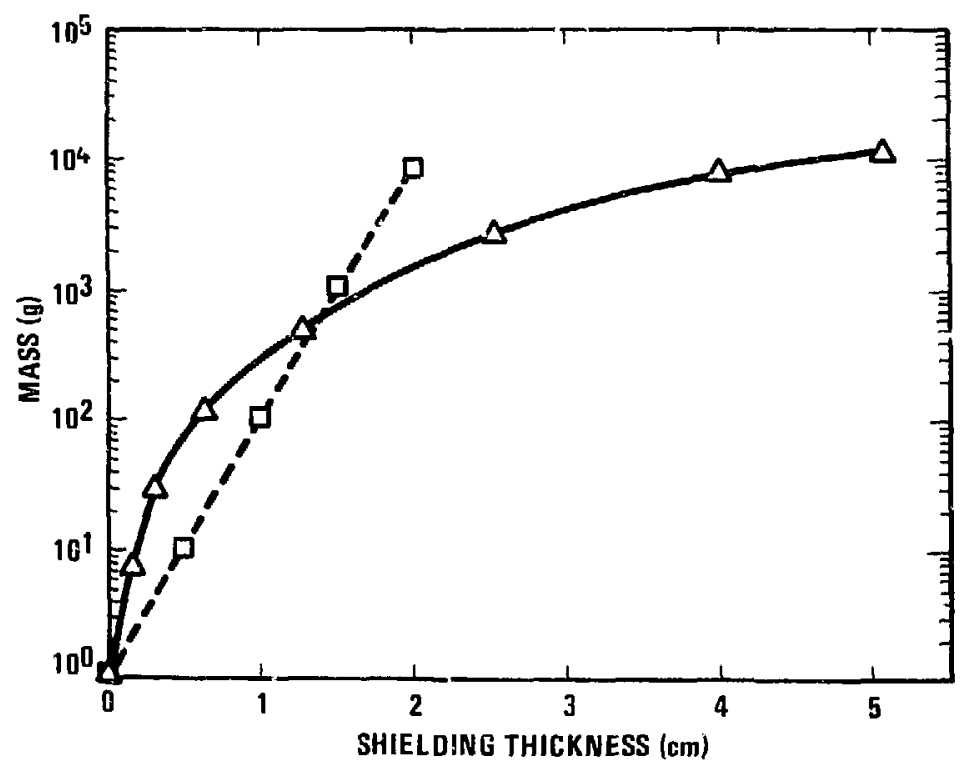

Fig. 18. Shielding can produce fluorescence radiation that is detected in an SNM monitor. The triangles show fluorescence radiation and neutron detection in one monitor after about $0.5 \mathrm{~cm}$ thickness while the squares for another monitor do not because the deteciors were shielded from fluorescence radiation and neutrons. 
period. During that time, the signal may be steady, as in a monitor that requires the person to wait, or it may vary, as in walk-through monitors that allow free passage. An illustration of the signal profile in a walkthrough pedestrian SNM monitor (Fig. 7 in Fart 1) shows significant variation. The quantity that is tested in the monitor's decision logic is a time integral of the signal, for example the constant count rate multiplied by the monitoring time in a wait-in monitor. In the walk-through monitor, the integral is the area underneath a curve such as the one in Fig. 7, and it is in seneral only about $60 \%$ as large as that for a stationary source located at the monitor's center. Part of the complexity of designing monitors is to obtain the greatest possible monitoring signal relative to background. This happens when the most intense part of the bell-shaped curve in Fig. 7 occupies a single counting interval. Techniques for obtaining this optimum situation in monitoring electronics are discussed in Sec. V.B.

A complementary effect to the source passage profile in Fig. 7 results when a monitor's occupant shields the radiation detectors from ambient background radiation. Background radiation is partly prevented from reaching the detectors by the occlipant's body. and as much as a $1.5 \%$ reduction in background response during passage of a pedestrian would not be unusual. The reduction is important because the alarm threshold may be only $4 \%$ above background so that a significantly larger signal must be provided to alarm the occupied monitor. The background reduction is difficult to compensate because the amount of background reduction can vary during occupancy, hence monitors operate with lower sensitivity than would otherwise be possible.

\section{SNM GAMMA-RAY SOURCE DETECTION}

SNM gamma-ray sources are detected when an increase in radiation intensity is sensed in a monitor. A monitor's ability to detect a significant increase is related to the statistical variation of its background count during monitoring. The size of source that can be detected by comparing source monitoring intensity with a previously measured background intensity is limited by the statistics of radiation detection, which are discussed in the following paragraphs.

\section{A. Statistics of Radiation Detection}

Gamme-ray sources randomly emit individual gamma rays. That is, during any given interval, even though the disintegration rate is consiant, the exact number of decays that take place during the interval varies from one such interval to the next. As a result, even a perfect radiation detection system that counts gamma rays would not get the same result every time it coun's what is considered to be a constant radiation intensit: Long counting periods average out shortterm variations in counting statistics and make a counting result more precise. But, the important thing is that the total number of counts in the result should be large, either because the count rate is high or the counting time is long.

If the result of a count is $\mathrm{N}$ counts on the average, the statistical variation in a series of such counts is the same whether it is from a low count rate and long counting time or from a high count rati and short counting time, as long as the average in each case is $\mathrm{N}$ counts. The variation in the count is called the standard deviation $\sigma$ and is equal to the square root of $\mathrm{N}$ for the counting that takes place in gamma-ray SNiv monitors. Figure 19 illustrates the result of a counting experiment where the average result is a number equal to 1000 counts. The vertical axis denotes the fraction of the time a particular numerical result is observed during a series of many individual counting periods. The width of the curve is related to the standard deviation of the measurement, as illustrated, and in fact, the standard deviation is just the half-width of the curve at about $60 \%$ of its maximum height.

The probability distribution for counting data is a Poisson distribution. The standard deviation of Poisson-distributed counts is equal to the square root of the average count value, $N$. As a result, the relative width of the curve becomes narrower as $\mathrm{N}$ increases (the relative wi $\mathrm{Jth}$ varies as $\sqrt{\mathrm{N}} / \mathrm{N}$ or $1 / \sqrt{\mathrm{N}}$ ). This reffects the fact mentioned earlier that the larger the value of $\mathrm{N}$, the smaller the relative variation in a counting result. Accurate measurement of radiation intensity requires adequately long counting times. Of course, there usually is a limit on the time available for counting; for SNM monitors, traffic flow may limit both monitoring time and background counting time. Variation in background radiation intensity also may limit background counting time in order to follow its variation. Monitoring periods must, of course, match the time that a diversion signal may be present, and background periods usually occur between monitoring periods, taking up to 20 times as long as the monitoring period.

Looking at Fig. 19 again, consider where the alarm threshold should be placed in a radiation monitor. If the alarm threshold were located at the average value, 1000 , the monitor would alarm half the time because 


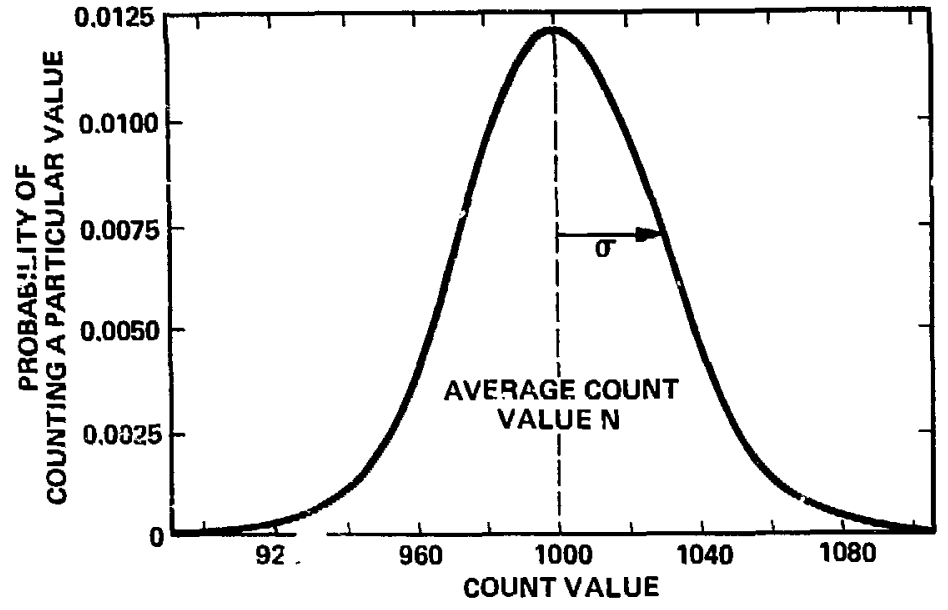

Fig. 19. The Poisson distribution of counts from a counting experiment with an average result of 1000. Count values well above and below the average value are common. The symbol $\sigma$ denotes the standard deviation of the count values plotted here. half of the counts are greater than 1000. These alarms would be statistical false alarms, alarms that are caused by the statistical variation in counting. To avoid most of these alarms, the alarm threshold must be far to the right side of the figure. If we express its numerical distance above the mean (background) value in terms of the standard deviation, then its statistical performance is the same as any other monitor employing the same alarm threshold measured in standard deviations. In general, defining an alarm threshold $A L$ in terms of the average count $\mathrm{N}$ and a multiple $\mathrm{M}$ of its square root provides a constant false-alarm rate at any background intensity. However, at higher backgrounds this method causes the detection sensitivity to diminish simply because the second term in the expression gets larger.

$$
A L=N+M \sqrt{N} .
$$

Following this definition, the false-alarm probability for a single monitoring decision can be found from statistical tables that give probabilities for exceeding the average value by a particular multiple of the standard deviation (a short examiple is listed in Table VI). The false-alarm rate per passage or per hour is the statistical alarm probability multiplied by the number of decisions per passage or per hour that the monitor must make. (Note that other detection schemes with fixed-value alarm levels can be analyzed as described here except that a separate analysis is needed for each different background intensity.)

The influence of a selected alarm threshold on source detection is illustrated in Fig. 20. The source contributes a number of counts $S$ (about 120 in the figure) so the total count distribution with a mean value of $\mathrm{N}+\mathrm{S}$ is displaced to the right of the background distribution by that amount. The new distribution is approximately as wide as the background distribution if the source is a relatively weak one.

False alarms are illustrated in the figure by a lightly highlighted area of the background distribution that lies above the alarm threshold. The heavier crosshatching illustrates the miss probability for which the source would not be detected. In this

\begin{tabular}{cc}
\hline \hline \multicolumn{2}{c}{ TABLE VI. Probability of Exceeding an Alarm Threshold of Mc } \\
\hline $\begin{array}{c}\text { Alarm Threshold } \\
\text { Multiplier M }\end{array}$ & $\begin{array}{c}\text { Probability of } \\
\text { Exceeding Mo }\end{array}$ \\
\hline 0.0 & 0.5 \\
1.0 & 0.159 \\
2.0 & 0.0225 \\
3.1 & 0.001 \\
4.0 & $3.16 \times 10^{-5}$ \\
6.0 & $1.0 \times 10^{-9}$ \\
\hline \hline
\end{tabular}

Estimated probabilities for the large count values typical of automatic monitors. 


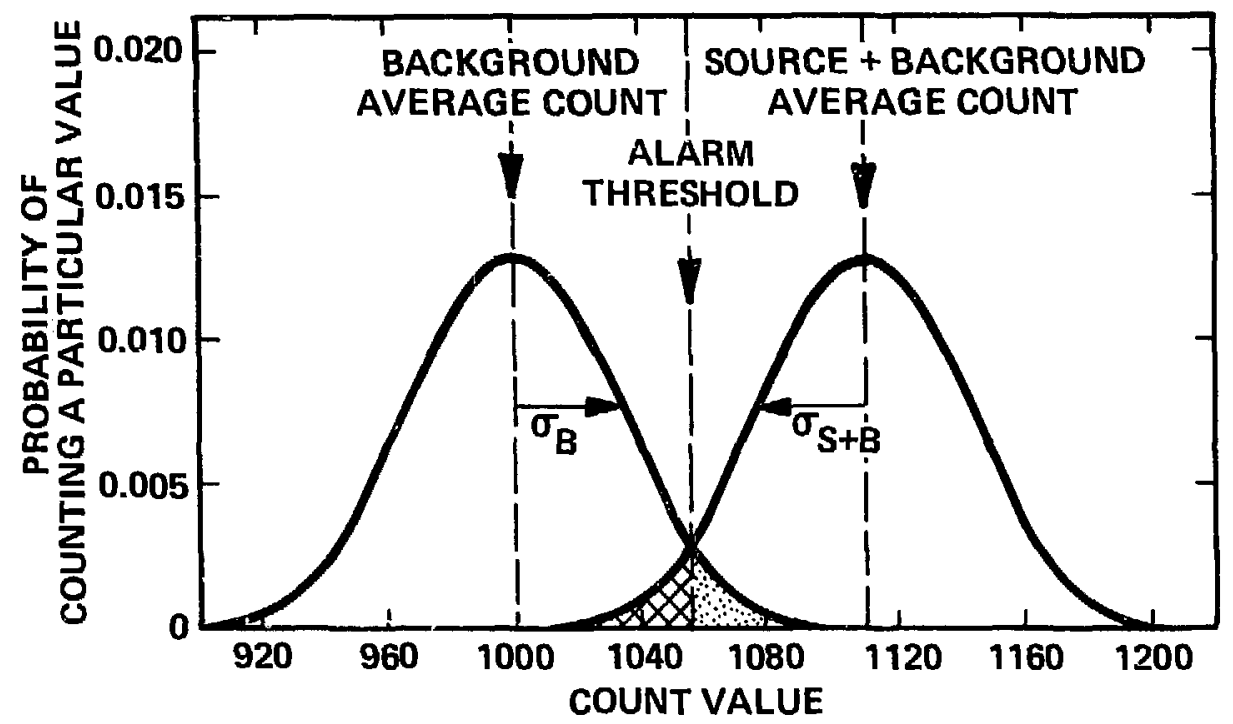

Fig. 20. The background distribution is plotted along with the distribution that results from adding a source to the background. The highlighted regions illustrate false alarms and nondetections.

example, the source will be detected more than $90 \%$ of the time.

\section{B. A Detection Method}

To illustrate a method to detect radiation sources, first suppose that a low false-alarm probability is desired. False alarms are undesirable because they are a nuisance to a guard. With a false-alarm probability of 1 in 44, corresponding to $2 \sigma$ in Table VI, the alarm threshold is at the point shown in Fig. 20 . In this case, a monitor making one monitoring decision per passage would experience about 1 statistical alarm in 44 passages. Walk-through monitors would more likely use $4 \sigma$ alarm thresholds (one alarm per 30,000 passages) and they often make. more than one decision per passage. If, for example, six monitoring decisions are made per passage, then there would be about one statistical alarm per 5000 passages.

An example of how the source size detected in a simple monitoring system varies with the background intensity is plotted in Fig. 21. The horizontal axis is the average background count, and the vertical axis is the additional source count that must be present to alarm $50 \%$ and $95 \%$ of the time it passes through a monitor with a $4 \sigma$ alarm threshold. Of course, any source signal above each curve will be more likely to alarm. Signf: alues below each curve will be less likely to alarm.
The figure shows the performance of a simple, single-interval test for detecting intensity increases. Other more complex detection methods may be used to achieve some particular result. For example, what is called "moving average detection" can be applied in portal monitors to detect moving sources; this technique makes many overlapping tests rather than a single test in order to catch the most intense portion of the source signal. The moving average technique tests more than once per passage, so it has more statistical alarms per passage unless the alarm threshold is increased. Raising the alarm threshold enough to retain the single test false-alarm rate does not detract much from the increased detection probability in this case. ${ }^{9}$ The reason is that catching the most intense part of the signal easily makes up for the increased alarm threshold.

Another specialized method for monitoring is sequential testing, designed to minimize the monitoring time in wait-in monitors. The method makes only enough very short monitoring tests to make a decision and typically shortens the average monitoring time considerably while maintaining a desired sensitivity. Its monitoring time varies with the perceived radiation intensity during monitoring and is extremely short for either background intensity or strong signals. At intermediate intensities near the alarm threshold, the decision requires more tests and the longest average monitoring time (Fig. 22). The sequential detection method also can be applied to 


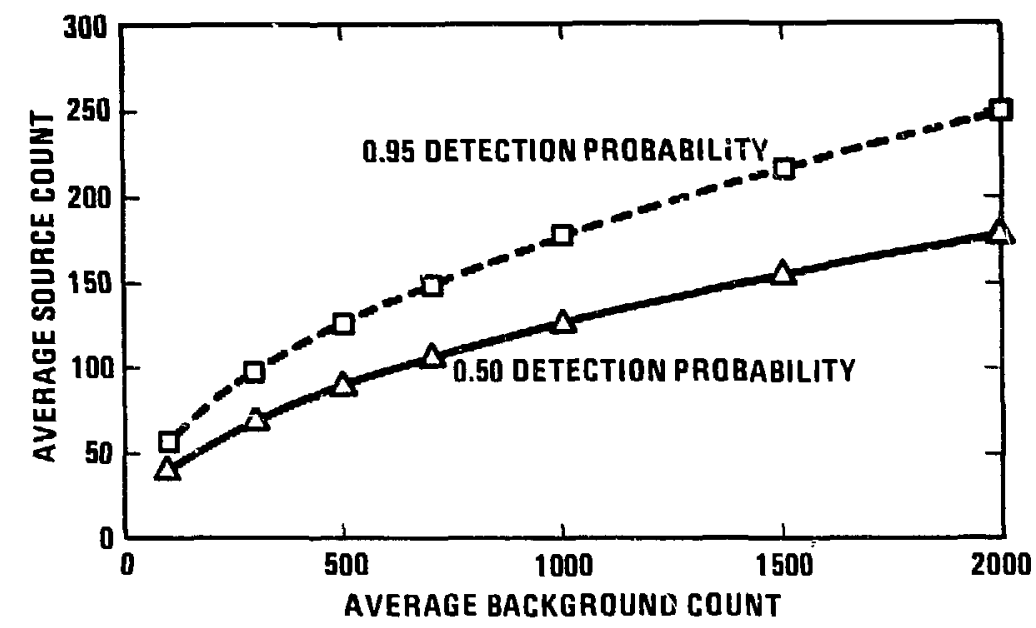

Fig. 21. The curves illustrate the average source count that is needed for 0.5 and 0.95 detection probability in a particular monitor. Higher background requires higher source intensity for detection in all cases.

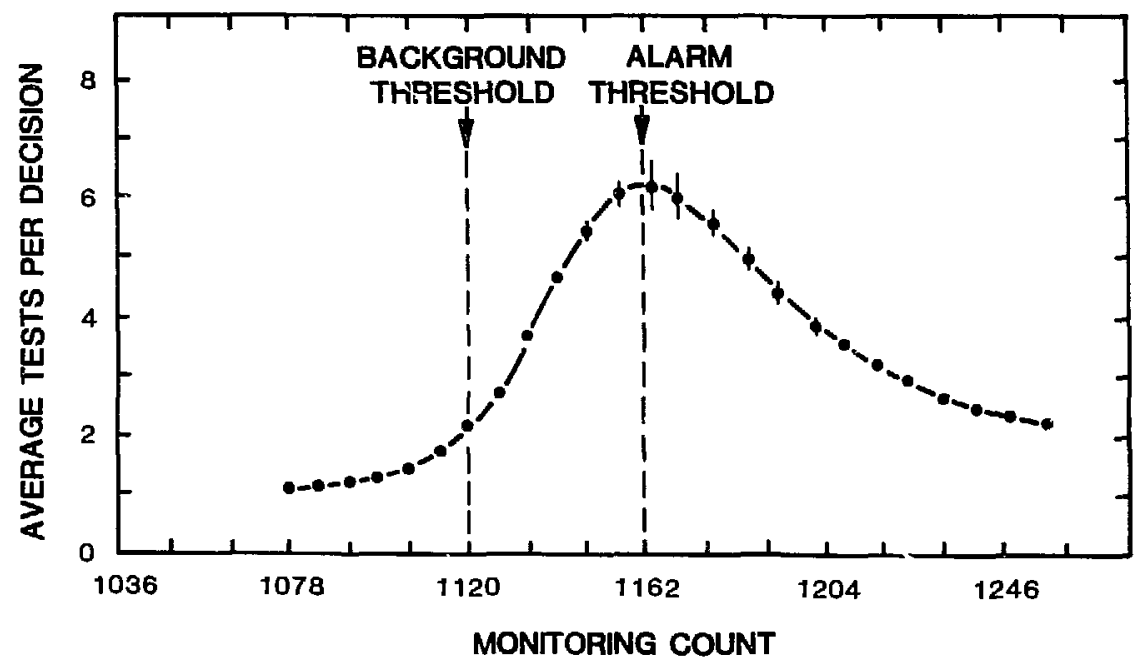

Fig. 22. The sequential detection method takes a variable amount of time to make a monitoring decision. It is quite rapid for background intensity and strong sources but may rake as long as other methods at its limit of detection. 
walk-through portal monitors where it has advantages similar to the moving average method. The versatility of the sequential method makes it an attractive way to detent SNM in monitors that may be used in different ways, walk-through or wait-in. ${ }^{10}$

\section{Shielding Effects}

Absorbing material between SNM and a detector decreases a monitor's sensitivity. Shielding may be a material placed around the SNM to absorb gammaray or neutron radiation or it may simply be an object or person irtervening between the SNM and detector, forming a shadow shield.

Shielding that transmits an SNM radiation intensity below the detection threshold will permit the SNM to go undetected. To accommodate the influence of significant shielding, monitoring systems are most often built with detection sensitivities that are much higher than required for detecting bare SNM alone. Higl. sensitivity allows detection of any transmitted gamma rays from SNM plus any buiidup radiation, such as fluorescence radiation from thick lead shields. The only drawback to highly sensitive monitors is evident in Fig. 21, where at larger background count the corresponding source count on either one of the curves becomes a smaller fraction of background. Hence in a highly sensitive monitor, a smaller variation in the natural background is more likely to cause an alarm should the monitor be occupied at the time. For example, a Category II monitor (in Table II) may alarm at a $10 \%$ increase in background whereas a more sensitive Category III monitor might alarm at an increase of only $4 \%$.

Another solution to detecting shielded sources is to detect the shielding material separately, but this method has its own drawbacks. Many shielding materials can be kept out of the monitoring area by visual surveillance. Some shielding materials that are not readily visible can be detected with a metal detector. But, a metal detector with appreciable sensitivity for nonferrous shielding material, detecting $100 \mathrm{~g}$ or so of solid lead for example, cannot detect granular lead and is often too sensitive to ferrous materials (iron or steel objects) for practical use. Unfortunately, metal detectors have high sensitivity for detecting such innocent ferrous items as eyeglass frames, wrist watches, safety shoes, and belt buckles when they are operated to detect small quantities of lead shielding As a result, facilities employ either lower sensitivity that passes both small ferrous ob- jects and small lead shields or high sensitivity, requiring employees to exchange street clothes for special clothing free of unnecessary ferrous items. Even when a charge room and metal-free population are present, the metal detectors still do not detect granular shielding material. Hence, high SNM monitor sensitivity is important for detecting shielded radioactive material whether or not metal detectors are employed.

\section{Detection Electronics}

In SNM monitors, monitoring and background measurements take place during separate periods of time. Sensing the presence or absence of a person tells the monitor what it should be doing. Occupancy monitors in the form of light beams, ultrasonic motion sensors, microwave motion sensors, or switchmats detect pedestrians and signal their presence to the monitor's control electronics. When occupancy sen ors are employed, their proper operation is esser ial to detecting SNM; if the occupancy sensor does not work properly, the monitor may not sense pedestrians and not monitor them. Because the occupancy sensors may not be tamper resistant, proper operation must be verified by a daily check. In addition, where surveillance of the monitoring area is by television, an audible indication of occupancy should be provided to the guard so that he has positive indication that monitoring takes place.

Another aspect of occupancy sensing and TV surveillance is that material thrown through the monitor may present a problem. When a guard is physically present at the SNM monitor, throwing material through the monitor is easily prevented. With TV sui veillane, thrown material is difficult for the guard to see. Hence, monitors operating under TV surveillance should monitor continuously, updating background with a long time constant and monitoring with a shori one, or else a maze and highly sensitive motion detector should be employed. Of course, the highly sensitive occupancy monitor then requires daily testing with a thrown object in addition to the normal monitor test with radioactive material.

Besides the occupancy sensor, radiation monitors have electronic circuits for radiation detector power and signal conditioning, and the: have electronic counting and analysis circuits to sense diversion signals and to give notice. Counting requires analog or digital circuitry to tally detected photons and sense significant changes in their number as mentioned in Sec. V.A. The sensitivity and false-alarn rate of the 
monitor both depend on how well this task is accomplished. We call this important part of the monitor the decision logic electronics.

One form of decision logic is a direct application of the single interval test (Sec. V.B) in digital electronic circuitry. Analog circuits can perform the same function, but require empirical calibration that is unnecessary in digital logic. Numerical digital circuit pararneters fully calibrate the decision logic without the need to recalibrate after each circuit repair or drift in circuit component value. Other digital methods that improve monitor performance were discussed in Sec. V.B.

When the decision logic alarms, the fact must be announced in some way. Both audible and visual indicators may be activated to announce an alarm. These indicators may latch and require the attendant to press an alarm reset or they rnay reset automatically after a second or two. In adoition to sensing diversion alarms, the decision logic also is comparing each new background intensity with thresholds for high and low background extremes. In this case, the idea is on one hand to sense low backgrounds from detector failure or tampering that introduces detector shielding and on the other hand to detect liigh backgrounds from detector failure or tampering that raises background. Background comparisons also signal alarms with audible or visual indications that persist and call for servicing the monitor.

Each alarm must be resolved in some way, either by service or investigation. In the case of diversion alarms, a person can sometimes explain why he is radioactive or the guard can locate a source on his person with a hand-held radiation detector. A manual scan by the guard with a hand-held monitor may serve to locate the position in the body of a medical isotope. Sometimes, assistance from health physics or supervisory personnel may be needed before releasing the individual.

\section{GAMMA-RAY DETECTORS}

Gamma-ray detection is based on collecting gamma-ray-caused ionization in a detector. Hence a detector material should have a high linear absorption coefficient for gamma rays and sufficient depth to absorb radiation and produce a signal. There are a variety of gamma-ray detectors that are useful for different purposes.'

- Gas-filled detectors such as ionization chambers, proportional counters, and GeigerMüller counters find application in contamination monitoring.
- Scintillation detectors such as liquid or solid organic (plastic) scintillators and $\mathrm{NaI}(\mathrm{Tl})$ are applied to kigh-sensitivity contamination monitoring and SNM monitoring as well as other tasks.

- Semiconductor detectors such as lithium-drifted germanium $[\mathrm{Ge}(\mathrm{Li})]$, lithium-drifted silicon [Si(Li)], or intrinsic or high-purity germanium (HPGe) are applied to gamma-ray spectroscopy.

The first and third groups find little application to SNM monitoring; the first has limited lifetime, low efficiency, and noisy operation and the third has great expense, is bulky, and requires cooling with liquid nitrogen. These detectors are not discussed further in this report. The scintillators in the second group are relatively inexpensive, are easily calibrated and maintained, and can be made with the high total detection efficiency required for sensitive radiacion monitoring. These detectors are described in ine following paragraphs.

\section{A. NaI(TI) Scintillation Detectors}

The inorganic scintillator $\mathrm{NaI}(\mathrm{Tl})$ is readily available in many sizes and has good intrinsic detection efficiency over a broad range of gamma-ray energies as a result of its high linear absorption coefficient. High absorption of the full energy of incident radiation in a series of photoelectric and Compton interactions makes $\mathrm{NaI}(\mathrm{Tl})$ suitable for gamma-ray spectroscopy and permits using relatively small individual detectors in SNM monitors (Fig. 23). As many as seven small $\mathrm{NaI}(\mathrm{Tl})$ detectors are mounted on each side of pedestrian" portal monitors, for example. $\mathrm{NaI}(\mathrm{Tl})$ scintillators have one shortcoming; they are hydroscopic and need protection from moisture. This shortcoming is overcome by encapsulating the detector material in a thin, metallic container with a glass window to transmit the scintillation light.

$\mathrm{NaI}(\mathrm{Tl})$ has the most intense scintillation and is one standard against which other scintillators are judged. High scintillation light intensity minimizes the requirements for amplification in the photomultiplier and amplifiers that convert scintillation light to electrical signals. The combination of high absorption and good light output makes NaI(TI) a highly effective scintillator that is easily applied. ${ }^{11}$ Its intrinsic efficiency curve (Fig. 24) displays the broad range over which $\mathrm{NaI}(\mathrm{Tl})$ has high detection efficiency. Its low gamma-ray energy performance is limited only by low energy absorption in the detector's encapsulating material. 


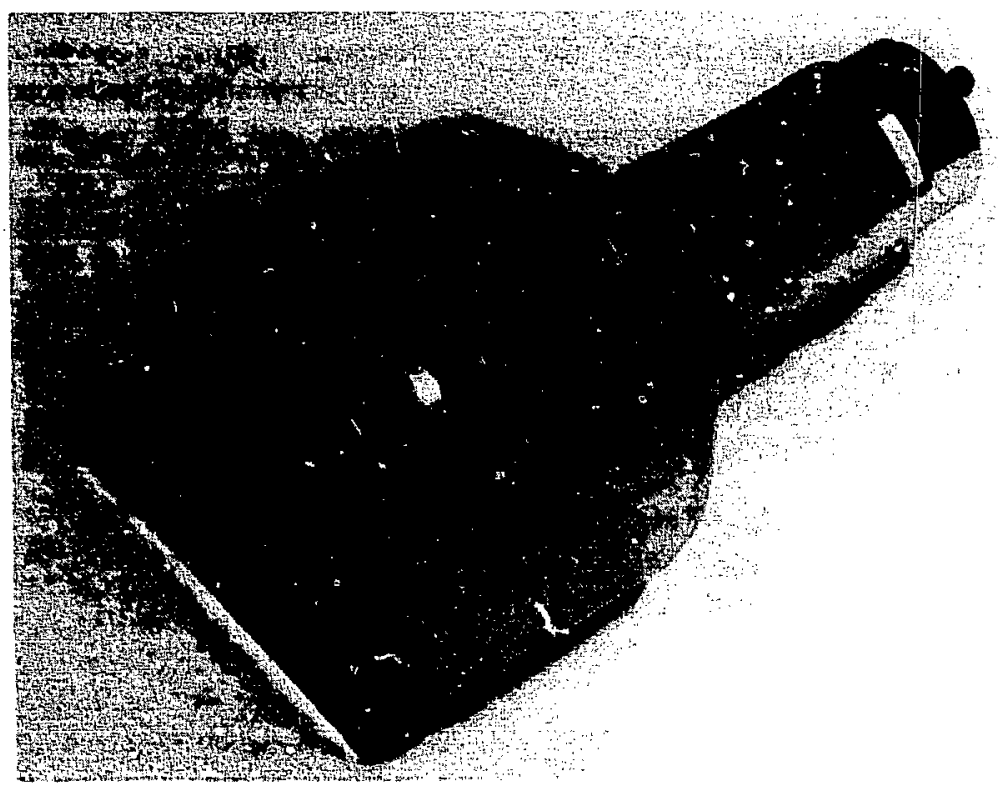

Fig. 23. Sodium iodide detectors are very compact and have high intrinsic efficiency. They do not require a large solid angle for SNM monitoring applications. This detector has a 5-in.-diam, 1.5-in.-thick scintillator.

Each $\mathrm{NaI}(\mathrm{Tl})$ photopeak, as in Fig. 10 or 15 for example, is not a narrow line representing a single energy as might be expected for a monoenergetic gamma ray. Instead, each peak is smeared out by the statistical nature of creating and collecting the scintillation light. The peak has a central value that represents that gamma-ray energy in the spectrum. The width of a photopeak represents the detector's energy resolution, and at $662 \mathrm{keV}$ the fractional fuilwidth-at-half-maximum height expressed in per cent of the peak height is a standard measure of NaI(T1) detector quality. Detectors with between 6 and $8 \%$ are common and essential ior gamma-ray spectroscopy, but for SNM monitoring, resolution is less important. Relatively good resolution (12\% or better) permits electronic selection of gamma-ray energies

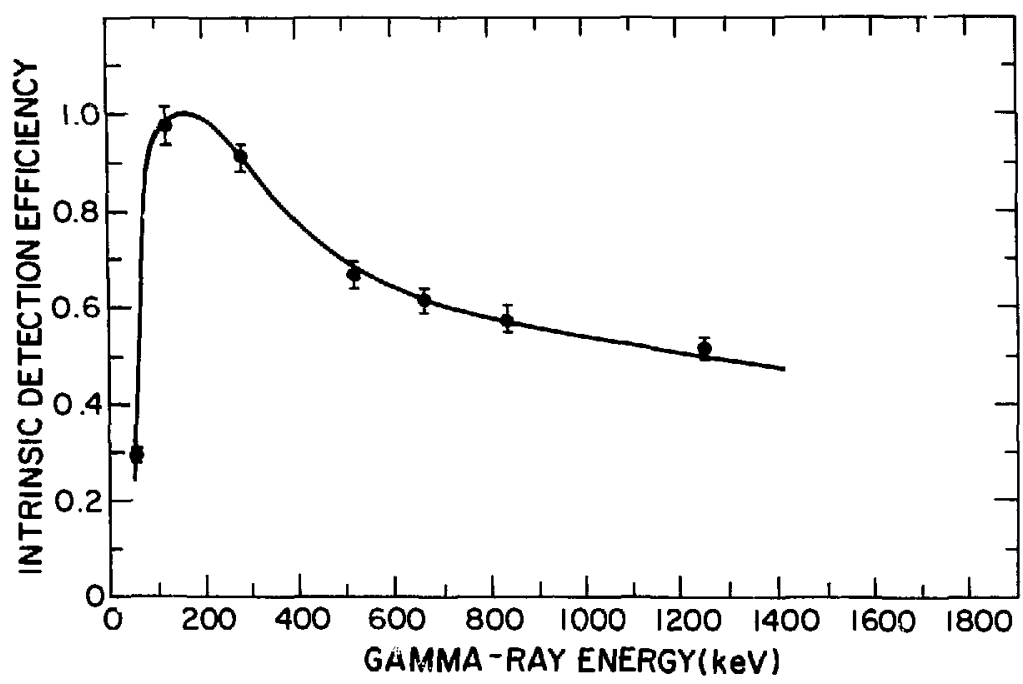

Fig. 24. The intrinsic efficiency a of 1.5-in.-thick $\mathrm{NaI}(\mathrm{Tl})$ detector is quite high in the low-energy region where SNM radiation is found. 
typifying SNM and makes it possible to display a monoenergetic gamma-ray peak on an oscilloscope while calibrating a detector array.

A complete $\mathrm{NaI}(\mathrm{Tl})$ detector comprises the scintillator, which is an inorganic crystal, an attached photomultiplier tube (PMT) to convert scintillation light to electrical charge, and perhaps a voltage divider circuit as a plug-on base to provide individual voltages at each photomultiplier dynode amplifica. tion stage. An alternative to the voltage divider is a power supply or battery to provide the individual photomultiplier dynode voltages. The individual dynode voltage supply is not only lighter but uses less power and allows hand-held instruments to operate longer on a single battery charge.

\section{B. Plastic Scintillation Detectors}

Low cost and extremely large area (Fig. 25) are advantages of plastic scintillation detectors. The large area not only is an asset that allows the detectors to provide more uniform detection sensitivity in a portal monitor but is necessary because organic scintillators have low intrinsic detection efficiency. The low intrinsic detection efficiency results from the low absorption coefficient and the low density of plastic. However, the combination of low efficiency and extremely large area enables organic scintillators to compete well with NaI(Tl) in SNM monitor applications. Figure 26 displays the intrinsic efficiency of a plastic scintillator and also the total efficiency that results for a plastic scintillation detector that provides performance equivalent to a particular $\mathrm{NaI}(\mathrm{Tl})$ detector in an SNM portal monitor.

The plastic scintillators have no useful photoelectric response so the gamma-ray spectra measured by plastic detectors show only the Compten recoil electron distribution in the detector. ${ }^{12}$ But the pulseheight response of a plastic detector is still related to the incident gamma-ray energy with the nonlinear relationship discussed in Sec. III.C. The maximum recoil electron energy appears in the pulse-height spectrum of a plastic scintillator at the center (halfheight) of the sloping region at the end of the knee that represents the Compton edge (Fig. 11). The

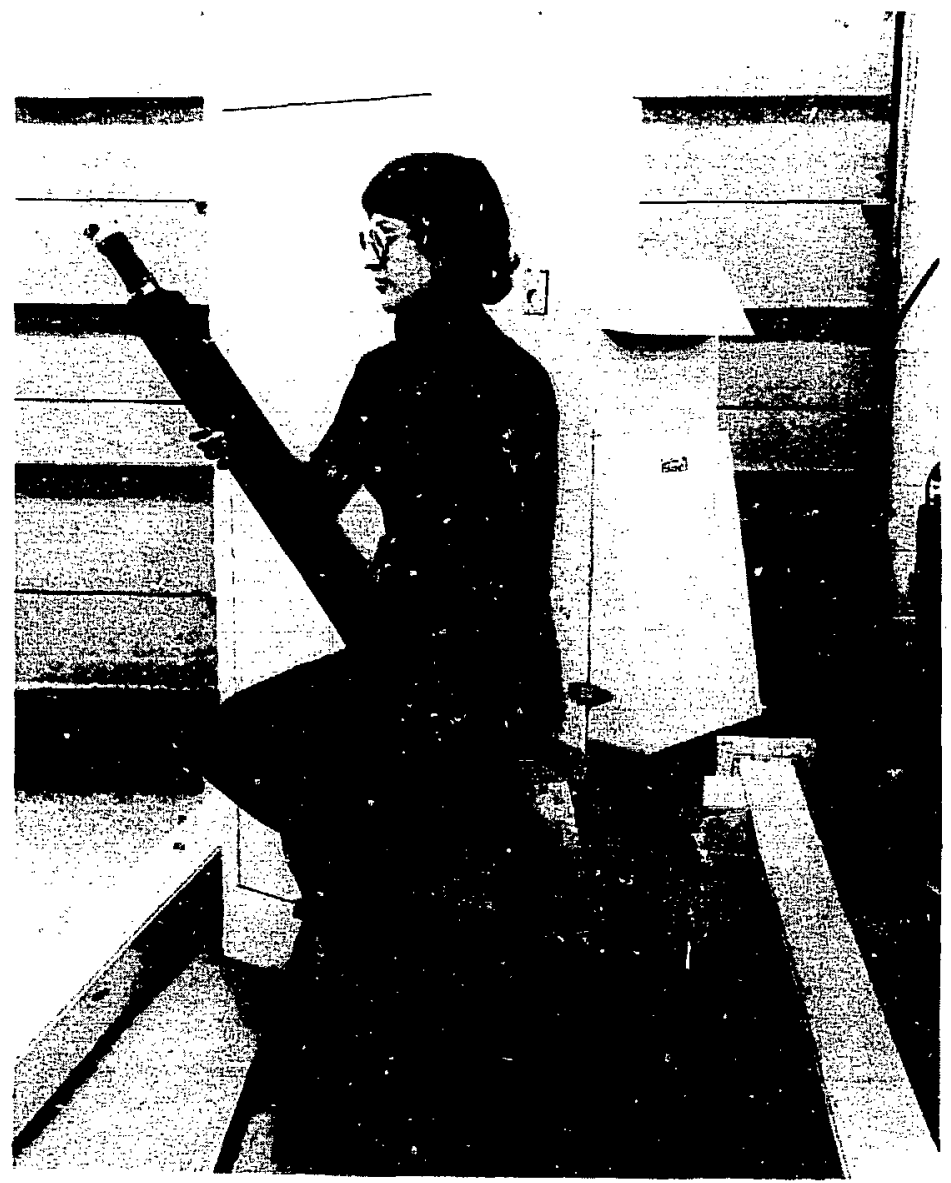

Fig. 25. Plastic scintillation detectors are relatively common in SNM detection systems because of their low cost and large area. Their large area allows them to monitor pertal regions with good uniformity. 


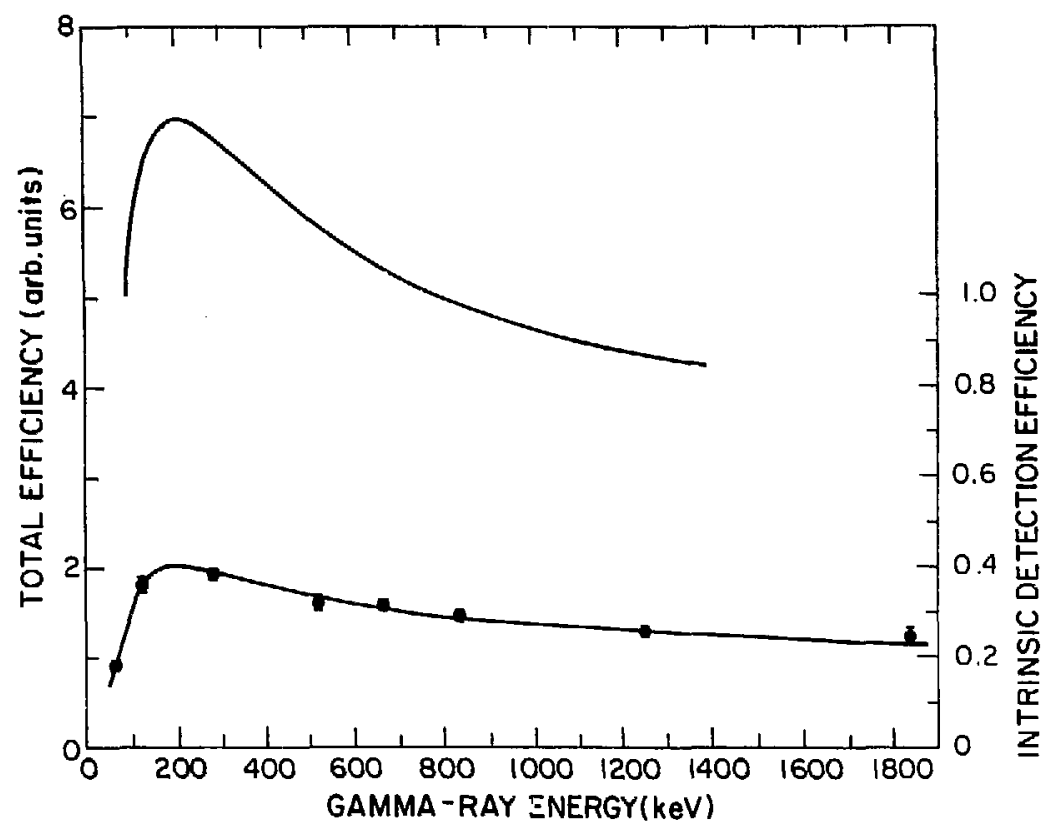

Fig. 26. The low intrinsic efficiency of 1.5-in.-thick plastic scintillators is compensated by large area, giving them performance equivalent to other smaller, more efficient detectors. The only possible shortcoming of plastic is its relatively iow efficiency at low gamma-ray energy.

maximum recoil energy is in turn related to the incident gamma-ray energy.

An example of the relationship between incident gamma-ray and recoil electron energies is plotted in Fig. 27. The maximum recoil energy is calculated from the incident gamma-ray energy and represents the pulse height at the half-height point of the Compton edge. The maximum recoil energy is what is

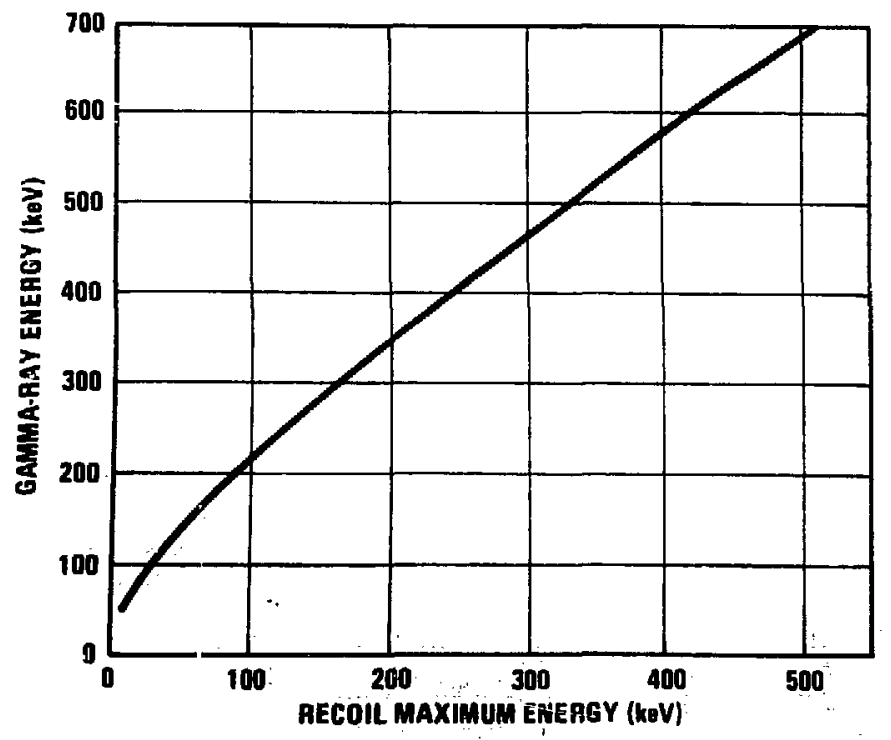

observed on an oscilloscope during calibration of the mouitor, but calibration sources are labeled with gamma-ray energies. Hence, setting a particular energy window for the monitor requires that the recoil energy for that particular window be set in the discriminators. Calculated values for window settings are discussed in Sec. VII.E.
Fig. 27. The electron recoil energies sensed by plastic scintillators are less than the incident gamma-ray energies by an amount that is different for each gamma-iay energy. Calibrating an SNM monitor must take account of the differences. 
In summary, plastic scintillators applied to SNM monitoring have the advantage of large area and low cost and their application is only slightly less straightforward than $\mathrm{NaI}(\mathrm{Tl})$. Additional information on plastic scintillation detector construction and application is available in the next section and in Ref. 13 , a conference paper on the topic.

\section{Scintillation Detector Construction.}

Scintillation detectors absolb radiation and produce light. Absorption of the incident radiation excites an atom in the scintillator, which either directly or through intermediate stages emits radiation in the visible region. The visible light is converted to electrical signals by a PMT having a photosensitive cathode surface, which emits photoelectrons in proportion to the amount of incident light. It is

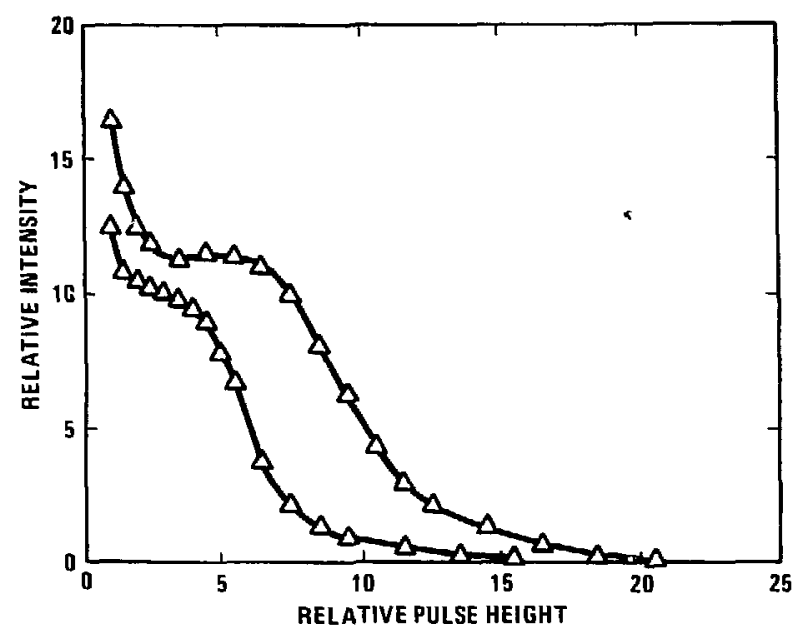

Fig. 28b. Adding a light pipe and shortening the scintillator produces a more homogeneous spectrum. followed by electron multiplying dynodes that amplify the phoioelectron current. The photosensitive surface must collect as much light as possible because the amount of light determines the pulse height in the following electronics.

Good light collection is necessary for good pulseheight resolution and effective use of energy discrimination circuits. A single PMT is most often adequate although large plastic scintillators might have two. Different amounts of ight are collected from different parts of large scintillators, causing pulse-height differences along the length of long plastic scintillators (Fig. 28a.) The inhomogeneity in response is least in relatively short (1-m-long or less) scintillators having a nonscintillating light pipe placed between the scintillator and PMT to reduce the height of unnecessary large amplitude signals that originate near the PMT (Fig. 28b).The smali size of

Fig. 28a. The pulse-height spectrum in the lower curve for a distant source is not only less intense but is shifted to lower energy than the curve for the same source near the photomultiplier.

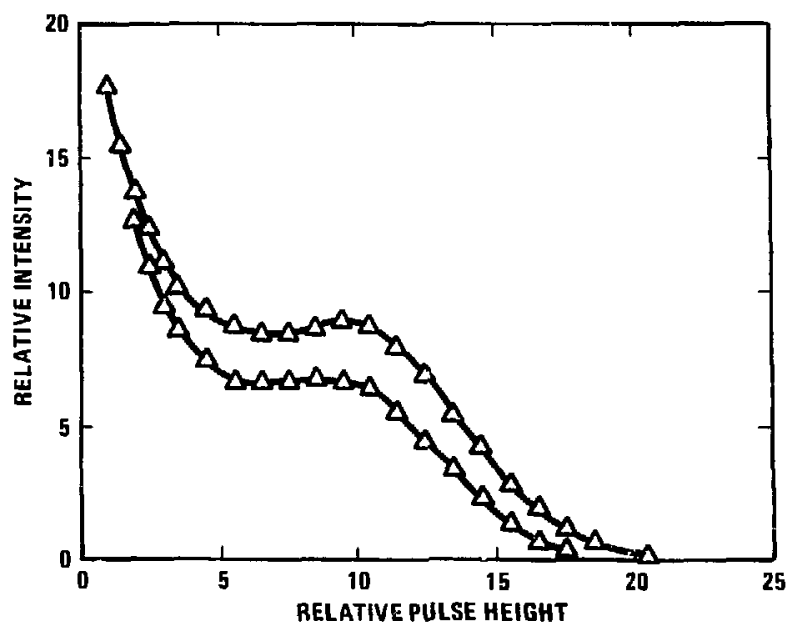


NaI(Tl) scintillators (Fig. 23) leads to good homogeneity; simply coating the interior surfaces with white reflecting material gives uniform light collection.

Light entering a PMT is partially absorbed by a photosensitive surface, the photocathode, just inside the PMT window. This end-window PMT geometry allows all light entering the PMT to transit the photosensitive region. The important characteristics of the photocathode are first its quantum efficiency, which is the probability that an incident scintillation light photon produces an electron, and second its photocathode dark current that represents noise. For SNM monitors, bialkali photocathodes offer both good quantum efficiency and the lowest dark current. Hence, bialkali photocathodes are both sensitive and quiet.

Bialkali photocathodes are most important for plastic scintillators and somewhat iess important for NaI(T1). The amount of light that is emitted in a plastic detector scintillation is only about $10 \%$ as much as in $\operatorname{NaI}(T \hat{i})$. As a result, pulse heights are smaller, and more PMT and amplifier gain is necessary to provide a suitable signal, which still may be relatively small. Two aspects of low pulse height in plastic scintillators are significant. First, low pulse height puts the signal amplitude closer to electronic noise. High PMT temperatures can increase the noise amplitude and move it into the signal window. Controlled temperature in PMTs with inherently low dark noise reduces the chance of this happening. The second aspect of low-intensity light emission is that the statistical spread in the number of collected electrons becomes relatively large. This statistical spread broadens the already wide Compton pulse-height distribution and, at low gamma-ray energies, results in a significant fraction of the signal pulses falling below the signal window and being lost.

A final word about light collection in plastic scintillators relates to the basic interaction, Compton scattering, which produces a pulse-height spectrum ranging from a maximum intensity down to zero. The monitcr must be able to sense most events from this broad spectrum of light intensity. Hence, the bias level (lower edge of the signal window) must be as low as possible. The effect of bias level on intrinsic detection efficiency is illustrated in Fig. 29. The best performance is obtained at the lowest possible bias level,

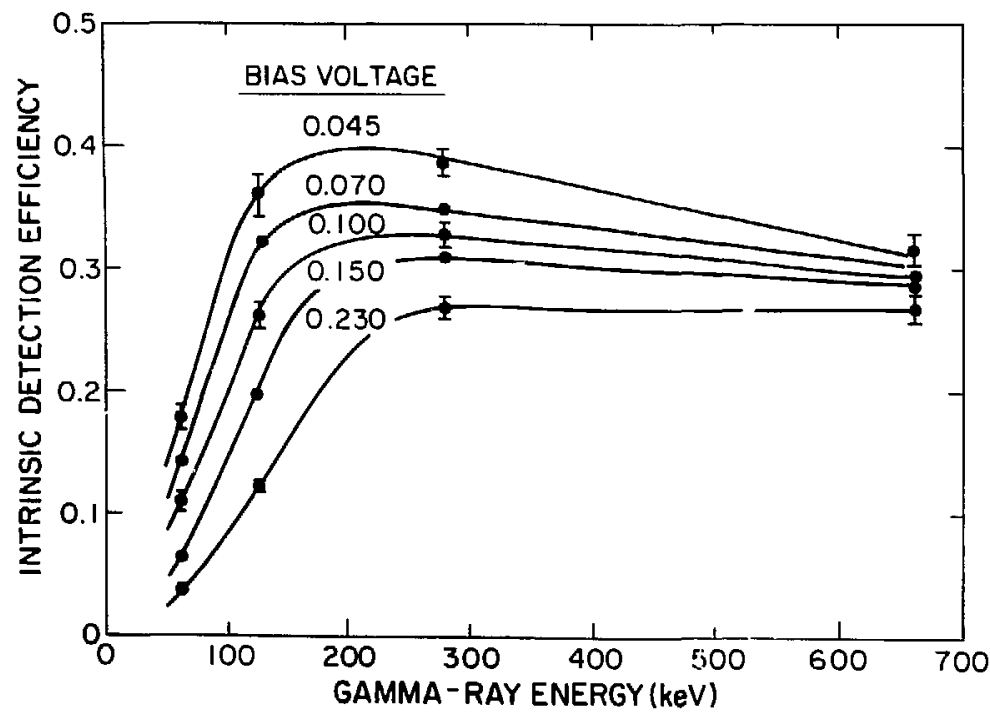

Fig. 29. Lowering the LLD bias voltage for a plastic scintillation detector improves its intrinsic efficiency over a broad range of gamma-ray energies. 
hence low-noise electronics and precise and accurate level discriminators discussed in the next section are essential for effective monitoring.

\section{SCINTILLATION DETECTOR ELECTRONICS}

\section{A. Power and Signal Conditioning}

Scintillation detectors require power supplies (low voltage for operating electronic circuits and high voltage for operating the PMTs) and signal-conditioning circuits (a preamplifier and linear pulse amplifier for the PMT signal). After detector ioniza-." tion is converted in the amplifier to voltage puises with amplitudes related to the incident gamma radiation, a following pulse-height discriminator circuit can select pulses having the desired pulse heights. A single-channel pulse-height analyzer with upper and lower level discriminators can select pulses within an energy region typifying SNM for further processing.

The electronic components of a radiation monitoring system must be as noise free as possible and not distort the statistical information in the detected signals. Good photocathode response to scintillation light ensures good transfer of gamma-ray energy information between scintillator and PMT. The pulseheight energy information is preserved by the linear current and voltage multiplication in the PMT and in the subsequent pulse-forming and -shaping electronics. Stable amplification factors immune to drift in power-line voltage or to the presence of power-line spikes preserve output linearity and pulse-height resolution. Proper response over a wide range of radiation source intensity will enable fail-safe operation in the presence of extremely high radiation intensity. That is, an alarm trill always sound at high intensity even though the electronic circuits may become saturated.

\section{B. Single-Channel Analyzers}

To reduce noise--signals other than the desired unes-by simple means, two voltage-level discriminators can be combined as a single-channel analyzer (SCA) to discriminate signals that are lower or higher than the desired ones. Two voltage-level discriminators, lower level and urper level, form an energy-acceptance window in radiation monitors. An energy acceptance window is very useful for monitoring HEU. The uranium spectrum in Fig. 10 lies in a very limited e-ergy region between about 50 and 220 $\mathrm{keV}$. When diversion signal intensities are compared with background, the most sensitive comparison is with a background in the source emission region. Even for plastic scintillation detectors with widespread Compton energy distributions, appropriate energy windows improve SNM detection. Data from Reference 3, reproduced here as Table VII, demonstrate performance improvement in a $\mathrm{NaI}(\mathrm{Tl})$ portal monitor as a result of appropriate energy windows. The figure of merit $\mathrm{S}^{2} / \mathrm{B}$ in the table is the square of the net signal, $S$, to noise (statistical noise)-a good measure of detectability. The detectable mass vas decreased by $34 \%$ with an optimum SCA window that was no wider than the source emission region. Tlyis result is significant because the alternatives had initially been chosen by some other criterion to achieve best results. Had other arbitrary windows been included, the improvement would have been even more striking.

\section{Electronics Diagnostic Techniques}

The simple high- and low-background tests mentioned in Sec. V.D are diagnostic techniques that have been applied in monitors to detect malfunctions or tampering. Other state-of-health monitoring techniques are now available to examine the counting

TABLE VII. $\mathbf{S}^{\text {? }}$; B Values in Three SCA Windows for a 10-g ${ }^{235} \mathrm{U}$ Spherical Source and $21-\mu R / h$ Background Intensity

\begin{tabular}{lccc}
\hline SCA Window (V) & Energy Window (keV) & $\mathbf{S}^{2} / \mathbf{B}$ & $\begin{array}{c}\text { Minimum Detected } \\
{ }^{235} \text { U Mass (g) }\end{array}$ \\
\hline 0.3-0.85 Optimum & $70-215$ & 62 & 10 \\
0.21-1.5 Rocky Flats & $46-385$ & 48 & 12.2 \\
TSA Systems & $70-1735$ & 36 & 15.2 \\
\hline \hline
\end{tabular}


statistics to verify that the counts follow a Poisson distribution and are legitimate radiation detections and not noise. A long-term method ${ }^{14}$ not yet applied in SNM monitors can diagnose problems even in the presence of varying background and sources. A simpler technique, variance analysis, ${ }^{9}$ has been included in a hand-held diagnostic tool, ${ }^{15}$ as a part of ar: SNM monitor control unit, ${ }^{16}$ and as part of a TSA Systerns, Inc.," hand-held SNM monitor.

Variance analysis simply calculates the variance* of a group of samples, 30 for example, and compares the variance with the mean value of the group of counts. The variance and mean should be identical for Poisson statistics, and the ratio of the two, called

"TSA Systems, Inc., 4919 North Broadway, Boulder, CO 80302, (303) 447-8553.

"The statistical term "ariance denotes the average squared deviations of a group of counts from their mean value. Its square root is the standard deviation that we discussed in Sec. V.A. the Feynman variance to mean ratio, is commonly applied to determine the state of health of radiation detectors. Practical application of the technique can average its results over a period of time to verify normal behavior. Noisy behavior, on the other hand, is quickly detected in one or a few measurements. Other useful applications of the variance analysis technique are in electrical circuit troubleshooting and plastic scintillator calibration.

\section{Detector Calibration}

The first step in calibrating scintillation detectors is to set the photomultiplier high voltage to $1000 \mathrm{~V}$ or so and then adjust the amplifier gain to place the pulse height from a ${ }^{137} \mathrm{Cs}$ source located near a detector at from 2-V to 4-V pulse heigit on an oscilloscope connected to the amplifier analog output (Fig. 30). Each detector must be adjusted to the same pulse height as the first by adjusting its gain potentiometer.

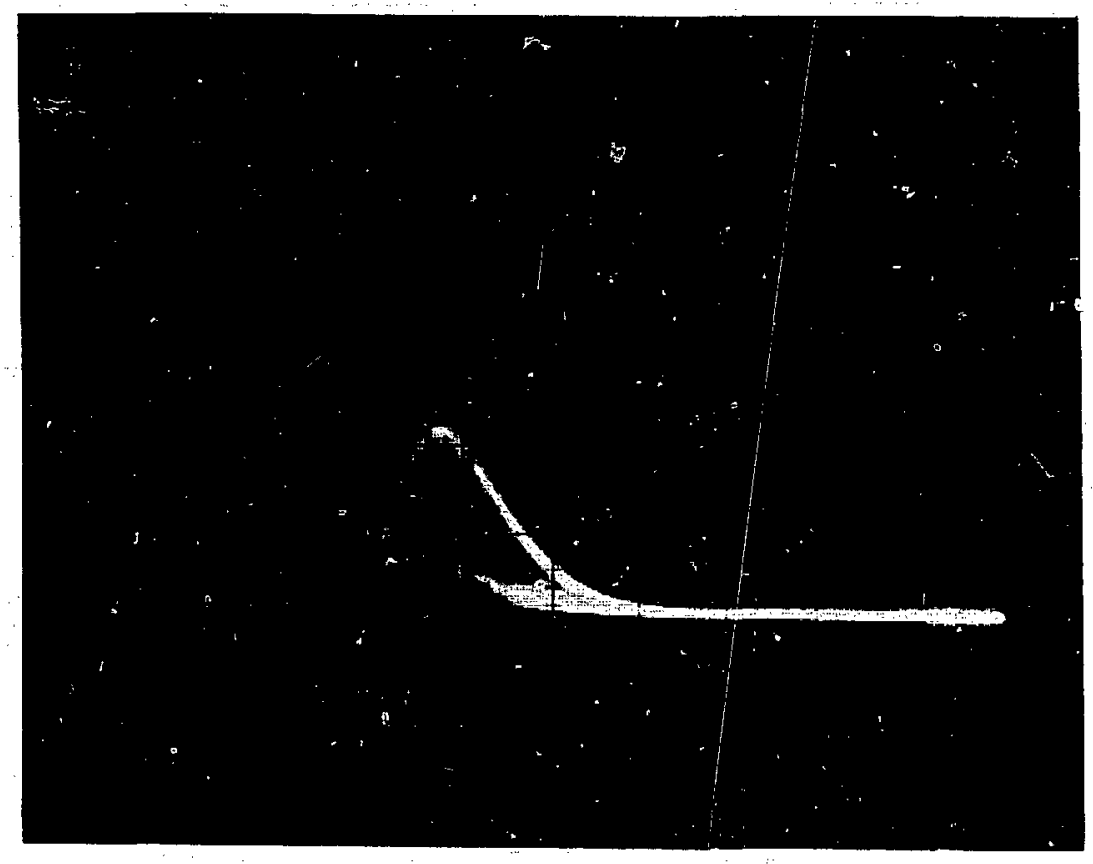

Fig. 30. SNM monitor calibration begins by setting the gain of the detection system to place a particular gamma-ray spectrum peak or knee at a 2- to 4-V pulse height on an oscilloscope or multichannel analyzer. Here the $662-\mathrm{keV}$ peak is at $2 \mathrm{~V}$. 
Each adjustrnent procedure should place the calibration source at the same location on a detector-the center of a $\mathrm{NaI}(\mathrm{Tl})$ detector or the foot of a long plastic detector, for example. The procedure is usually rapid after the detectors have been balanced once. The task is quite easily acconıplished with a nominal $5-\mu \mathrm{Ci}{ }^{137} \mathrm{Cs}$ source and an oscilloscope; one with a filtered viewing hood if room lights or sunlight makes observation difficult.

\section{E. SCA Calibration}

The SCA upper level discriminator (ULD) can be set by triggering an oscilloscope with the SCA output pulse and observing the scope trace of the delayed amplifier output amplitude. With the $662-\mathrm{keV}{ }^{137} \mathrm{Cs}$ peak at $3.3 \mathrm{~V}$ for example, the plutonium upper window level for $450 \mathrm{keV}$ would lie at about $2 \mathrm{~V}$ for plastic scintillators (Sec. III.C and Table VIII below) and at $2.25 \mathrm{~V}$ (by direct interpolation) for $\mathrm{NaI}(\mathrm{Tl})$ scintillators; the ULD can be adjusted to place the maximum oscilloscope trace height there. The lower level discriminator (LLD) can be set similarly to about $0.3 \mathrm{~V}$ for $\mathrm{NaI}(\mathrm{T} 1)$ scintillators, although lower settings usually are possible that are still above the noise.

Table VIII lists the maximum Compton recoil electron energy in plastic scintillators for certain gamma-ray energies along with the equivalent pulse heights for a systern having $662-\mathrm{keV}$ at $3.3 \mathrm{~V}$ pulse height. Other pulse heights for different $662-\mathrm{keV}$ calibration heights are obtained by scaling the values in the right-hand column of the table.

The appropriate window for detecting uranium is from above the noise, $60 \mathrm{keV}$ perhaps, to about 220 $\mathrm{keV}$. For plutonium the same window suffices for bare material, but $60 \mathrm{keV}$ to $450 \mathrm{keV}$ would more likely be used when the plutonium might be shielded. From the table, the appropriate SCA window for plutonium would be from $0 . \mathrm{C} 80 \mathrm{~V}$ or less up to $1.98 \mathrm{~V}$ for plastic scintillators. In practice the LLD adjustment is done in one of two ways.

Organic scintillator LLDs can be set by source-in and source-out measurements using plutonium or uranium as is appropriate. The idea is to maximize the detectability, $S^{2} / B$, where $S$ is the ret source count and $B$ the background count. Ordinarily, this approach requires a great deal of time. A quicker method to set the LLD uses a variance analyzer (Sec. VII.C) to detect the onset of electronic noise. The LLD is simply adjusted until the variance analyzer result is consistently smaller than about $0 . i$ or 0.2 , taking only a few moments instead of an hour or so for source-in and source-out adjustment. More SNM monitor controilers are including the variance analysis in their repertoire, and variance analyzers similar to the one in Fig. 31 are becoming commercially available.

\section{F. Periodic Calibration Checks}

An important daily test of a SNM monitor determines whether it is functioning at the start of each day's work. If a low-intensity check source $-1 \mu \mathrm{Ci}$ of ${ }^{133} \mathrm{Ba}$ for walk-through doorway monitors for example-is used for testing, not only is the continuity of the monitor's electronics verified but adequate sensitivity is also verified to some extent. A more thorough test with SNM in threshold quantities should be performed no !ess than once each quarter as part of periodic monitor recalibration.

\section{AN EXAMPLE OF AN SNM PORTAL MONITOR}

SNM monitors comprise radiation detectors, signal-conditioning electronics, signal-processing electronics, a monitor control unit, an occupancy sensor, output devices, and power supplies. Discrete components to carry out the functions represented by this

\begin{tabular}{ccc}
\hline \hline TABLE VIII. Compton Recoil Electron Maximum Energy \\
\hline $\begin{array}{c}\text { Incident Gamma-Ray } \\
\text { Energy (keV) }\end{array}$ & $\begin{array}{c}\text { Compton Electron } \\
\text { Maximum Energy (keV) }\end{array}$ & $\begin{array}{c}\text { Pulse } \\
\text { Height (V) }\end{array}$ \\
\hline 662 & 480 & 3.3 \\
450 & 287 & 1.98 \\
220 & 102 & 0.693 \\
100 & 28,1 & 0.193 \\
60 & 11.4 & 0.078 \\
\hline
\end{tabular}




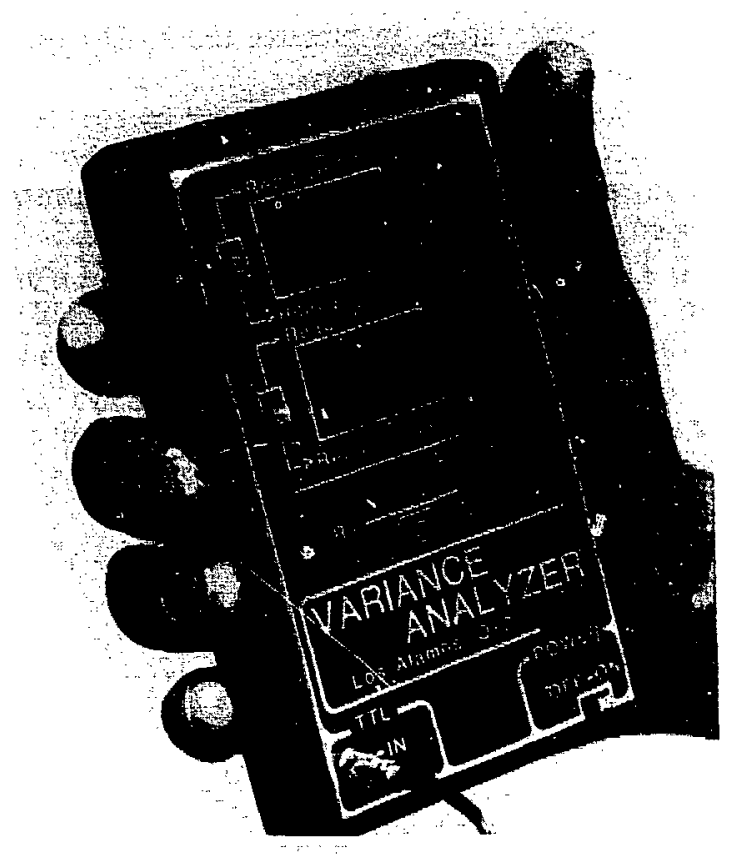

Fig. 31. The variance analyzer allows rapid LLD adjustment in room-temperature organic detectors. TSA Systems manufactures the hand-held device.

list are not always present but the tasks are always carried out in some manner. The brief specific component functions are as follows:

- Detector. Detect gamma-ray or neutron radiation with particular emphasis on a designated region of space, that is, between two detector columns or within the field of view of a collimated detector.

- Signal-Conditioning Electronics. Transform the detected radiation into electrical signals that are suitable for transmission and further analysis.

- SCA. Select the electrical signals that represent incident radiation typical of SNM. The window is best limited to the gamma-ray energies emitted by a particular material but it sometimes includes everything above a threshcld energy. Output is 1 standard logic pulse per selected input detector signal.

- Control Unit. Count the logic pulses and use the result when unoccupied to derive an expected background and an alarm level; test and display the background or the background count rate. When the monitor is occupied, count the logic pulses and compare the result with the alarm level. Use the oc- cupancy sensor output to establish time periods when background can be measured and when it is necessary to monitor an occupant. In attended monitors that menitor continuously, use the occupancy sensor output to enable sounding alarms only when the monitor is occupied. Carry out state-of-health monitoring on demand or periodically.

- Occupancy Sensor. Sense the presence of a person who must be monitored. When direction of traffic is important, sense both presence and direction and output the monitoring command for outgoing traffic only.

- Output Device. Communicate monitoring results to the attendant by means of visual (flashing lights) and audible (chirp) signals.

- Power Supplies. Convert line power to the necessary direct current voltages needed to operate the detectors and electronics.

A good example of a radiation monitor is a walkthrough SNM monitor, which is a doorway-shaped space surrounded by gamma-ray scintillation detectors as in Fig. 1. The monitor's control unit keeps track of the background with unoccupied measurements and keeps the alarm level up to date from the background information. Occupancy suspends background measurement and begins the monitoring process. Monitor counting intervals are tailored to the circumstances; for example, in a walk-through portal monitor, a count period of about $0.6-0.8 \mathrm{~s}$ covers the time that a walking person is near the detectors. When it is completed, the monitoring count is compared with the alarm level and appropriate action is taken.

\section{EVALUATING AN SNM MONITOR}

SNM mūnitors are evaluated for a number of reasons. Laboratory evaluations can verify performance levels for cusiation monitors in a standard cormparative manner as well as discover shortcomings in monitor design. In-plant evaluations involve more simple tests to verify expected performance levels for monitors installed in an operating environment. These tests also may discover operational interference or other shortcomings in the particular application of a monitor. Two important parts of either kind of evaluation are determining the monitor's statistical alarm performance and its source-detection sensitivity. 


\section{A. Statistical False-Alarm Measurement}

A good place to begin an evaluation is by observing the monitor's statistical false-alarm performance. This requires interrupting the monitor's occupancy sensor automatically for part of repeated short test periods (1 $\mathrm{min}$ or so). Time is allowed to update the background between test periods. The results of falsealarm tests are easily recorded automatically on a strip chart recorder that displays the monitor's count rate as a continuous trace interrupted by event marks denoting alarms. The false-alarm probability is calculated from the total number of tests that were made-usually about one-half million are needed for $4 \sigma$ alarm levels-and the number of observed alarms. The false-alarm rate per passage is then calculated based on the number of tests that the monitor makes per passage.

Results of false-alarm testing should fall within a factor of 2 of the expected result once enough tests have been made. For example, at a $4 \sigma$ alarm threshold, an average result between 1 statistical alarm in 15,000 and 1 in 30,000 tests might not be unreasonable if averaged over 500,000 tests. Laboratory false-alarm results can be very close to the expected result because they are conducted in a controlled environment. Any significant discrepancy may be caused by noisy circuits or other design problems. On the other hand, a laboratoiy-verified SNM monitor that does not come up to expectation during in-plant tests would call for investigating the need for repair or recalibration and the possible interference from real background intensity changes.

Another way to conduct in-plant statistical falsealarm tests is to require that records be kept during the monitor's normal use. Records may be guard entries in a $\log$ (the less reliable method) or strip chart records as described above. In this case, the results would indicate whether a hoped-for goal of one statistical false alarm per 8-hour-!ong work shift or per work day is achieved over the long term. In this case, the testing rate is limited by the normal passage frequency so significant results may require months of record keeping. Resolution of higher than expected alarm rates in this case would be the same, that is, look for calibration or hardware defects and background intensity excursions.

\section{B. Determining Detection Sensitivity}

For quick and approximate evaluation of a monitor's sensitivity, an estimate can be made by measuring the monitor's response to standard SNM sources placed in the monitor at the minimum-sensitivity location. A single location or a series of locations may be used to obtain a count rate profile as SNM moves through the portal (Fig. 7). Most often the profile data can establish the best detection logic parameters for the monitor as part of a laboratory evaluation. SNM source intensity measurcment at the lowest sensitivity location may be useful for both laboratory and in-plant purposes because it establishes a figure of merit, $S^{2} / B$, that helps compare monitors. For example, the ratio of the squared net SNM intensity measured at floor level center to the the background intensity in a walk-through monitor can, by comparison with results in other monitors, guide the progress of laboratory walk-through testing. In other cases, the results of single location measurements can conipare the expected performance for monitors at differcnt locations in a plant.

In this and all other tests, the test sources should be metallic spheres of SNM. This geometry has the greatest self-attenuation of gamma radiation and is a worst-case test. Uranium test sources are the best choice but if plutonium must be used, it must have low 60-keV emission (Fig. 32) to make it a worst-case test source. Then, the monitor in normal use can be expected to have better detection sensitivity. The size of the HEU-sphere test source for Category II monitors in Table II is $10.7 \mathrm{~g}$. Monitors in other categories would use other appropriately sized test sources or simply perform better or worse with the Category II source.

Walk-Through Testing. Walk-through testing for laboratory $t$,valuation must use as many different individuals as necessary to reach a $95 \%$ confidence conciusion that $50 \%$ or greater detection probability is achieved for the source being used. Each individual makes a few, 5 to 15 total, walk-throughs a few at a time to allow the individual style of passing through the monitor to be varied. The graph (Fig. 33) derived from the binomial confidence-interval tables of Dixon and Massey ${ }^{17}$ determines a stopping point. When the results fall in the $50 \%$ or greater region, testing may stop. The total number of tests and the fraction of detections then determine a detectionconfidence interval from the Dixon and Massey tables themselves. If the accumulated testing results do not seem to approach the allowed regirn after many passages, testing should cease with negative result.

In-plant evaluation can also use the plot in Fig. 33 if the results of testing are good enough, for example if most passages are detected. However, a monitor that just meets the detection requirements needs 


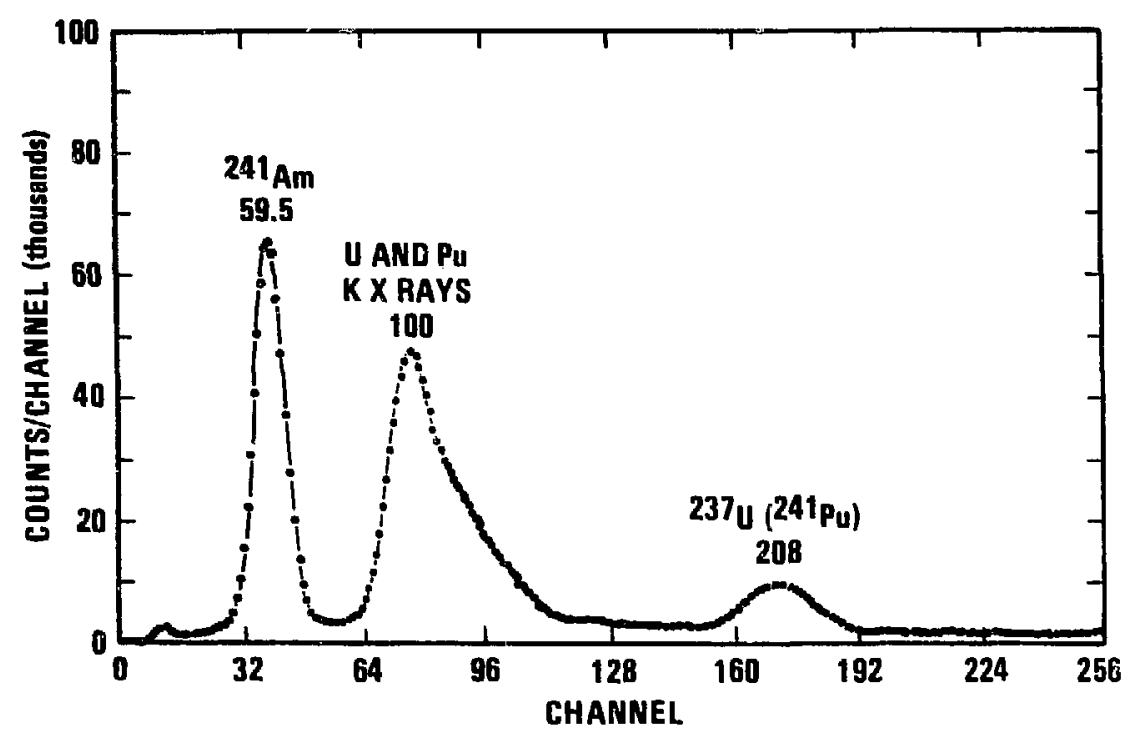

Fig. 32. Low-bumup plutonium test sources should exhibit little evidence of the ${ }^{241}$ Am daughter peak at $59.5 \mathrm{keV}$. Unless these sources are replaced with new ones made from recently separated material each year or so, they should not be used. Substitute HEU or ${ }^{133} \mathrm{Ba}$ sources as test sources wherever frequent replacement of plutonium sources is not possible.

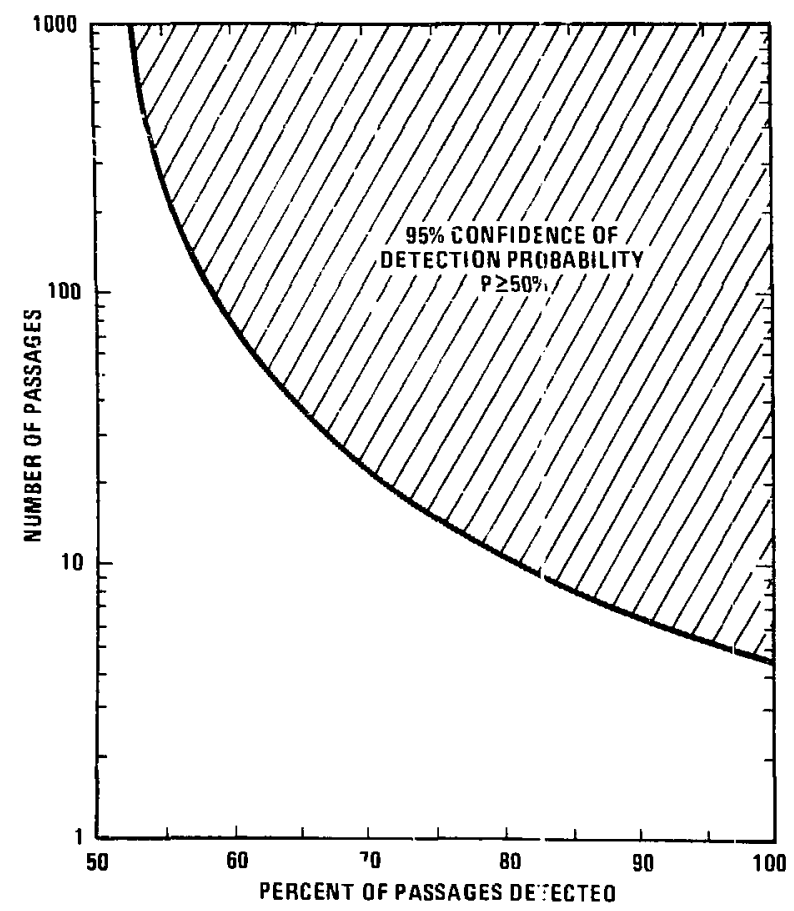

Fig. 33. Adequate confidence in the result of testing a monitor for $50 \%$ detection probability is achieved when test results fall into the shaded region. Otherwise testing continues, unless the per cent of detections is so low that ultimate success is unlikely. 
many more passages to verify the fact with this method when installed at a plant. An alternative method that accommodates most monitors is outlined in Reference 18. This method requires quarterly walk-through tests having 15 walk-through passages with the source positioned in a least sensitive location, which may be attached to an interior ankle of one leg. The results are interpreted after each quarterly evaluation and after looking at the immediate results and the tallied results of up to four evaluations. A confidence table (Table IX) lists the degree of confidence given by the results that the monitor has a 50\% probability of detecting the test source.
In this method, results falling into the $95 \%$ confidence column are the same as described for laboratory evaluation and are fully acceptable. Results falling into the $70 \%$ column are accepted conditionally until the results for 4 quarters, 60 walk-throughs, are available. At that point, if results for 60 passages still fall short of the $95 \%$ column, remedial werk to try to bring the monitor up to standard is justified. Results falling in the $50 \%$ confidence column justify immediate work to improve the performance and then conditional acceptance until the results for four quarters are analyzed as just described. Results falling below the $50 \%$ column call for immediate inspection and repair.

\begin{tabular}{|c|c|c|c|}
\hline \multicolumn{4}{|c|}{ TABLE IX. Confidence Limits for 50\% Detection Probabilit } \\
\hline \multirow[b]{2}{*}{$\begin{array}{l}\text { Number of } \\
\text { Passages }\end{array}$} & \multicolumn{3}{|c|}{ Minimum Number of Detections } \\
\hline & $\begin{array}{c}50 \% \\
\text { Confidence }\end{array}$ & $\begin{array}{c}70 \% \\
\text { Confidence }\end{array}$ & $\begin{array}{c}95 \% \\
\text { Confidence }\end{array}$ \\
\hline 15 & 8 & 9 & 12 \\
\hline 30 & 16 & 18 & 21 \\
\hline 45 & 24 & 26 & 30 \\
\hline 60 & 32 & 34 & 38 \\
\hline
\end{tabular}




\section{PART 3}

\section{A CATALOG OF SNM RADIATION MONITORS*}

In this part, each of the SNM pedestrian monitors being used by DOE contractors is briefly described.

\footnotetext{
'Reference herein to any specific commercial product, process, or service by trade name, trademark, or manufacturer does not necessarily constitute or imply its endorsement, recommendation, or favoring by the United States Government or agency thereof.
}

Other monitors that are just being introduced and a few monitors that are commercially available in other countries are also described.

The monitors described here fall into different performance categories, and where impartial evaluations have taken place, the results are mentioned. The business address for each manufacturer of commercially available monitors is listed. Further information on the monitors may be available from the manufacturer or, as time goes on, from the author of this publication. 


\section{HAND-HIELD SNM RADIATION MONITORS}

Three types of hand-held monitors having batteryoperated radiation detectors and digital electronics are illustrated below. The monitor at the left was developed at Los Alamos and is now in widespread use at many DOE facilities. It is applied to both pedestrian and vehicle SNM monitoring as well as to high-sensitivity contamination monitoring. It serves as the primary monitoring method in some cases and in others it is a back-up monitor for stations having automatic pedestrian and vehicle SNM monitors. A back-up monitor helps to continue SNM monitoring during automatic equipment failure and also serves to precisely locate SNM detected by an automatic system. This monitor has a sodium iodide radiation detector and sensitive digital detection electronics that sense background gamma-ray intensity and detect small intensity increases near SNM or other radiation sources. This monitor is commercially available in one form as the HM-3 from National Nuclear Corp." [specify 1.5-in. diam b:- 1.5-in-long $\mathrm{NaI}(\mathrm{Tl})$ detector or $\mathrm{NNC}$ will substitute a less suitable size] and in slightly different form (but with proper size detector) as the DRM-2 from CMS, Inc.-

The monitor in the center also has a sodium iodide detector. It is a newly developed Los Alamos monitor that is a second generation monitor intended to replace the monitor at the left. The monitor incorporates Los Alamos and commercial manufac-

\footnotetext{
National Nuclear Corp., 1904 Colony Street, Mountain View, CA 94043, (415) 962-9220.

"CMS, Inc., 6446 Caroldale Place, Goleta, CA 931 17, (805) 964-7451.
}

turer improvements that make it much lighter and give it improved sensitivity for some applications. Although it is lighter, it has a much longer-battery lifetime that makes it more suitable for applications where frequent charging is not always possible. At the time of writing, purchase specifications are being prepared for comrnercial versions of the new monitor, called the Los Alamos Programmable Radiation Monitor (LAPRM), to be made available for field evaluation. Information on the status of this monitor is available from the author."

The monitor at the right is a new monitor called the HHD $\mathbf{4 4 0}$ having a plastic scintillation detector. It was developed by TSA Systems, Inc." and is much heavier than either of the other two monitors. The HHD-440 applies Los Alamos-developed transient signal detection technology that gives the monitor sensitivity as good as the other monitors even though it applies a low-efficiency plastic scintillation detector. Its weight makes it unsuitable for continuous use but it has found many applications in SNM monitoring that require short-term hand-held operation or other temporary applications. It has been used for temporary construction-area SNJM monitoring in a stationary manner and, with additional electronics and detectors, it has been applied as a stationary vehicle SNM monitor. Other HHD-440 applications to health physics monitoring use its relatively flat detector response and microprocessor control circuit to monitor a broad range of radiation energies and intensities.

P. E. Fehlau, Los Alamos National Laboratory, MS-J562, Los Alamos, NM 87545, (505) 667-5372 or FTS 843-5372. TSA Systems, Inc., 4919 North Bruadway, Boulder, CO 80302, (303) 447-8553.

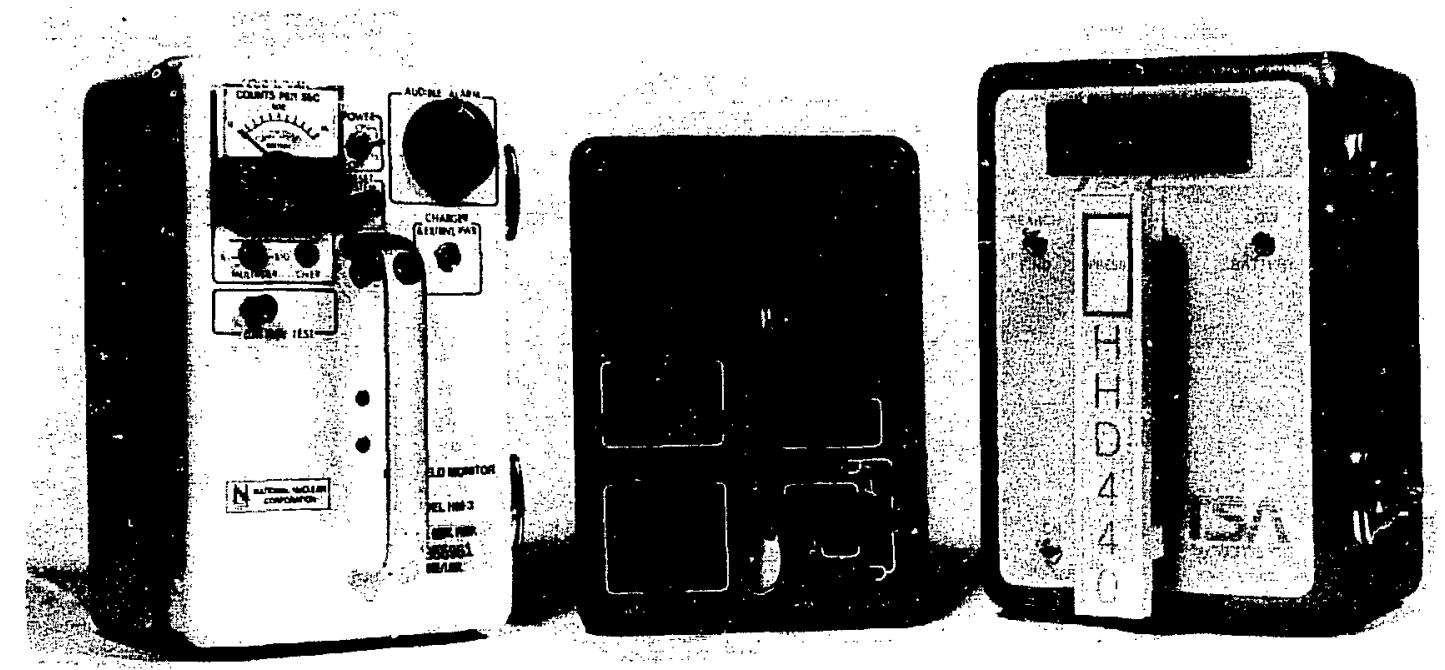




\section{NATIONAL NUCLEAR CORPORATION DM-2 PEDESTRIAN SNM MONITOR}

The National Nuclear Corp." model DM-2 has been available in one form or another $f-r$ more than 10 years. It has found application at many DOE facilities including Los Alamos, Savannah River, Argonne West, and Rockwell Hanford Operations. Goodyear Atomic at Piketon, Ohio, applies a version of the monitor that incorporates a dual sensitivity metal detector. The monitor has very long plastic scintillation detectors and either analog or digital detection circuits. The analog detertion circuit was present in the monitor evaluated at Los Alamos. That

National Nuclear Corp., 1904 Colony Street, Mountain View, CA 94043, (415) 962-9220. evaluation incorporated modifications in the monitor to obtain Category II detection sensitivity at low false-alarm rates. Shortening the very long detectors and adding light pipes could greatly improve this monitor's performance.

The analog detection circuit of the DM-2 is troublesome to calibrate initially but once calibrated, the monitors often operate well for long periods between major adjustments. The analog monitor operates without an occupancy monitor although one is often used to suppress alarm signals when the monitor is unoccupied. A digital logic circuit introduced to simplify calibration has not been evaluatec. Other changes have been introduced to other parts of the monitor over the years and some of these may affect monitor operation. A calibration manual ${ }^{7}$ prepared by Los Alamos lists the original components of the monitor that was evaluated there.

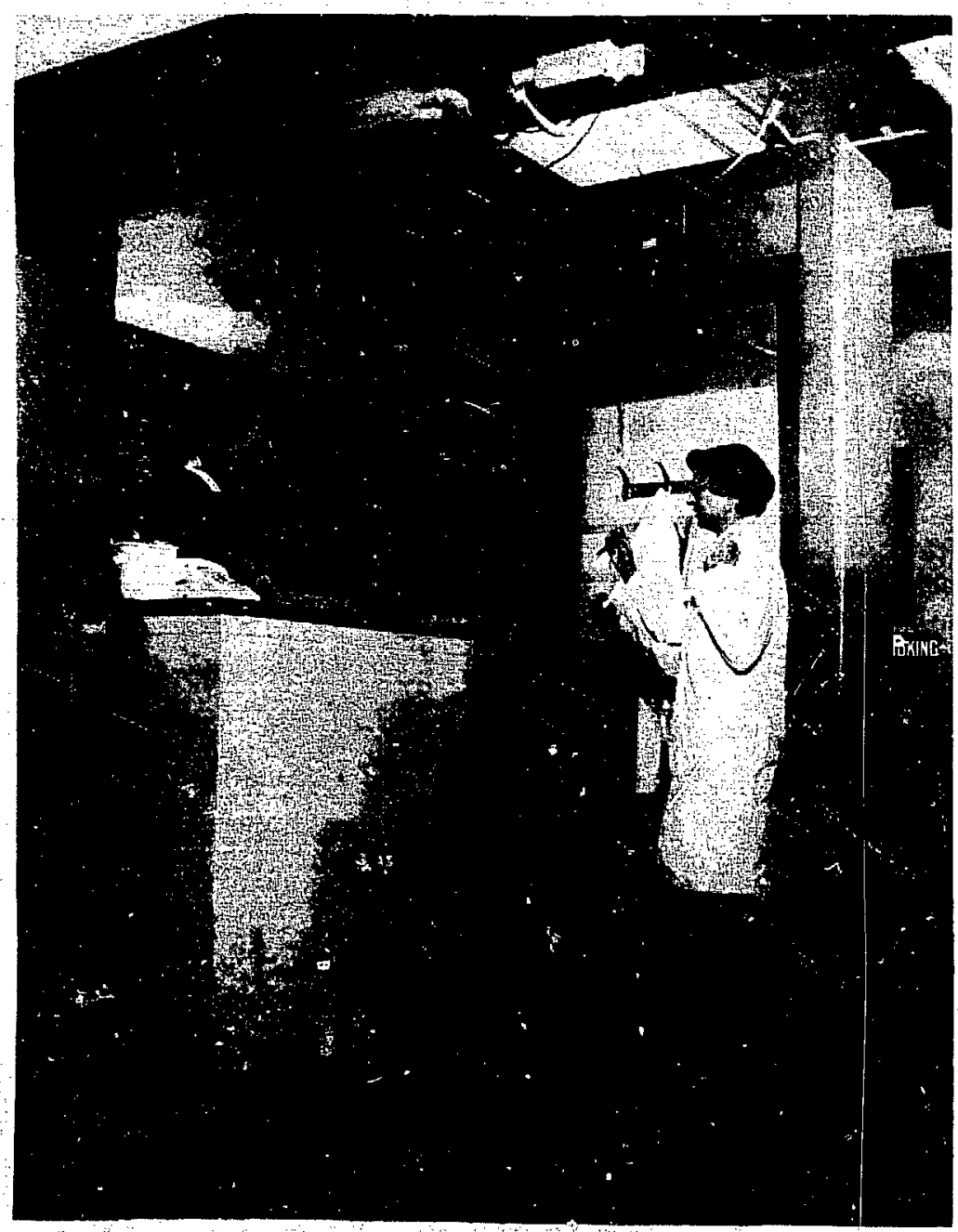




\section{IRT CORPORATION PRM 110 PEDESTRIAN MONTTOR}

The IRT Corp:" model PRM 110 is another monitor that has been applied to SNM monitoring for about 10 years. It has liquid-organic scintillation

"IRT Corp., 3030 Callan Rd., San Diego, CA 92121, (619) 450-4343. detectors that are unique in SNM monitoring. The PRM 110 was evaluated by Los Alamos in 1974. At that time the manufacturer made changes in the monitor's digital detection logic to achieve reasonable false-alarm rates so that the monitor just met Category II sensitivity. Now the monitor is available with later, multipurpose electronics that decrease its effectiveness for SNM monitoring. The PRM 110 monitor has been succe;sfully applied to ${ }^{238} \mathrm{Pu}$ monitoring at Mound Laboratory.

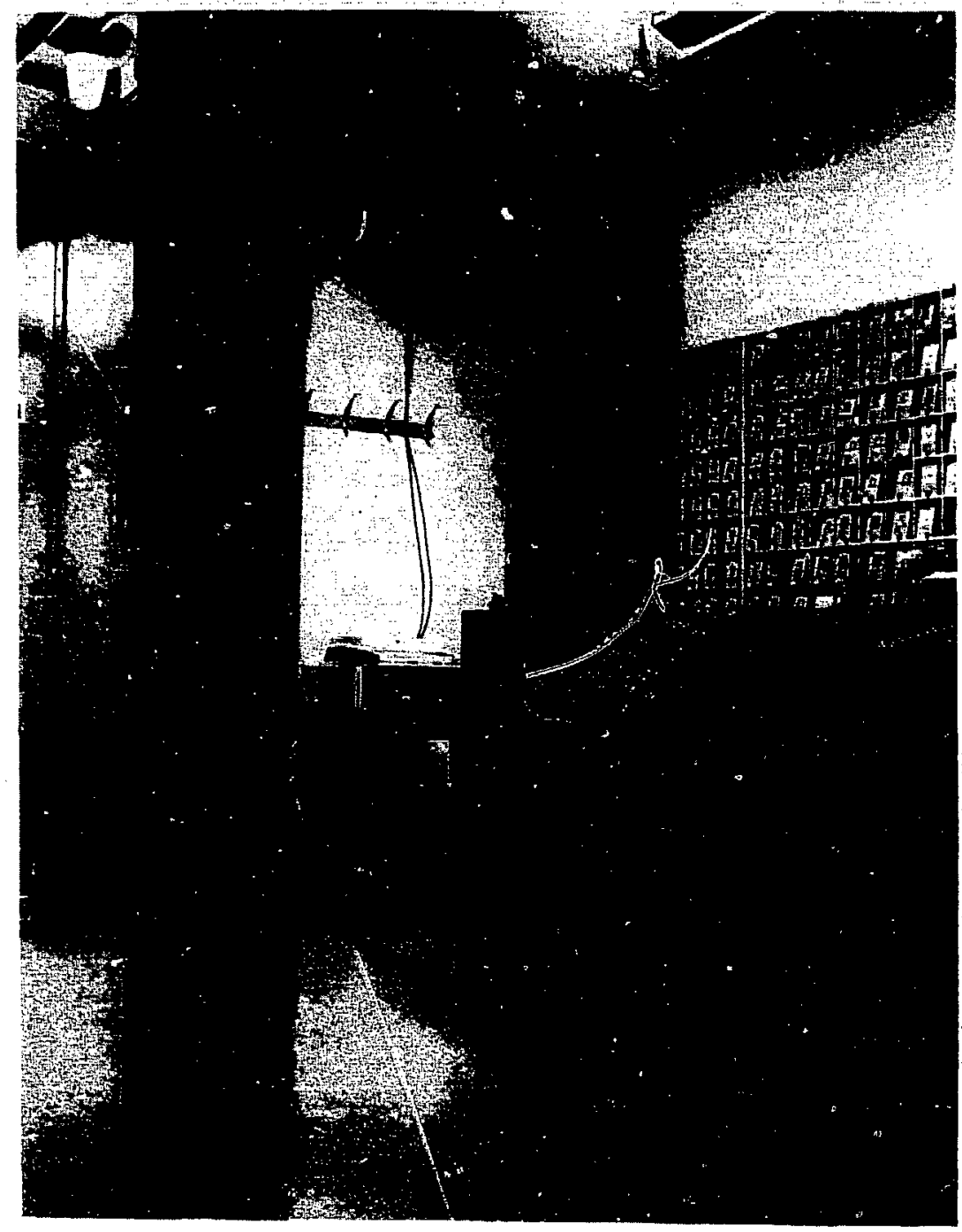




\section{IRT ${ }^{*}$ CORPORATION PRM 120 PEDESTRIAN MONITOR}

This recently evaluated monitor with extremely large liquid scintillators has been marketed as a con- tamination monitor and did not perform well at SNM monitoring. It has only Category I sensitivity and its manufacturer is no longer offering it as a SNM monitor.

'IRT Corp., 3030 Callan Rd., San Diego, CA 92121, (619) 450-4343.

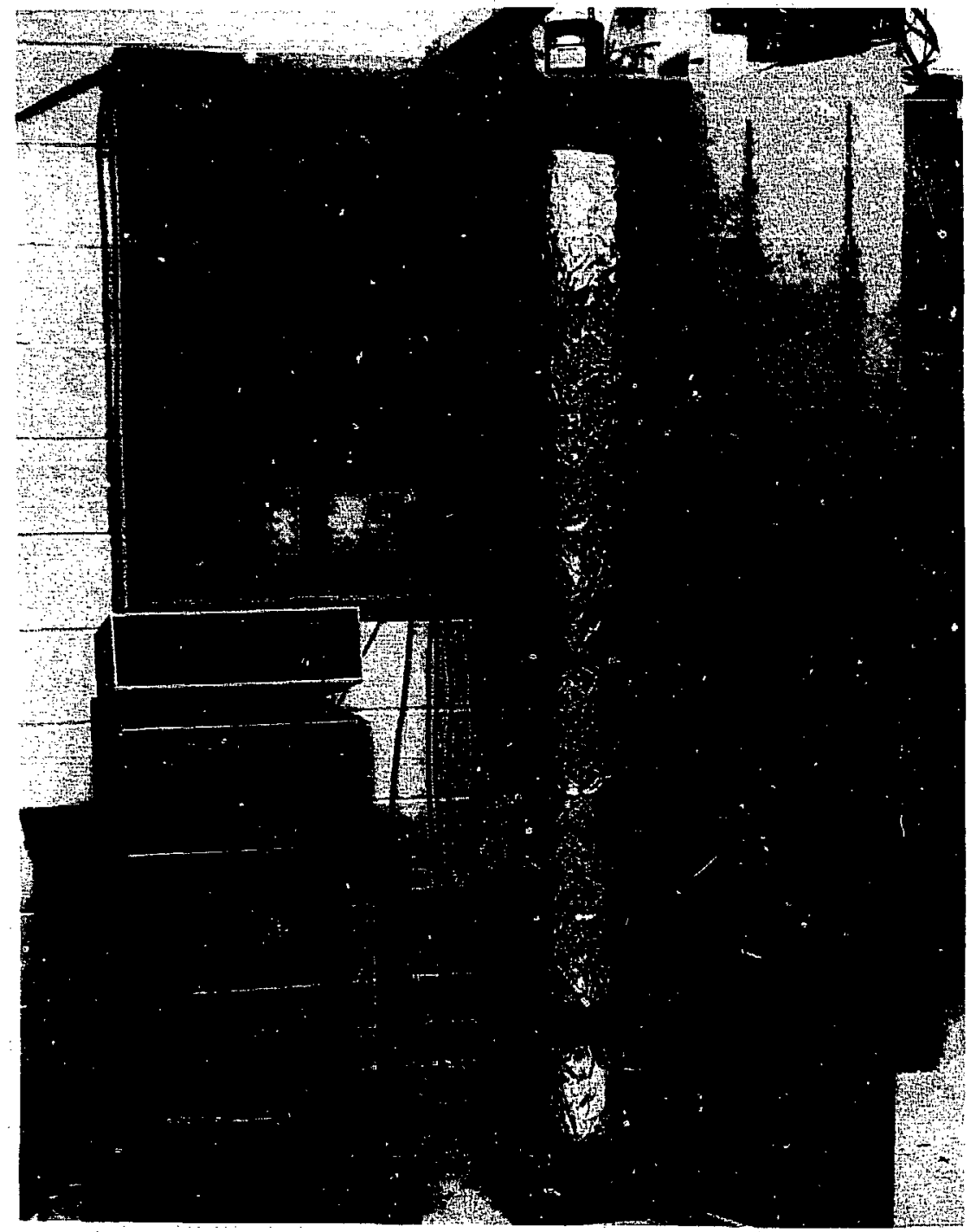




\section{TSA" SYSTEMS PM 203/101 PEDESTRIAN MONITOR}

This monitor has small sodium iodide detectors positioned along the sides of the portal. The monitor was evaluated at Los Alamos and required very few changes to achieve Category II performance. Over the years, the manufacturer provided a wide variety of other control modules for this monitor under the designation model 301, and these modules incorporate TSA Systems signal-conditioning electron-

TSA Systems, Inc., 4919 North Broadway, Boulder, CO 80302, (303) 447-855. ics in place of standard units, locating them near the microprocessor electronics in a single module. Some noise is introduced thereby, and the monitor falsealarm rate is somewhat higher. Where this presents a problem, the manufacturer can revise the control module to correct it or to permit using external modules for the amplifier and single-channel analyzer. Los Alamos has prepared a calibration manual for this monitor. ${ }^{8}$ The monitor has been used at Los Alamos, Mound Laboratory, Argonne West, and at Rockwell Hanford Operations. Westinghouse Hanford uses a version built by another manufacturer.

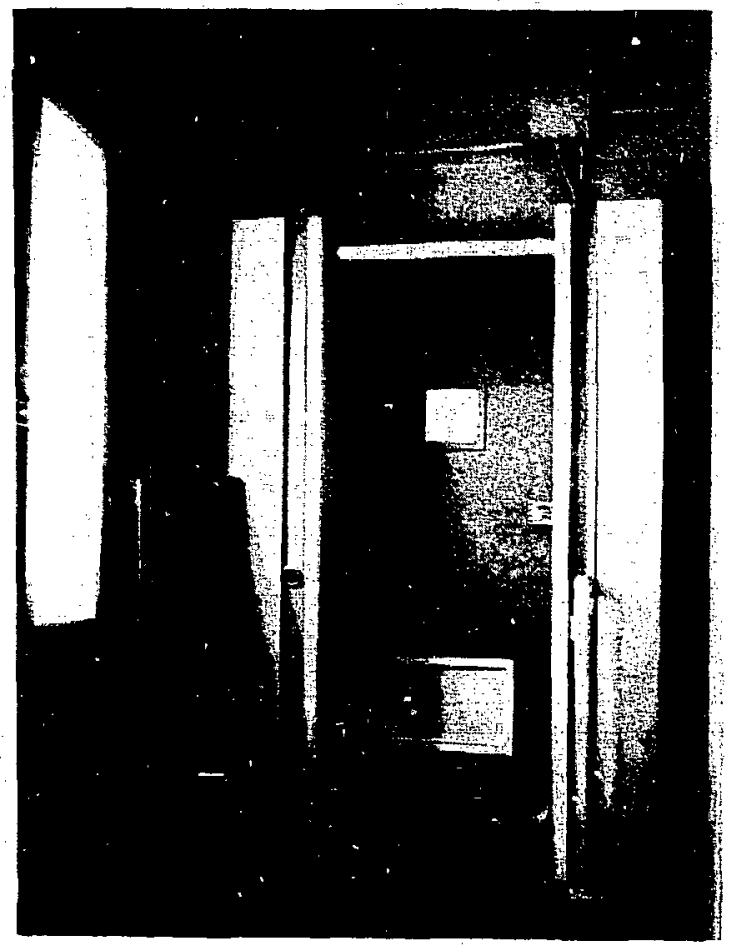




\section{TSA` SYSTEMS PM 310 PEDESTRIAN MONITOR}

This monitor was developed by TSA Systems to meet new requirements at Rocky Flats by applying Los Alamos technology. The new requirement is to monitor pedestrians for plutonium with a detector portal at least $8 \mathrm{ft}$ wide at a location inside a materialaccess area. Evaluation of the monitor at Los Alamos revealed a false-alarm rate 10 times above that expected from statistical analysis. The cause of the problem has been identified in independent analysis and can be corrected in later versions of the PM 310.

"TSA Systems, Inc., 4919 North Broadway, Boulder, CO 80302, (303) 447-8553.
As evaluated, the monitor achieved Category II sensitivity but it is capable of better performance than that. Its performance is limited by the thick steel cabinets needed to exclude scattered radiation inside material-access areas in which the monitor operates and by the high LLD settings needed to limit the false-alarm rate in our evaluation. With a redesigned model 310 control module and aluminum cabinets, the monitor should achieve better than Category II performance when applied outside material-access areas. This monitor will become the standard monitor at Rocky Flats, providing perimeter SNM pedestrian monitoring and also accountability monitoring for unrecorded movements inside a materialaccess area.

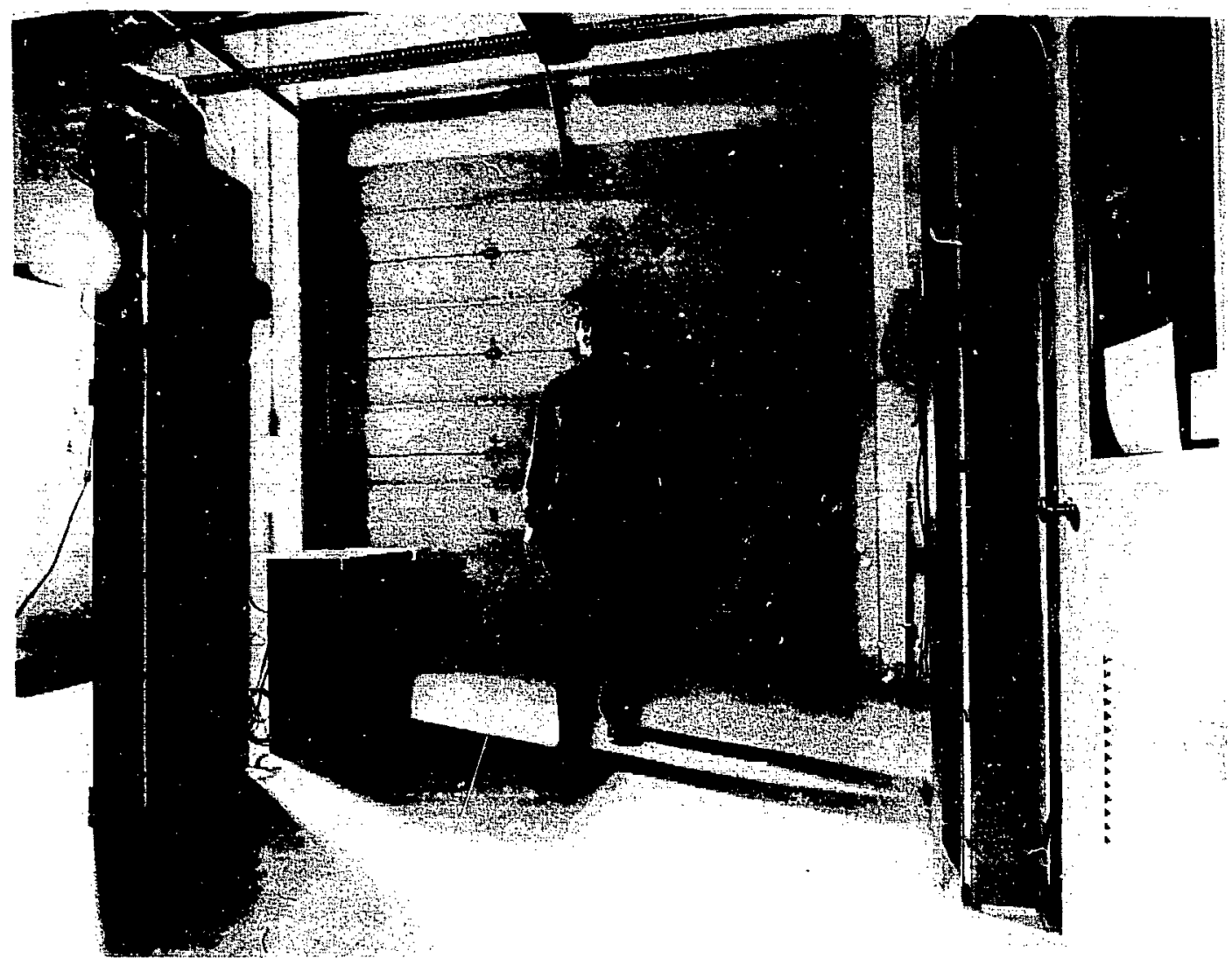




\section{OAK RIDGE Y-12 PLANT PEDESTRIAN NONITOR}

The Y-12 pedestrian SNM monitor is a very effective in-house design that maintains sensitivity as background increases. Although the monitor was not formally evaluated, Los Alamos review of Y-12 data placed the monitor at Category II sensitivity. The monitor ha. 14 sodium iodide detectors in its portal and an analog detection system that maintains its sensitivity as background intensity increases. This is accomplished by adding a fixed increment to the background to obtain the alarm threshold. This system maintains detection sensitivity while its falsealarm rate increases with the background intensity. When false alarms are too frequent, background must be decreased by removing nearby process materials.
The Y-12 plant also applies high-sensitivity metal detection to detect shielding material. Uranium can thus not easily be shielded to subvert the SNM monitor. The high-sensitivity metal detection requires that individuals wear relatively metal-free protective clothing rather than the business attire in the illustration.

The Y-12 SNM monitor was originally manufactured for them by Harshaw Crystal Electronics Division but in recent years has been supplied by Gull Engineering. Gull can supply this monitor as a commercial product.

"Gull Engineering, Inc., 78 Mitchell Rd., Oak Ridge, TN $37830,(615)$ 483-4787.

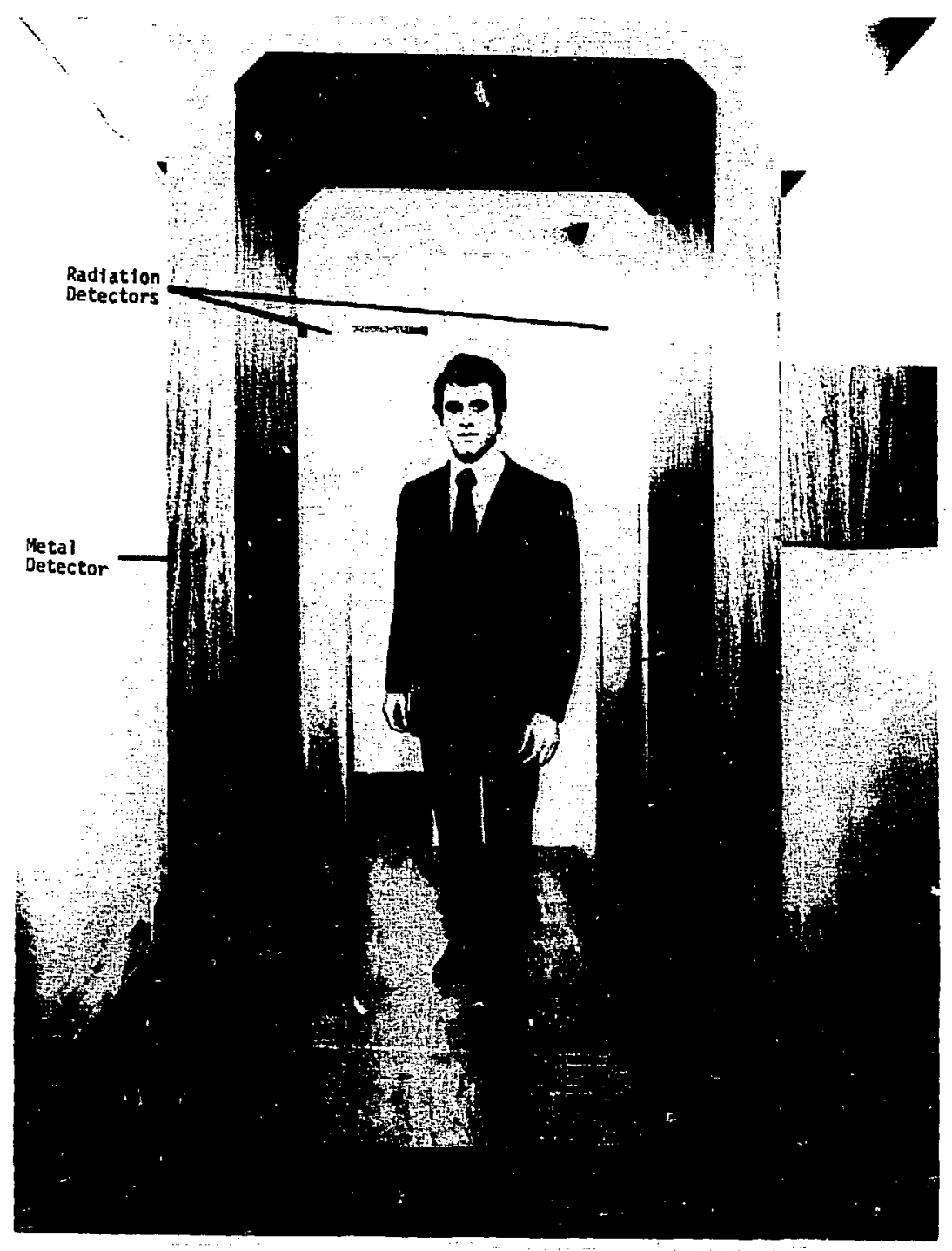




\section{LOS ALAMOS PEDESTRIAN SNM MONTTOR}

The Los Alamos pedestrian SNM monitor prototype has been operating for evaluation purposes for some years. It was developed as a vehicle SNM portal monitor and proposed as an emergency-exit pedestrian SNM monitor for the DOE Y-12 plant $^{5}$ but has not been used for either task. The prototype monitor achieved Category III performance in an informal evaluation reported in Reference $\mathbf{j}$. It was further developed as a multipurpose SNM monitoring system by applying the sequential detection method, leading to its use for pedestrian SNM monitoring at Los Alamos. Commercially produced monitors are being manufactured for Los Alamos by Gull Engineering."

The monitor has multipurpose operation because teletype input of parameters allows it to function as a walk-through pedestrian monitor, a " vit-in monitor with minimum monitcring delay, or a vehicle portal monitor. The monitor may also operate with teletype output of all significant monitoring results and with computer-generated voice commands to the operator. The monitor has large plastic scintillation detectors, and its microprocessor controller includes a variance analysis program to assist calibration of the detectors.

"Gull Engineering, Inc., 78 Mitchell Rd., Oak Ridge, TN $37830,(615)$ 483-4787.

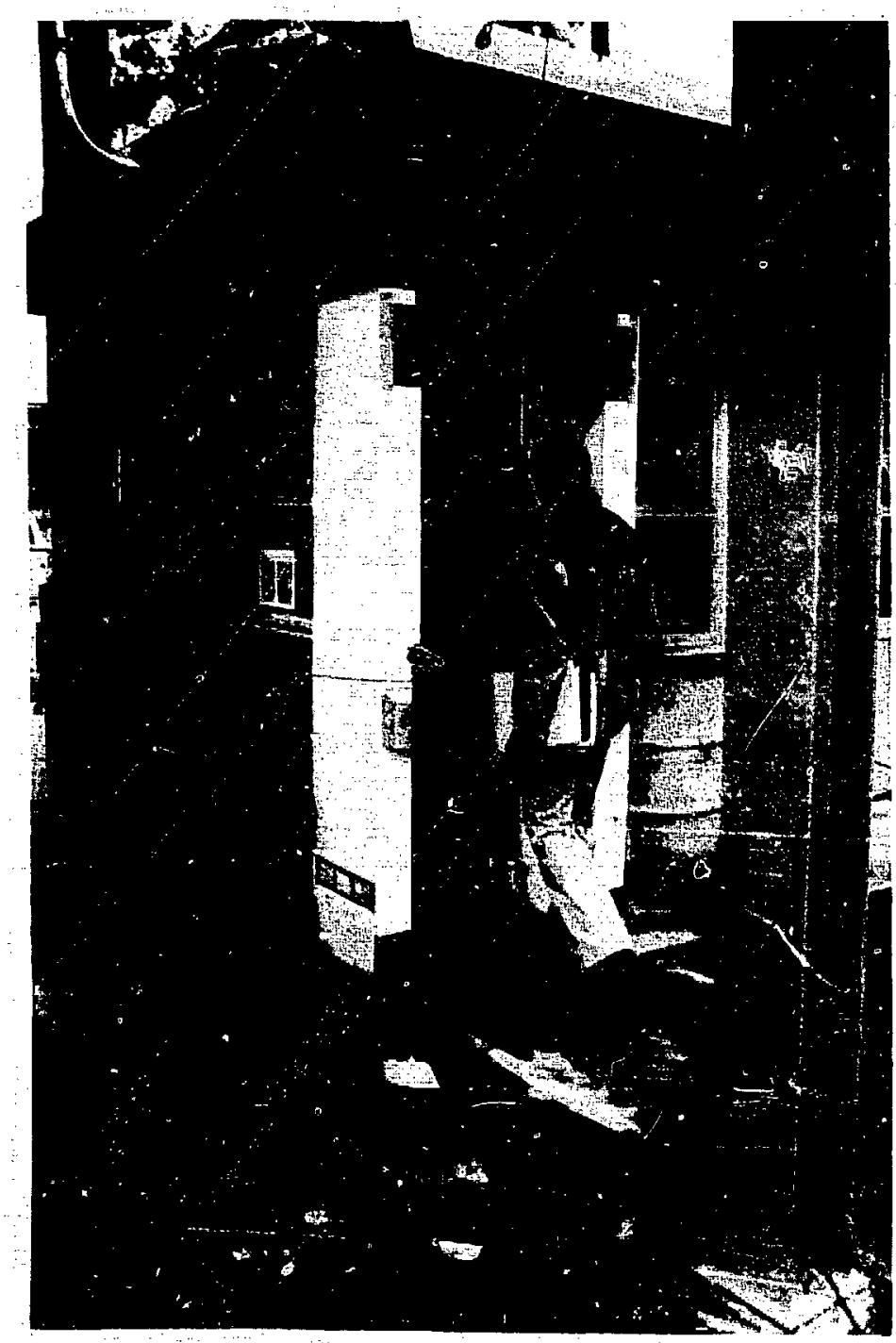




\section{ICPP(WINCO) PORTAL MONITOR}

The ICPP monitor applies contamination monitoring techniques to SNM detection. The detectors are gas flow proportional counters that detect lowenergy radiation. The ICPP product material is granular, emits large amounts of very low energy radiation, and is easily detected by the monitor when the material is located on exterior surfaces of $a$ pedestrian. As a pedestrian passes through the monitor, the detector panels are pressed near his body to obtain maximum signal. The monitor would not be suitable for diversion monitoring at other locations vere the material may be metallic or encapsulated.

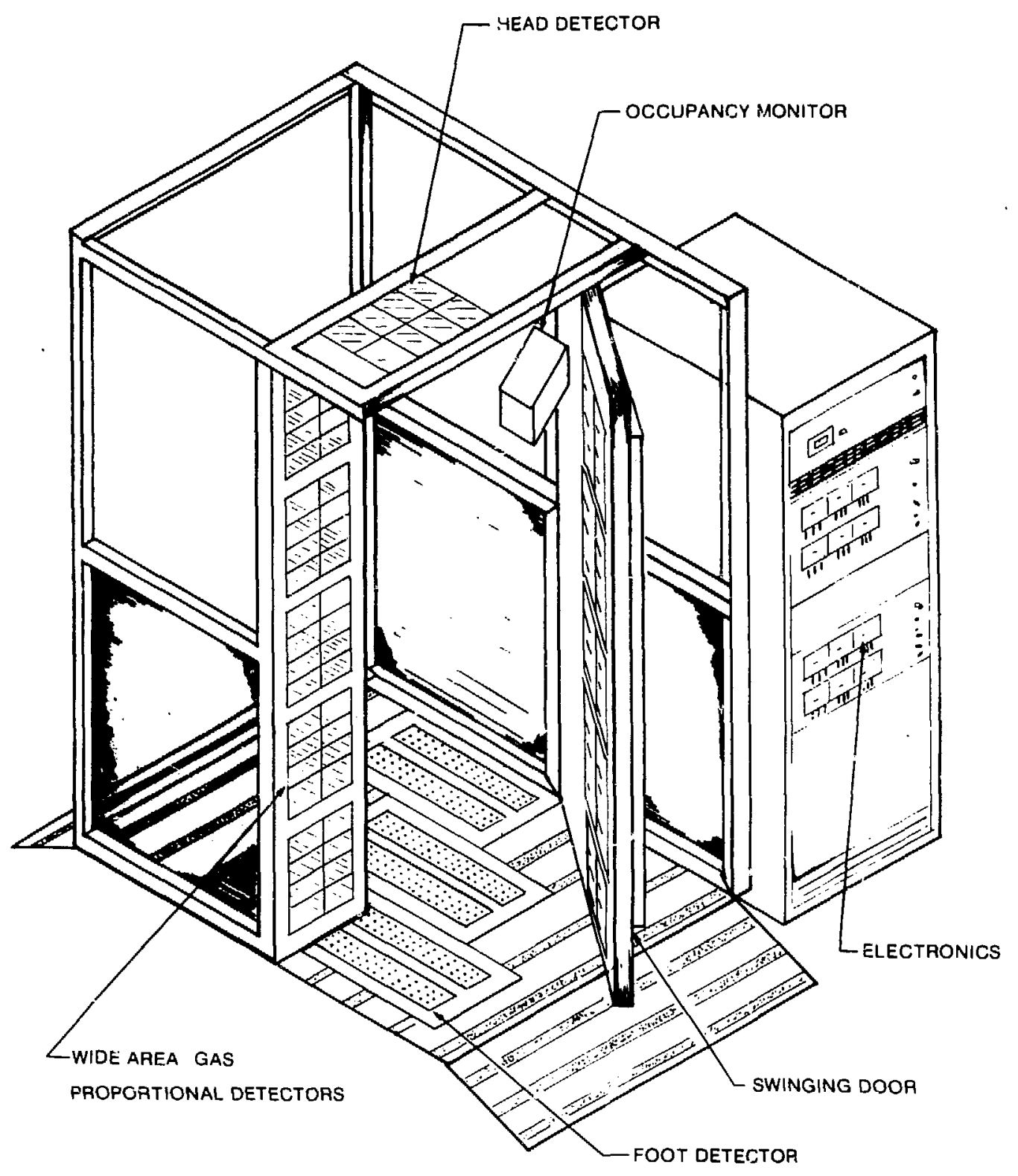




\section{SANDIA ENTRY CONTROL PORTALS}

Sandia National Laboratories provides entry control/SNM-monitoring booths for integrated safeguards systems being applied at the Westinghouse Hanford Fuel Material Evaluation Facility (FMEF). The booths include SNM monitoring as well as handgun-metal detection and entry control personnel identification systems. The SNM monitoring system is derived from one that was developed by Sandia for international safeguards at the Gas Centrifuge En- richment Plant at Piketon, Ohio. The booth SNM monitors, manufactured for Sandia by National Nuclear Corp." have not been evaluated. A version of the SNM monitor operating as a walk-through monitor is applied at FMEF and was also made available to Argonne West. It also has not been independently evaluated.

National Nuclear Corp., 1904 Colony Street, Mountain View, CA 94043, (415) 962-9220.

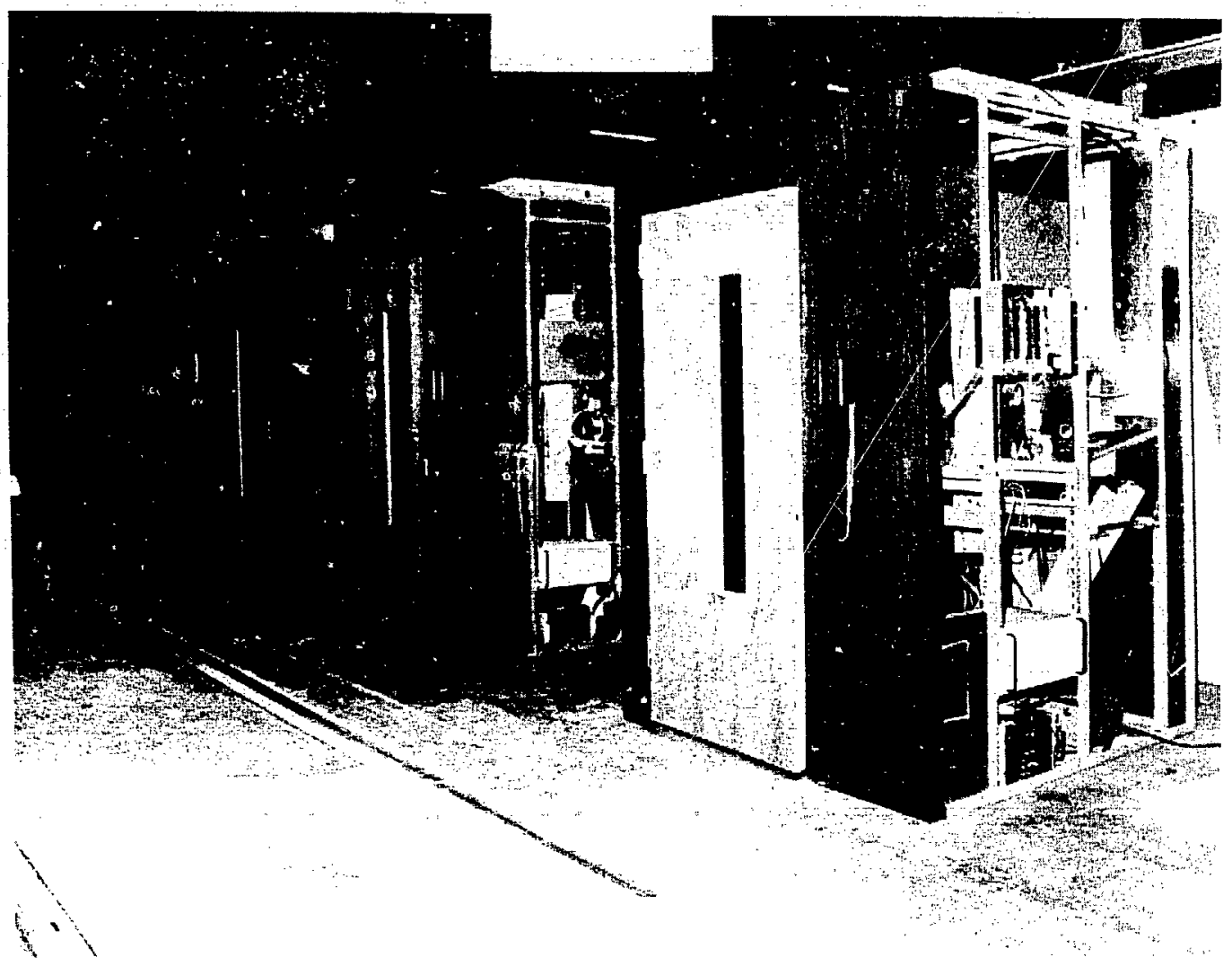




\section{HERFURTH GAMMA DOORWAY MONITOR}

This German-made SNM monitor by Herfurth GMBH* applies large $\mathrm{NaI}(\mathrm{Tl})$ scintillation detectors to radiation monitoring. It has microprocessor control and analysis that allow variable monitoring times

'Herfurth GMBH, 2000 Hamburg 50, Postfach 500 648, Beerenweg 6-8, Hamburg, West Germany, 0213623. to be selected. Passage is interrupted and the pedestrian must wait until the monitor signals audibly that the monitoring time has ended. The detection logic applied in this monitor is somewhat more complex than is usually applied in SNM monitors. Detector signals are summed into groups in various arrangements that give better detection sensitivity in problem regions and make monitoring more uniform. The monitor has not been evaluated. Cost of the monitor in this time of favorable exchange fate is only slightly higher than for US-made monitors.

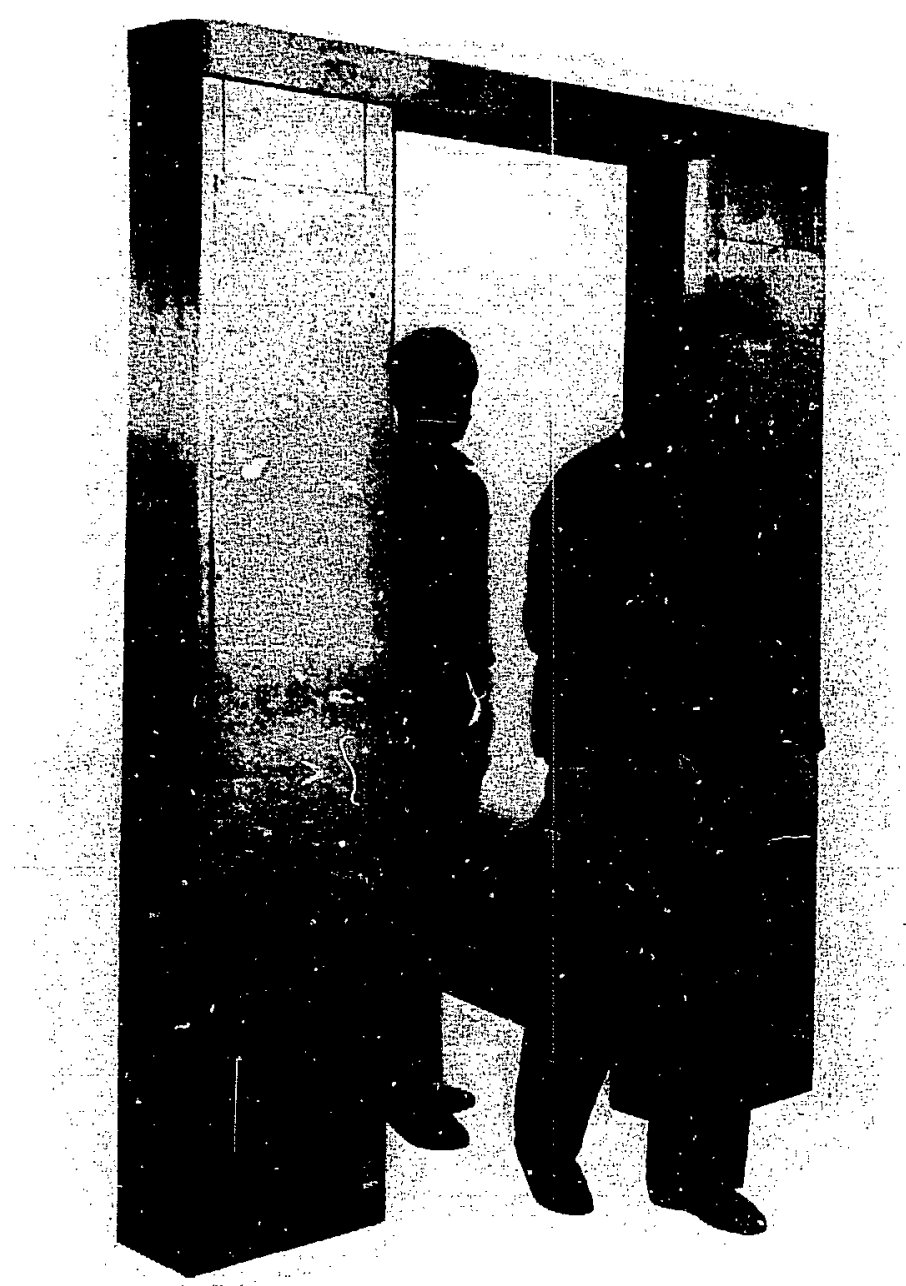




$$
\text { Ih }
$$




\section{HARWELL SNM DOORWAY MONITORS}

The United Kingdom's Atomic Energy Research Establishment Harwell manufactures two types of pedestrian SNM monitors for sale to other UK facilities. The type 3257 gamma-ray monitor has operated successfully for many years with high reliability. The monitor applies digital data analysis and incorporates metal detection and turnstile control as

Instrumentation and Applied Physics Division, Bldg. 347.3, AERE Harwell, Oxfordshire OXII ORA, England, Telex 83135 . additional physical protection features. The monitors are used side by side to accommodate high traffic flow, and turnstiles may be configured for inlet or outlet for traffic management at difierent times of day.

The type 3261 neutron monitor has microprocessor control and applies up to $20 \mathrm{BF}_{3}$ neutron proportional counters to achieve adequate sensitivity for detecting plutonium. Individual proportional counters are monitored continuously to detect faulty behavior, and the monitor can automatically disregard signals from noisy tubes.

Neither monitor has been independently evaluated.

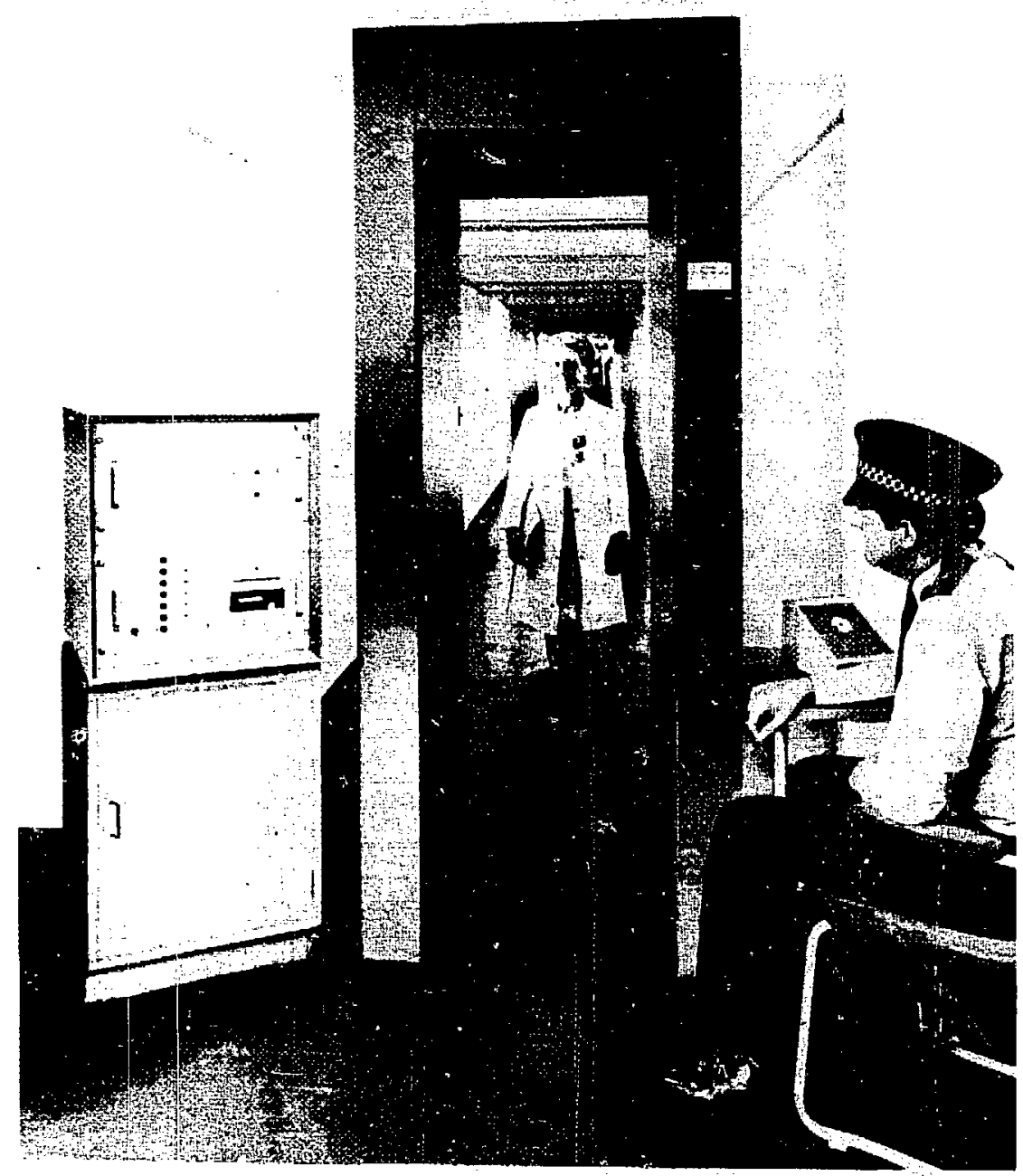




\section{ACKNOWLEDGMENTS}

I thank the members of the Advanced Nuclear Technology Group who from time to time have assisted me to develop and evaluate radiation monitors. I am also indebted to my colleagues for helpful reviews of the report, particularly Tom Sampson who also provided data plotted in three of the figures.

\section{REFEIRENCES}

1. P. E. Fehlau, "Hand-Held Search Monitor for Special Nuclear Materials, User's Manual," Los Alamos National Laboratory brochure LALP-84-15 (1984).

2. P. E. Fehlau, "Technical Evaluation of National Nuclear Corporation Model DM-2 Doorway Monitor," U.S. Department of Energy, Office of Safeguards and Security (March 1975).

3. P. E. Fehlau, "Technical Evaluation of IRT Corporation Model PRM-110 Doorway Monitor," U.S. Department of Energy, Office of Safeguards and Security (March 1975).

4. P. E. Fehlau, "Technical Evaluation of Tom Scurry Associates Model PM-203 Doorway Monitor," U.S. Department of Energy, Assistant Secretary for Defense Programs, Office of Safeguards and Security report DOE/DP-0006 (July 1978).

5. P. E. Fehlau, "SNM Monitor Applications: Diversion Safeguards for Emergency Exits and Detection of Undeclared Feed in Enrichment Plants," Los Alamos National Laboratory report LA-9310-MS (April 1982).

6. W. H. Chambers, H. F. Atwater, P. E. Fehlau, R. D. Hastings, C. N. Henry, W. E. Kunz, T. E. Sampson, T. H. Whittlesey, and G. M. Worth, "Portal Monitor for Diversion Safeguards," Los Alamos Scientific Laboratory report LA-5681 (December 1974).
7. P. E. Fehlau, "Calibrating the National Nuclear Corporation Personnel SNM Monitor, Nodel DM-2," Los Alamos National Laboratory cocument LA-UR-85-2399.

8. P. E. Fehlau, "Calibrating the TSA Systems NaI(Tl) Pedestrian SNM Monitor, Model PM 203," Los Alamos National Laboratory cocument LA-UR-85-2303.

9. P. E. Fehlau, J. C. Pratt, J. T. Markin, and T. Scurry, Jr., "Smarter Radiation Monitors for Safeguards and Security," Nucl. Mater. Manage. XII (Proceedings Issut), 122 (1983).

10. P. E. Fehlau, K. L. Coop, and J. T. Markin, "Application of Wald's Sequential Probability Ratio Test to Nuclear Materials Control," Proceedings of ESARDA/INMM Joint Specialists Meeting, Ispra, Italy, September 10-12, 1984, M. Franklin, L. Stanchi, and J. T. Markin, Eds. (Commission of the European Communities, Joir.t Research Center, Ispra, Italy).

11. R. L. Heath, "Inorganic Scintillators, a Review of Techniques and Applications," Nucl. Instrum. Methods 162, 431 (1979).

12. F. D. Brooks, "Development of Organic Scintillators," Nucl. Instrum. Methods 162, 477 (1979).

13. P. E. Fehlau and G. S. Brunson, "Coping with Plastic Scintillators in Nuclear Safeguards," IEEE Trans. Nucl. Sci. NS-30, 158 (1983).

14. E. Appel, M. Giannini, and A. Serra, "A New Method of Self-Diagnosis for Pulse Measuring Systems, I," Nucl. Instrunı. Methods 192, 341 (1981).

15. K. V. Nixon and C. Garcia, "Hand-Held PulseTrain-Analysis Instrument," IEEE Trans. Nucl. Sci. NS-310, 331 (1983). 
16. P. E, Fehlau, K. L. Coop, and K. V. Nixon, "Sequential Probability Ratio Controllers for Safeguards Radiation Monitors," Proceedings of the 6th Annual ESARDA Symposium on Safeguards and Nuclear Materials Management, Venice, Italy, May 1984, L. Stanchi, Ed. (Commission of the European Communities, Joint Research Center, Ispra, Italy).
17. W. J. Dixon and F. J. Massey, Introauction to Statistical Analysis (McGraw-Hill Book Co., New York, 1969).

18. P. E. Fehlau, T. E. Sampson, C. N. Henry, J. M. Bieri, and W. H. Chambers, "On-Site Inspection Procedures for SNM Doorway Monitors," NUREG/CR-0598, Los Alamos Scientific Laboratory report LA-7646 (August 1979). 